June 1989

\title{
A Study on the Changes in Mechanical Properties and structure of Fiber-Reinforced Composite Wires as a Result of Thermoforming.
}

Anil P. Patel

\section{Recommended Citation}

Patel, Anil P., "A Study on the Changes in Mechanical Properties and structure of Fiber-Reinforced Composite Wires as a Result of Thermoforming." (1989). SoDM Masters Theses. 12.

https://opencommons.uconn.edu/sodm_masters/12 


\title{
A STUDY ON THE CHANGES IN MECHANICAL PROPERTIES AND STRUCTURE OF FIBER - REINFORCED COMPOSITE WIRES AS A RESULT OF THERMOFORMING
}

\author{
Anil P. Patel \\ B.D.S., The University of Wales, U.K., 1981 \\ D.M.D., The University of Connecticut, 1986
}

A Thesis

Submitted in Partial Fulfillment of the

Requirements for the Degree of

Master of Dental Science

at

The University of Connecticut 


\title{
APPROVAL PAGE
}

Master of Dental Science Thesis

\section{A STUDY ON THE CHANGES IN MECHANICAL PROPERTIES AND}

\section{STRUCTURE OF FIBER - REINFORCED COMPOSITE WIRES AS A RESULT

\author{
OF THERMOFORMING
}

\author{
Presented by
}

Anil P. Patel, B.D.S., D.M.D.

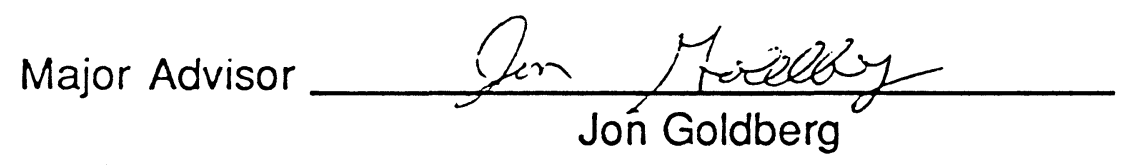

Associate Advisor $\frac{e \& \text { Queulowo }}{\text { Charles J. Burstone }}$

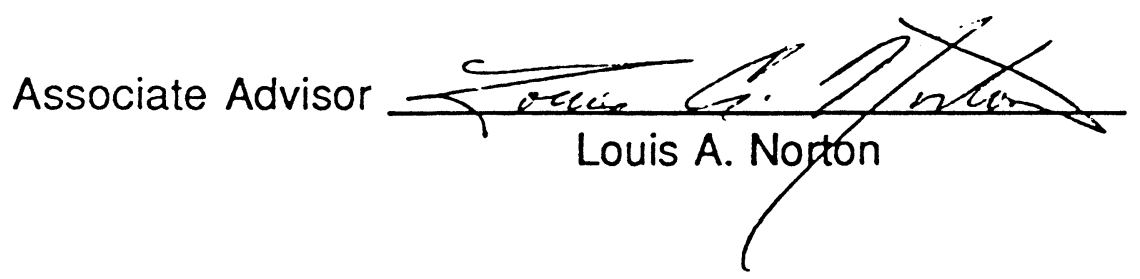

The University of Connecticut

1989 


\section{ACKNOWLEDGMENTS}

I am most grateful to the members of my research committee, Drs. Jon Goldberg, Charles Burstone and Louis Norton for their advice during the course of my study.

I wish to express my greatest appreciation to Drs. Jon Goldberg and Charles Burstone, under whose guidance this research was made possible. I will always carry with me their special wealth of knowledge, experience, and advice which they have so freely given to me.

I dedicate this thesis to my parents, whose special support and personal sacrifice throught my life has made everything possible. 


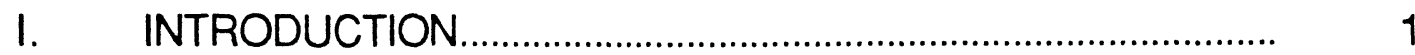

II. STATMENT OF THE PROBLEM

A. Properties of an ideal orthodontic wire...................... 4

B. Potential advantages of a fiber-reinforced composite (FRC) orthodontic wire.............................. 6

III. LITERATURE REVIEW

A. History of materials used for orthodontic wires / appliances.

B. Characteristics of a composite

1. Definition.................................................................... 11

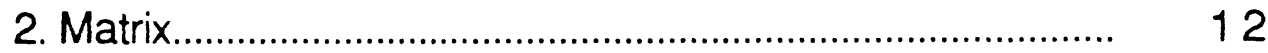

3. Dispersed phase ................................................................. 13

4. Interface and coupling agents................................. 15

5. Long fiber-reinforced composites......................... 16

IV. PURPOSE OF THE STUDY ..................................................... 22

V. SPECIFIC OBJECTIVES ...................................................... 23

VI. MATERIALS AND METHODS

A. Materials............................................................................. 24

B. Heating experiments using straight samples of FRC in mold and heat press

1. Procedure

2. Mold.

3. Flexural test and apparatus.

4. Microscopy technique and preparation...................... 33

C. Forming experiments using a heating chamber

1. Forming with $10.0 \mathrm{~mm}$ deflection.

2. No forming with $0 \mathrm{~mm}$ deflection............................ 38

3. Forming with $7.0 \mathrm{~mm}$ deflection............................ 38 
D. Other heating parameters

1. Duration and method of heating................................ 40

2. Predrying and vacuum heating..................................... 41

3. Calibration of a warm-air gun and measurement of air temperatures during clinical forming of orthodontic retainers...................................................... 42

VII. RESULTS

A. Heating experiments using straight samples of FRC in mold and heat press.

B. Forming experiments using the Instron heating chamber and material $\times 10333 \mathrm{~A}$

C. Other heating parameters

1. Duration and method of heating

2. Predrying and vacuum heating

3. Calibration of a warm-air gun and measurement of air temperatures during clinical forming of orthodontic retainers.

VIII. DISCUSSION

61

IX. SUMMARY AND CONCLUSION

73

BIBLIOGRAPHY

APPENDIX C: SPECIAL APPARATUS

A. Hewelett-Packard measurement and plotting recorder.

B. Thermocouple to Millivolt Converter

C. Type T Thermocouples.

D. Carver Laboratory Model C Hydraulic Press.

E. Instron Oven 


\section{LIST OF FIGURES}

FIG.

PAGE

1. Composite. 11

2. Custom made copper mold. 28

3. Arrangement of torque meter. 32

4. Schematic drawing of bend test fixture. 32

5. Heating Chamber. 39

6. Shape of wire after heating in oven. 54

7. Change in modulus with heating using mold- X10333A. 83

8. Maximum moment vs Heating temperature using mold - X10333A.

9. Maximum deflection vs Heating temperature using mold $-X 10333 A$.

10. Moment vs Deflection curves using mold- X10333A.

86

11. SEM of straight samples of $X 10333 \mathrm{~A}$ heated at RTP, $200 \mathrm{~F}$ and $400 \mathrm{~F}$ after fracture test.

12. Optical micrographs of cross sections of straight samples of X10333A after heating to RTP and $300 \mathrm{~F}$. Mag:100X.

13. Change in modulus with heating using mold- $X 10364$.

14. Maximum moment vs Heating temperature using mold - X10364.

15. Maximum deflection vs Heating temperature using mold $-X 10364$.

16. Moment vs Deflection curves using mold- X10364.

17. SEM of straight samples of $\times 10364$ heated at RTP, $200 \mathrm{~F}$ and $500 \mathrm{~F}$ after fracture test.

93

18. Optical micrographs of cross sections of straight samples of X10364 after heating to RTP and $350 \mathrm{~F}$. Mag:100X.

19. Change in modulus with heating using mold- X10333B. 95

20. Maximum moment vs Heating temperature using mold - X10333B.

21. Maximum deflection vs Heating temperature using mold - X10333B.

22. Moment vs Deflection curves using mold- X10333B. 
23. Change in modulus with heating using mold- $X 10361$.

24. Maximum moment vs Heating temperature using mold

- X10361.

25. Maximum deflection vs Heating temperature using mold - X10361.

26. Moment vs Deflection curves using mold- $X 10361$.

102

27. Change in modulus with heating using mold- X10354.

103

28. Maximum moment vs Heating temperature using mold - X10354.

29. Maximum deflection vs Heating temperature using mold - X10354.

105

30. Moment vs Deflection curves using mold- $X 10354$.

31 . Change in modulus with heating using mold- $113 \mathrm{AZH}$.

107

32. Maximum moment vs Heating temperature using mold - 113AZH.

33. Maximum deflection vs Heating temperature using mold - 113AZH.

34. Moment vs Deflection curves using mold- 113AZH.

35. Change in modulus with heating using oven- $0 \mathrm{~mm}$ def - X10333A.

36. Change in modulus with heating using oven $-10 \mathrm{~mm}$ def - X10333A.

37. Change in modulus with forming/temperature

- X10333A.

38. Effect of method and duration of heating at $410 \mathrm{~F}$.

39. Effect of pre-drying and vacuum heating at $400 \mathrm{~F}$.

40. Temperature vs time heating and cooling curves for heat press and mold (bench cooled).

41. Temperature vs time heating curve for mold (quenched).

42. Temperature vs time cooling curve for oven.

43. Graph showing temperature gradient between nozzle of heating gun and specimen one inch away.

44. Graph showing temperature at nozzle of heating gun and various locations on the specimen during formation of a bonded lingual retainer on a study cast.

45. Hewelett-Packard measurement and plotting recorder. 147

46. Thermocouple to millivolt converter.

47. Carver laboratory model $C$ hydraulic press. 


\section{LIST OF TABLES}

TABLE

PAGE

1. Change in modulus with heating using mold- X10333A. 121

2. Maximum moment and maximum deflection vs Heating temperature using mold- X10333A.

122

3. Moment vs Deflection curves using mold- X10333A. 123

4. Change in modulus with heating using mold- X10364. 124

5. Maximum moment and maximum deflection vs Heating temperature using mold- X10364.

125

6. Moment vs Deflection curves using mold- X10364. 126

7. Change in modulus with heating using mold- X10333B. 127

8. Maximum moment and maximum deflection vs Heating temperature using mold- X10333B.

128

9. Moment vs Deflection curves using mold- X10333B. 129

10. Change in modulus with heating using mold- X10361. 130

11. Maximum moment and maximum deflection vs Heating temperature using mold- X10361.

131

132

12. Moment vs Deflection curves using mold- X10361.

133

14. Maximum moment and maximum deflection vs Heating temperature using mold- X10354.

134

15. Moment vs Deflection curves using mold- X10354. 135

16. Change in modulus with heating using mold- $113 \mathrm{AZH} . \quad 136$

17. Maximum moment and maximum deflection vs Heating temperature using mold- $113 \mathrm{AZH}$.

18. Moment vs Deflection curves using mold- $113 \mathrm{AZH} . \quad 138$

19. Change in modulus with heating using ovenOmm def- X10333A.

20. Change in modulus with heating using oven $-10 \mathrm{~mm}$ def- X10333A.

21. Change in modulus with forming/temperature- X10333A. 141

22. ANOVA table (3-factor repeated measures) showing significance of forming, temperature, and repeated measure- $\mathrm{X} 10333 \mathrm{~A}$.

23. Effect of method and duration of heating at $410 \mathrm{~F}$. 143 
24. ANOVA table (3-factor repeated measures) showing significance of method and duration of heating at $410 \mathrm{~F}$, and repeated measure.

25. Effect of pre-drying and vacuum heating at $400 \mathrm{~F}$.

26. ANOVA table (2-factor repeated measures) showing significance of pre-drying, vacuum heating at $400 \mathrm{~F}$, and repeated measure- $\mathrm{X} 10333 \mathrm{~A}$. 



\section{INTRODUCTION}

Man's long history of technological development has been marked by a continuing search for improved materials. This effort has resulted in a vast array of new materials which have affected nearly every aspect of contemporary life, including orthodontics.

A significant advance in orthodontic materials was made in the late 1930's and 1940's when stainless steel wire and appliances became widely available, replacing gold-based alloys. Since that time there has been a continuous evolutionary improvement in the strength and resilience of wires used for orthodontic treatment, including the introduction of beta-titanium (TMA, Ormco Corporation, Glendora, CA.) and nickel-titanium (Nitinol, Unitek Corporation, Monrovia, CA.; and Chinese NiTi) alloys.2-7

Fiber-reinforced composites are an emerging new class of engineering materials. The ability to tailor-make composite materials and structures offers exciting opportunities for a broad spectrum of applications including orthodontic wires and appliances. The features of the fiber composites that make them so promising as industrial and engineering materials are their low 
density, high specific strength (strength/density), high specific stiffness (modulus/density), and the opportunities to tailor the material's properties through the control of fiber and matrix combinations and processing. The most common uses of fiberreinforced composites have been recreational products, for example, boats, fishing rods, rackets, high performance air craft and space vehicle applications. However, increasing uses of these materials are being made and they will make a major impact on our daily lives.19-33

In dentistry, applications of fiber-reinforced composites have been proposed in the literature, but such usage has not been reduced to common clinical practice. These reports have suggested the use of carbon/graphite fiber-reinforced poly (methyl methacrylate) in implant-fixed dental bridges, denture base acrylic reinforced with high modulus aramid fibers, and resin fiberglass bonded orthodontic retainers. ${ }^{14-18}$

It is proposed in this study that long fiber-reinforced thermoplastic composites have several unique properties which would be advantageous in an orthodontic wire or appliance. Its unique 
properties are its tooth color or clarity, high formability, weldability, and direct bonding to enamel.

The purpose of this thesis will be to investigate and evaluate the mechanical properties and structure of fiber-reinforced composite wires after varying conditions of thermoforming. 


\section{STATMENT OF THE PROBLEM}

\section{A. Properties of an ideal orthodontic wire}

The following are some of the desirable properties for an orthodontic wire:1,2,11

1) Biological:
a) non-toxic
b) non-irritant
c) non-allergenic
d) non-carcinogenic

2) Chemical:
a) insoluble in saliva or fluids taken orally
b) inert
c) corrosion resistance

3) Asethetics: Either clear or tooth colored.

4) Mechanical: a) High elastic limit (yield strength). This represents the greatest stress which can be applied to the wire without the occurance of permanent deformation.

b) Low modulus of elasticity / low stiffness.

Stiffness is defined as the force or moment produced for each unit activation. The modulus of elasticity describes the resistance to elastic deformation and determines the magnitude of force 
delivered by a wire activated within the elastic range. Clinically, a wire with a low modulus or stiffness will have a low load-deflection rate. It should allow the wire to fill the bracket for control and at the same time produce lighter forces. A wire with a higher modulus should be more resistant to deformation caused by orthodontic tractional forces.

c) Large spring back (maximum elastic strain)

i.e., it should be possible to deflect the wire over long distances without permanent deformation. The ratio of the yield strength to the elastic modulus describes the spring back for linear materials (c.f. nickel-titanium alloys). The calculated value of spring back is affected by the percentage offset used to calculate the yield strength, particularly if the elastic region of the stress-strain curve is not well defined. Higher values of spring back indicate the capacity for an increased range of activation clinically and thus the ability to engage teeth which are more misaligned. This would also mean fewer 
visits to reactivate the appliance /wire.

d) Maximum moment. This is defined as the largest bending couple that a wire is capable of delivering.

Varying types of tooth movement require the delivery of different magnitudes of force. Unless an orthodontic wire is capable of delivering an adequate moment before permanently deforming, it may not be satisfactory for a given application.

5) Easy joining of attachments or onto itself by welding, etc.

6) High formability and easy to fabricate.

It should be capable of being easily shaped, bent and formed into complicated configuration e.g., loops without fracture.

7) Economical to manufacture and use.

B. Potential advantages of a fiber-reinforced composite (FRC) orthodontic wire

Fiber-reinforced thermoplastic composites offer the opportunity to utilize some of their unique properties in orthodontic wires. With proper selection of the FRC it is aesthetic. It can be directly bonded 
to the etched enamel surface with currently available dental adhesive systems. It has very high formability which would allow fabrication of custom shaped arch wires or appliances by application of moderate heat and pressure within a dental office setting. The material can also be directly welded using ultrasonics. In addition desired properties may be obtained by altering composition or processing conditions.

Although significant advances have been made in the field of composites, less information is available for thermoforming continuous fiber-reinforced composites. Currently, little or no research has been done on the suitability of these materials for orthodontic wires or appliances. The scientific questions which need to be addressed involve both processing and performance. 


\section{LITERATURE REVIEW}

\section{A. History of materials used for orthodontic wires /appliances}

In recent years austentic stainless steel has been the primary alloy used for orthodontic wires. Excellent formability, good corrosion resistance, high values of stiffness and resilience, and moderate cost have been responsible for its popularity. 1-4,6, 8,9

Elgiloy (Rocky Mountain Orthodontics, Denver, Co.) is a cobaltchromium-nickel alloy with a nominal composition of $40 \%$ cobalt, $20 \%$ chromium, $15 \%$ nickel, $7 \%$ molybdenum, $16 \%$ iron. Although the mechanical properties of Elgiloy and stainless steel are similar, the former can be given a strengthening heat treatment which allows manipulation of the wire in a softened state. This can be followed by a hardening heat treatment to obtain the desired resilence. Elgiloy has excellent corrosion resistance. It can be soldered, but, as with stainless steel, the technique is demanding.2-4,6-9

Within the last decade newer alloys have become available for use in orthodontics. The first nickel-titanium alloys (Nitinol) were introduced in orthodontics by Andreasen in the late 1970's and are based on the original research of Buehler in the early 1960's. Nitinol 
is approximately $52 \%$ nickel, $45 \%$ titanium, and $3 \%$ cobalt. It has unusual thermal characteristics which are responsible for the "shape memory" effect, although this feature is not used clinically. Its outstanding elasticity is reflected in its very high spring back characteristics. These feature makes the wire desirable for applications where large deflections and low forces are required as well as allowing a large working range. Nitinol has limited formability and sharp bends predispose the wire to failure or breakage. Spring back properties are decreased after bending. It cannot be soldered or successfully welded to itself without annealing the wire.2-6,8

Beta-stabilized titanium alloy (TMA) is becoming increasingly popular. It was developed and introduced to orthodontics by Burstone and Goldberg in the early1980's. It has a high spring back (maximum elastic strain) with a low stiffness thus allowing an increased working range with more constant and lower forces than is possible with stainless steel wires. Other important characteristics include easy workability which allows it to be formed into complicated configurations and direct weldability without appreciable losses in mechanical properties.3,4,6,8 
A new nickel-titanium alloy (Chinese $\mathrm{NiTi}$ wire) has recently been introduced in this country by Burstone, having been developed in China by Dr. T. Hua Cheng and associates. It has several unique properties with a high spring back, increased working range, low stiffness and the capacity to deliver light constant forces.7 At least six different nickel-titanium alloys are available on the market today.

\section{B. Characteristics of a composite}

Composite materials occur widely in nature. Bone and dentine, for example, contain a protein constituent, collagen, and a mineral material, apatite. Wood consists of strong and flexible cellulose fibers held together by lignin, which makes the material stiff.

It is not surprising that man has imitated nature by combining two materials to produce a composite, either to improve the properties of one constituent, or to yield a material with properties that are different from either constituent.

Neither is it surprising that composites are beginning to find applications as dental materials, due to the limitations of existing 
materials and the very exacting conditions of the oral environment and dental/orthodontic therapy.

\section{Definition}

A rigorous definition of a composite is not really desirable since it would have to be rather complex to cover the great variety of composite materials. In simple terms, a composite can be defined as "a combination of two or more chemically distinct materials on a macroscopic level, having a distinct interface between them and acting in concert to produce a desired set of properties which are a function of the properties of the constituents and not possessed by any of the constituents alone."22,24,28

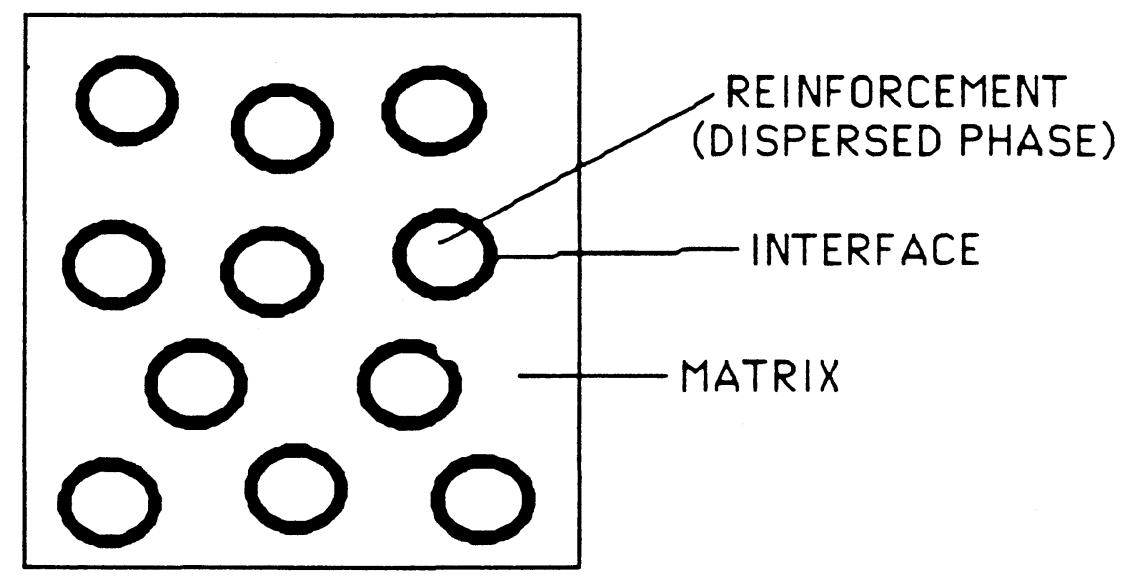

Fig. 1: Composite. 


\section{Matrix}

The matrix (continous phase) serves several critical functions in overall composite performance beyond simply holding the reinforcement in place. Since many reinforcements tend to be brittle, the matrix protects their surface against abrasion or environmental corrosion, both of which can initiate fracture. More importantly, the matrix distributes the load born longitudinally by the reinforcements. Because it is the matrix which holds the composite components together, the general thermo-mechanical behavior is dominated by the resin's heat resistance. Although the reinforcements provide much of the tensile and flexure strength and stiffness, a composite's shear, compression, creep, flow, dielectric and transverse tensile properties are usually matrix dominated. The matrix also determines the relative ease of incorporation of the discrete phase and processing of the mixture.19,20,22,24,26,28

The matrix is most often a polymeric resin. Polymers consist of small molecules joined chemically in chains or networks of repeating units to form high molecular weight molecules with an infinite variety of possible three-dimensional structures. The size, internal arrangement, chemical bonding, and spatial distribution of 
the molecules are directly affected by processing, and these features have a direct influence on the final properties of the polmer and the composite. The polymer can be thermoplastics, for example, poly-ethylene terephthalate glycol (PETG), polycarbonate (PC) and poly 1,4- cyclohexylene dimethylene terephthalate glycol (PCTG) which soften and behave as viscous liquids when heated above their glass transition temperature (amorphous thermoplastics) or above their melting temperature (crystalline thermoplastics). Polmer matrices can also be thermosetting resins which undergo a transformation from a low molecular weight, viscous, liquid-like resin to a hard or rubbery polymerized solid, in the presence of appropriate heat, light and / or chemical initiation.

\section{Dispersed phase}

The dispersed phase (discrete phase or reinforcement system) is primarily responsible for such structural properties as strength and stiffness. Whether particulate, microsphere, or fiber, the reinforcement is the key to optimizing cost / performance for a given application.19,25 Different forms of fibers are used for example, they may be short (chopped) or long (continuous). 
The most widely used reinforcement is unquestionably fiberglass, which accounts for some $90 \%$ of the reinforced-plastic market. It was first commercialized in 1939 by the Owens-Corning company. The two most common reinforcement grades of glass fiber are "E" (for electrical) and "S" (for strength).

E-glass provides a high strength-to-weight ratio (roughly twice that of steel wire), good fatigue resistance, outstanding dielectric properties, retention of $50 \%$ tensile strength to $650 \mathrm{~F}$ and excellent chemical, corrosion, and environmental resistance. This balance of properties is made even more attractive by a low price - often less than $\$ 1 /$ lb. E-glass is available as continuous filament, chopped fibers, random fiber mats, and many other forms suitable for a variety of methods of resin impregnation and composite fabrication. These fibers are further tailored for use in composites by surface treatment with specific coupling agents which make them especially compatible with particular resin systems without changing the basic character of the glass fiber.

Use of coupling agents and sizings improves overall composite mechanical properties, especially in the areas of moisture/chemical resistance and interlaminar shear strength. 
S-glass was developed and improved through the 1960s. It offers up to $25 \%$ higher compressive strength, $40 \%$ higher tensile strength, $20 \%$ higher modulus of elasticity, and $4 \%$ lower density, however at up to four times the price. S-glass also has higher resistance to strong acids than does E-glass, but is more susceptible to attack by strong bases. It does not offer the same wide range of commercial surface treatments as does E-glass.

Designing with fiberglass is much simpler than designing with some other composite systems because of the large body of empirical data collected over the years and the availabilty of standard systems from many manufactures with well documented properties.

\section{Interface and coupling agents}

The overall performance of a composite also depends to a large degree on the nature of the bond between matrix and the fiber.24 This bond, or interface, determines how impact energies or stresses and strains are transferred from matrix to fiber, controlling the mechanical performance. Also, the smaller the gap between the two phases of the composite, the less likely environmental moisture, gases, or chemicals will be able to preferentially permeate the 
composite component. Also the better the fiber wet-out, the greater the continuity and uniformity of properties throughout the part. Bridging this interfacial gap is done by coupling agents.

Coupling agents are a group of speciality chemicals with special pro perties that allow the fabrication of normally incompatible materials into a composite. Coupling agents usually consist of a short organic chain which has at one end an organo-functional group which is particularly compatible with a given matrix resin. At the other end of the chain is an inorganic functionality which is especially compatible with a given reinforcement surface. The coupling agent, when applied to the reinforcement and mixed with resin, acts as a chemical bridge between the two.24

Silanes are the most common commercial coupling agents. They usually have the form X3SiY, where $X$ is typically a chlorine or alkoxy group and $Y$ is the organofunctionality. These chemicals are usually applied from an aqueous solution to fibrous reinforcements, or dry blended with particulates.

\section{Long fiber-reinforced composites}

Long fiber-reinforced composites have a number of significant 
performance advantages over their short-fiber counterparts.29 Among these advantages are enhanced load-bearing capabilities, superior strength and stiffness in the fiber direction which is retained at elevated temperatures, higher creep resistance, increased torque strength, enhanced flexural properties, higher dimensional stability at elevated temperatures and humidities, improved abrasion resistance, better impact resistance, and reduced crack propagation. Crack propagation is inhibited by the reinforcement network; hence structures tend to remain intact outside the impact region, rather than shattering catastrophically as is usually seen in short fiber structures. This may allow certain components to continue to function for a limited time until repairs may be effected. This provides a safer impact failure mode than short-fiber systems. However, short-fiber composites have processing advantages over the long-fiber systems.

\section{a. Thermoplastic FRC}

Historically, long fiber-reinforced polymer systems have been dominated by thermoset matrix resins such as epoxies, polyesters, and many polyimides. Their main deficiencies include limited shelf life, insufficient toughness (i.e., brittleness or low strain- to 
failure), complicated and multiple step processing, and moisture sensitivity. 30

Recently, a myriad of new products based on thermoplastic matrices have been introduced. These products are combinations of a thermoplastic matrix with long-fiber reinforcement-generally glass, carbon, or aramid. The matrices include amorphous, semicrystalline, pseudo-thermoplastic (i.e., curing/heat-treatment required) and liquid-crystal polymers.30

Thermoplastic matrices generally provide greater toughness than conventional thermoset systems, which translates to improved damage tolerance in molded structures. However, the most important advantage offered by thermoplastic composites is the potential for fast, easy, and less costly fabrication.24,30,32,33

Thermoplastic composites containing long-fiber reinforcement can be divided into two broad categories, those containing long fiber in the form of random mat (thermoplastic stampable sheet) and those containing continuous fiber in unidirectional or fabric forms (oriented tapes). These materials differ in performance, price, and processing characteristics. 
It is well established that continuous fiber-reinforced composite products such as pre-formed rods and tapes provide the highest levels of mechanical properties in fiber-reinforced composites(FRC). Unidirectional composites are continually finding new engineering applications because of their directional load bearing capability. Unfortunately, unidirectional composites are often weak in interlaminar shear and when stresses are transverse to the fiber direction, primarily because the embedded fibers act as inclusions, raising the local stress at the fiber-matrix interface. This characteristic behavior can limit both the useful life cycle and structural integrity of these composites.31

Some of the problems with long fiber-reinforced thermoplastics have been the resistance of the polymer to solvents, fiber wetting (necessary for load transfer between fibers to provide proper reinforcement) difficulties, high temperature capabilities, molding procedures, creep, and the difficulty of obtaining good impregnation of a high volume percentage of the reinforcement fibers, which is crucial to their successful production. Also coupling of long fibers to the matrix has been difficult, although the pultrusion process of composite fabrication may help overcome this problem. Developing 
technology has overcome part, if not all, of these problems, and several thermoplastic based products are now available, either on a developmental basis such as the composites used in this study, or on

a commercial basis. 29,30

b. Processing of long fiber-reinforced thermoplastics

It is well known that composites made from identical raw materials but processed differently can have very different properties. This is because processing directly affects the structure of the final material. In this context, structure refers to both macroscopic features, such as flaws and voids, and molecular features.

Pultrusion processing is a continuous method for molding parts with a constant cross section, for example, pipe, rods, beams, etc. It involves pulling continuous roving or strand through a resin bath, then drawing the impregnated reinforcement through a die which controls the stock shape and the resin/reinforcement ratio. Very high strengths are possible due to the high fiber orientation and concentration. Pultrusion and filament winding are two of the fastest growing composite fabrication methods.19,24 The fiberreinforced composite wires in this study were made by pultrusion processing. 
The long fiber-reinforced thermoplastics are conveniently processed or refabricated by heating to temperatures near or slightly above the softening point (glass transition temperature) of the matrix resin and applying pressure in the 50 to 200 psi range. This easy processibilty allows field repair of products from these materials without complex equipment. Development of products from these advanced long fiber-reinforced thermoplastics has just begun and the processing techniques and parameters are not yet optimized but offer good potential.

Component design is made even more flexible by the wide range of bonding methods appropriate for thermoplastic composites. Adhesive bonding, ultrasonic welding, induction welding, fusion bonding, and other welding methods have been used. Moreover, the inherent toughness of these composites allows the use of many conventional fastening methods, including self-tapping screws in some cases.30 Their unique combination of physical strength, toughness and easy processibility with growing fabrication process sophistication and productivity will guarantee fiber-reinforced composite thermoplastics a place in the advancing composites arena. 


\section{PURPOSE OF THE STUDY}

It is hypothesized that long fiber-reinforced thermoplastic composites have several unique properties which would be advantageous in an orthodontic wire or appliance. Its unique properties are its tooth color or clarity, high formability, weldibility, and direct bonding to enamel.

The purpose of this thesis will be to investigate and evaluate the mechanical properties and structure of fiber-reinforced composite wires after varying conditions of thermoforming. 


\section{SPECIFIC OBJECTIVES}

The specific aims of this laboratory investigation were to determine the influence of the following factors on the flexural and structural properties of fiber - reinforced composite (FRC) wires after heating from room temperature to at least $200 \mathrm{~F}$ above the glass transition temperature:

* Temperature.

* Degree of forming.

* Method of heating.

** Mold and a laboratory heat press.

** Oven.

* Material composition.

* Duration of heating and rate of heating and cooling.

* Pre-drying and vacuum heating.

In addition the following were also undertaken:

* Standardizing of a warm-air gun used clinically in forming orthodontic retainers.

* Measuring the temperature range which is used clinically when forming retainers with the warm-air gun. 


\section{A. Materials}

The materials used for the study were fiber-reinforced composite wires of cross sectional dimensions of $0.021 \times 0.025$ inch and length 0.3937 inch. The reinforcement was in a continuous form with a silane coupling agent. The wires were produced by pultrusion processing.

CODE IYPE \& FIBER MATRIXRESIN IQ** OF RESIN CONTENT \%WT

$\begin{array}{lllll}\times 10333 \mathrm{~A} & \text { S2 } & 57 \% & \text { PETG } & 165 \mathrm{~F}(74 \mathrm{C}) \\ \times 10364 & \text { S2 } & 57 \% & \text { PC } & 282 \mathrm{~F}(139 \mathrm{C}) \\ \times 10333 \mathrm{~B} & \mathrm{~S} 2 & 50 \% & \text { PETG } & 165 \mathrm{~F}(74 \mathrm{C}) \\ \times 10361 & \text { S2 } & 55 \% & \text { PCTG } & 174 \mathrm{~F}(79 \mathrm{C}) \\ \times 10354 & \mathrm{KV} & 43 \% & \text { PETG } & 165 \mathrm{~F}(74 \mathrm{C}) \\ 113 \mathrm{AZH}^{\star} & \mathrm{E} 2 & 40 \% & \text { PETG } & 165 \mathrm{~F}(74 \mathrm{C})\end{array}$

NOIE: PETG = Polyethylene terephthalate glycol $P C=$ Polycarbonate PCTG = Poly 1,4-cyclohexylene dimethylene terephthalate glycol $\mathrm{KV}=$ Kevlar

"This material was supplied as a tape 4.0 in wide and 0.021 in thick.

** $\mathrm{Tg}=$ Glass transition temperature 
B. Heating experiments using straight samples of FRC in mold and Heat Press

\section{Procedure}

All of the above listed formulations were tested. For each material eight experimental groups, with six samples per group were formed. Each sample was initially tested to a deflection of 7.5 degrees to determine the flexural modulus (for details refer to section B.3.) prior to heating. This low deflection was well within the elastic limit of the wires, so there was no permanent deformation. The same samples were then heated at different temperatures. The groups were: room temperature (control), $200 \mathrm{~F}, 250 \mathrm{~F}, 300 \mathrm{~F}, 350 \mathrm{~F}$, $400 \mathrm{~F}, 425 \mathrm{~F}$, and $450 \mathrm{~F}$.

In order to minimise the variability, samples from the same batch and section of wire were taken. The group tested at room temperature was the control for comparing changes in maximum moment, maximum angle of deflection, moment vs deflection characteristics, as well as change in modulus. The approach of retesting the same samples provided an even greater precision for monitoring the change in modulus before and after heating. 
Thermocouples were placed in the center of a custom made copper mold (for details refer to section B.2. and Appendix C) as well as the upper and lower heating platens of the heat press (Fig. 47). These were connected to the HP 7090 Recorder (Fig. 45) via the TAC 80 convertor (Fig. 46). The heating temperatures at the three locations were recorded continuously during the experiments (Fig. 40).

The heat press with the mold was heated to the experimental temperature. Once the temperature was achieved, the mold was quickly removed and a light coat of silicone lubricant was applied to the groove. This was to prevent samples from adhering to the mold surface and facilitate their removal. The wire samples were placed in the groove and the mold placed back in the heat press. The mold dimension was such that three samples approximatly $25 \mathrm{~mm}$ in length could be simultaneously placed in the mold. The mold was returned to the heat press and the platens brought together until they were in light contact with the mold. Thus only heat without pressure was applied to the mold.

The experimental temperature was held for 5 minutes so that a temperature equilibrium was reached. The mold was then removed 
from the heat press and allowed to bench cool to room temperature before removing the samples.

All samples were then tested to failure at room temperature, as 10 $\mathrm{mm}$ free-end cantilever beams, to determine the flexural modulus, maximum bending moment and maximum deflection as described in section B.3.

Light and scanning electron microscopy examination were performed on the samples after standard metallurgical preparation as described in section B.4.

\section{Mold}

The split mold was custom designed and constructed for the study. It was designed (Fig. 2) to hold the samples so that the cross sectional shape would be maintained during the heating experiments whilst facilitating its easy removal when required. Copper was used due to its high thermal conductivity.

The mold consisted of four machined pieces, A, B, C and D as shown below. The bottom piece $A$ had overall dimensions of $106 \times 69 \times 12$ $\mathrm{mm}$. The cavity was $100 \times 50 \times 6 \mathrm{~mm}$. The other components were the middle plates $B$ and $C$, and the cover plate $D$ which fitted snugly 
into this cavity. Both plates $B$ and $C$ were $100 \times 25 \times 3 \mathrm{~mm}$. Plate $B$ had a groove with a width of 0.025 in and depth of 0.021 in machined at the inner-upper edge of the plate. The cover plate $D$ fitted on top of $B$ and $C$. Its dimensions were $100 \times 50 \times 3 \mathrm{~mm}$.

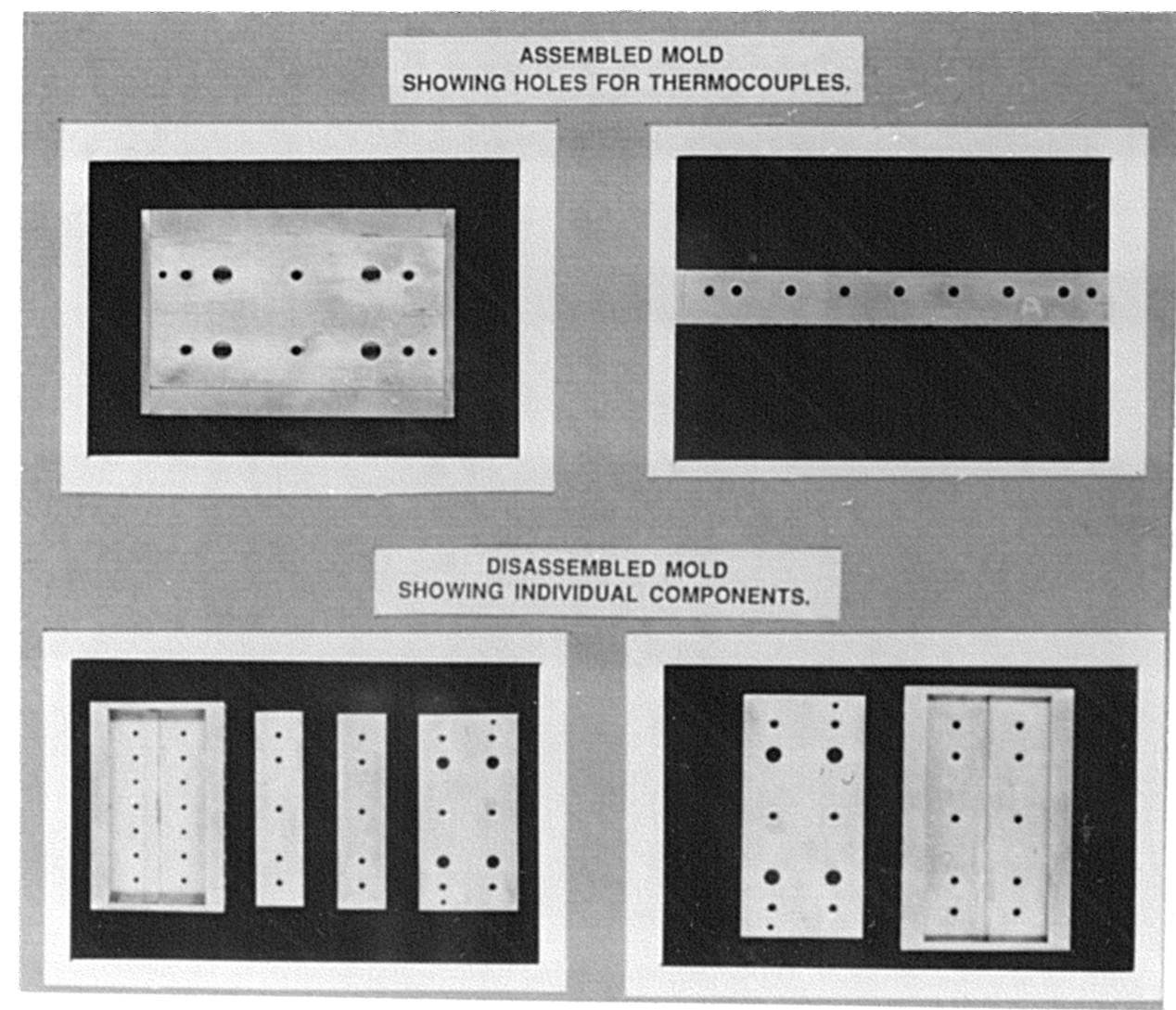

Fig. 2: Custom made copper mold.

When all the components were assembled, the groove in plate B was totally enclosed. The open side was enclosed by the inner side of 
plate $C$ and the top was enclosed by the bottom surface of plate $D$. The sample wire was placed in the groove. Individual adjustment in fit of the plates was possible through the use of adjusting screws. Holes were present in the side of the container which reached the inner edge of plates $B$ and $C$. This allowed the insertion of thermocouples so that the precise temperature at different locations and in the proximity of the wire could be measured.

Due to the softness of copper, care was taken when handling the mold to prevent any scratches or nicks especially in the groove.

\section{Flexural test and apparatus}

The mechanical properties of orthodontic wires are typically determined under bending conditions because this mode of deformation is considered more representative of clinical use than the conventional tensile test. As a consequence of this philosophy, American Dental Association specification no. 32 contains a cantilever bending test for the evaluation of orthodontic wires.4,11,40 All wires were submitted to a flexural test using a cantilever configuration with a modification of the ADA method. A torque gauge apparatus was used to apply an angular deflection to the wires at 
the fixed ends as shown below in Figures 3 and 4 . This apparatus allowed measurement of the bending moment as a function of the angular deflection of a cantilever specimen. The angular deflection of the wires at this support was measured with a protractor. The couple necessary to create the angular displacement was measured by a torque gauge. The couple was resisted by a force at the free end through an anvil placed against the wires. The force remained normal to the wires throughout the range of activation. The wire was held so that the width was 0.025 in and the thickness was $0.021 \mathrm{in}$. The force was applied normal to the width aspect of the wire.

Cantilevers with a span of $10.0 \mathrm{~mm}$ (0.3937 in) and cross sectional dimensions of approximately 0.021 in $\times 0.025$ in were used. The width and the thickness were measured at three points along the length and a mean for each calculated. Each wire was loaded at a constant rate in increments of 2.5 degrees and both the bending moment and the angular deflection were recorded until the fracture point. The testing was under room temperature ambient conditions. To determine the flexural modulus only the initial slope of the moment vs deflection curve was used i.e. values of deflection up to 7.5 degrees. This low deflection was well within the elastic limit of 
the wires, so there was no permanent deformation. The flexural modulus, maximum moment and the maximum deflection were calculated and converted to values for a standardized wire $10.0 \mathrm{~mm}$ long, 0.025 inch wide and 0.021 inch thick. The maximum angle of deflection for a standardized wire was obtained using the equation : Angle of Deflection $=$ average measured thickness $X$ measured angle (standard) standard thickness of 0.021 in

The cantilever beam relationship derived from elementary strength of materials concepts and represented by the following equation was used in determining the flexural modulus for a known moment at the fixed end:

$$
\begin{array}{rl}
E=\underline{M L 2} & =\text { flexural modulus of elasticity } \\
31 y & I=\text { section modulus of beam } \\
L & =\text { beam length } \\
M & =\text { moment at fixed end } \\
y & =\text { vertical deflection at simply supported end }
\end{array}
$$




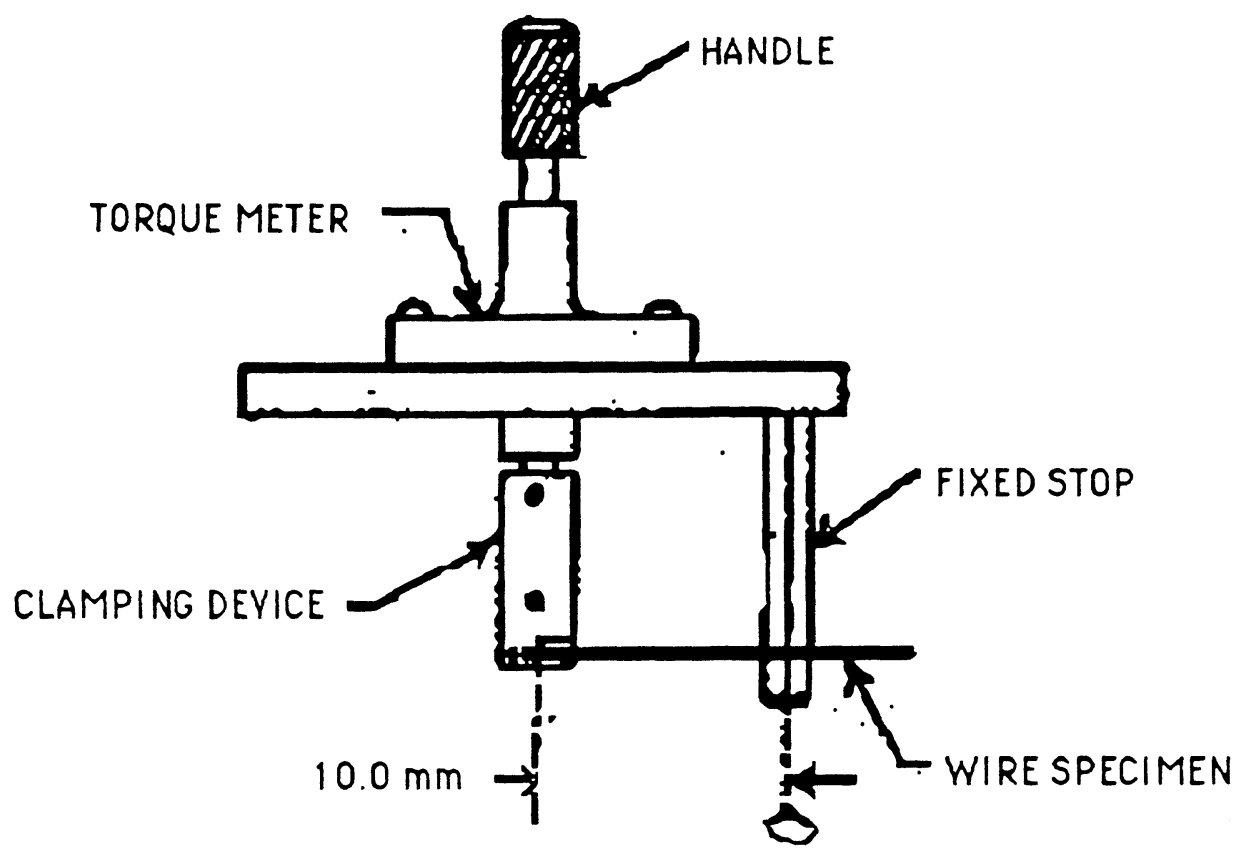

Fig. 3: Arrangement of torque meter.

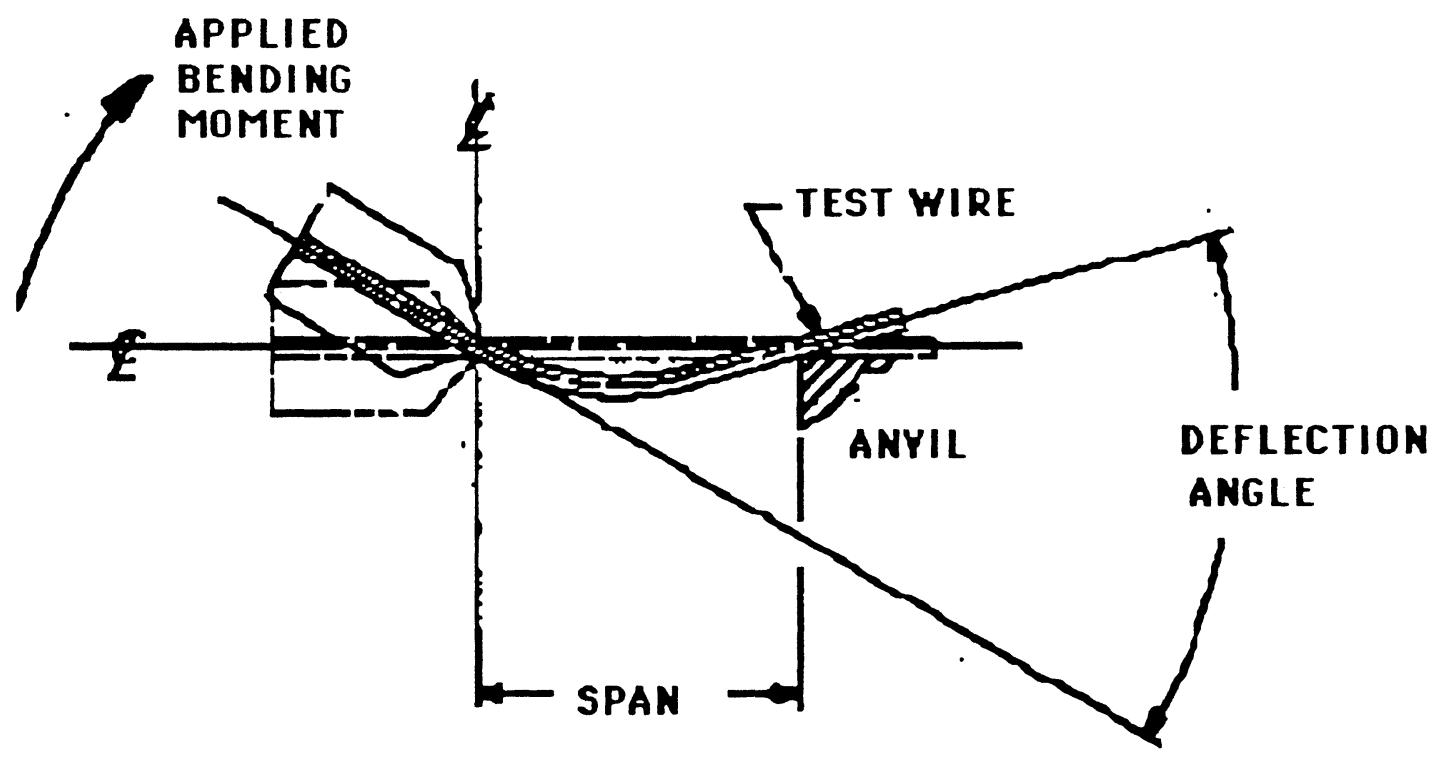

Fig. 4: Schematic drawing of bend test fixture. 


\section{Microscopy technique and preparation}

For this part of the study, the specimens examined were limited to samples of material X10333A and X10364 from the mold heating experiment. For the scanning electron microscopy the fractured surfaces of the specimens were examined after the flexural test.

For material X10333A two representative samples were selected at room temperature (no heating), $200 \mathrm{~F}$ and $400 \mathrm{~F}$. For material X10364 two representative samples were selected at room temperature (no heating), $200 \mathrm{~F}$ and $500 \mathrm{~F}$.

\section{a. Light microscopy technique and preparation}

The mounting medium used was a transparent room temperature cure epoxy resin (Sty cast 1266, Emerson and Cuming Inc., Canton, MA.).

The specimen were placed in the mold and the epoxy resin mixed as per manufacture's instruction. It was then poured into the mold. The casting was allowed to stand at RTP for at least 8 hours before removing it from the mold and polishing. The cross section of the specimen (Fig. 12 \& 18) were examined at magnifications of $\mathrm{X} 100$ using a Zeiss ICM 405 light microscope. 


\section{b. Scanning Electron microscopy technique and preparation}

Samples were mounted with double stick tape on aluminium stubs.

Colloidal graphite was used to anchor the ends. For each test condition two samples were mounted; one to examine the tension surface and the other to examine the compression surface. $25 \mathrm{~nm}$ of gold was sputter coated on the samples. Specimen were examined using a Joel JSM-35CF scanning electron microscope. Photographs were taken at 20X, 100X and 1000X magnification for each sample (Fig. $11 \& 17)$. 


\section{Forming experiments using a heating Chamber}

\section{Forming with $10.0 \mathrm{~mm}$ deflection}

A heating chamber was arranged to allow different degrees of bending of straight samples while at various temperatures. An Instron environmental chamber (also referred to as a heating chamber/oven) was used as described in Appendix C. A vice was placed inside the chamber which held one end of the sample. A 3.0 $\mathrm{mm}$ diameter stainless steel rod was fabricated, as shown in Figure 5 , so that one end (deflection end) was parallel to the vice and one inch away from it. The other end (measuring end) protruded out from the top surface of the chamber. This end was surrounded by a measuring column. The measuring column was a stainless steel tube 1.5 in long, $2.5 \mathrm{~mm}$ thick with a hole of $3.5 \mathrm{~mm}$. It was modified to hold a measuring tape and had tap screws to hold the rod in place. Moving this end of the rod vertically resulted in the other end of the rod moving by the same amount in the same direction. The movement could be measured directly with the measuring tape.

A thermocouple was placed in the chamber to accurately monitor the temperature within the chamber. The thermocouple was connected to 
the HP 7090 recorder via the TAC 80 convertor as decribed in Appendix C.

Material $\times 10333 \mathrm{~A}$ was used for the forming experiments. Five experimental groups with six samples per group were formed. Each sample was initially tested to a deflection of 7.5 degrees to determine the flexural modulus (for details refer to section B.3.) prior to heating. This low deflection was well within the elastic limit of the wires, so there was no permanent deformation. The same samples were then heated at different temperatures. The groups were; room temperature (control), $175 \mathrm{~F}, 250 \mathrm{~F}, 300 \mathrm{~F}$, and $350 \mathrm{~F}$.

In order to minimise the variability, samples from the same batch and section of wire were taken. The group tested at room temperature was the control for comparing changes in maximum moment, maximum angle of deflection, moment vs deflection characteristics, as well as change in modulus. The approach of retesting the same samples provided an even greater precision for monitoring the change in modulus before and after heating.

The samples were placed in the chamber so that one end was held in the vice. This point on the sample was marked using an indeliable 
ink. The indelible mark allowed the forming and testing to be done at the same location on the sample. The samples were all parallel to each other and approximately $3.0 \mathrm{~mm}$ apart. The deflection rod was then adjusted so that it was in passive contact with the wires, a distance of 1.0 inch away from the vice.

The chamber was then heated from room temperature to the forming temperature. When the forming temperature was achieved, the deflection rod was raised $10.0 \mathrm{~mm}$. This resulted in the formation of a bend in the wire. The deflection rod was fixed in the new position and the temperature maintained for 5 minutes. Heating was then ceased and the chamber door opened to allow rapid air cooling to room temperature before removing the samples. The time temperature sequence is shown in Figure 42.

The curved samples were held at the location of the indelible mark in the flexural tester. Thus the forming and testing was done at the same location on the sample. All samples were then tested to failure at room temperature, as $10 \mathrm{~mm}$ free-end cantilever beams, to determine the flexural modulus, maximum bending moment and maximum deflection as previously described in section B.3. 
2. No forming with $0 \mathrm{~mm}$ deflection

The above experiment was repeated except that the deflection was $0 \mathrm{~mm}$. Thus no forming was done. A group at temperature of $400 \mathrm{~F}$ was included. This experiment served as the control for the above experiments and was intended to differentiate the influence of forming from heating.

3. Forming with $7.0 \mathrm{~mm}$ deflection

The above experiment was repeated at a temperature of $250 \mathrm{~F}$ using a $7.0 \mathrm{~mm}$ deflection. Thus the curvature in the wire that was formed was less pronounced than that with a $10.0 \mathrm{~mm}$ deflection. 


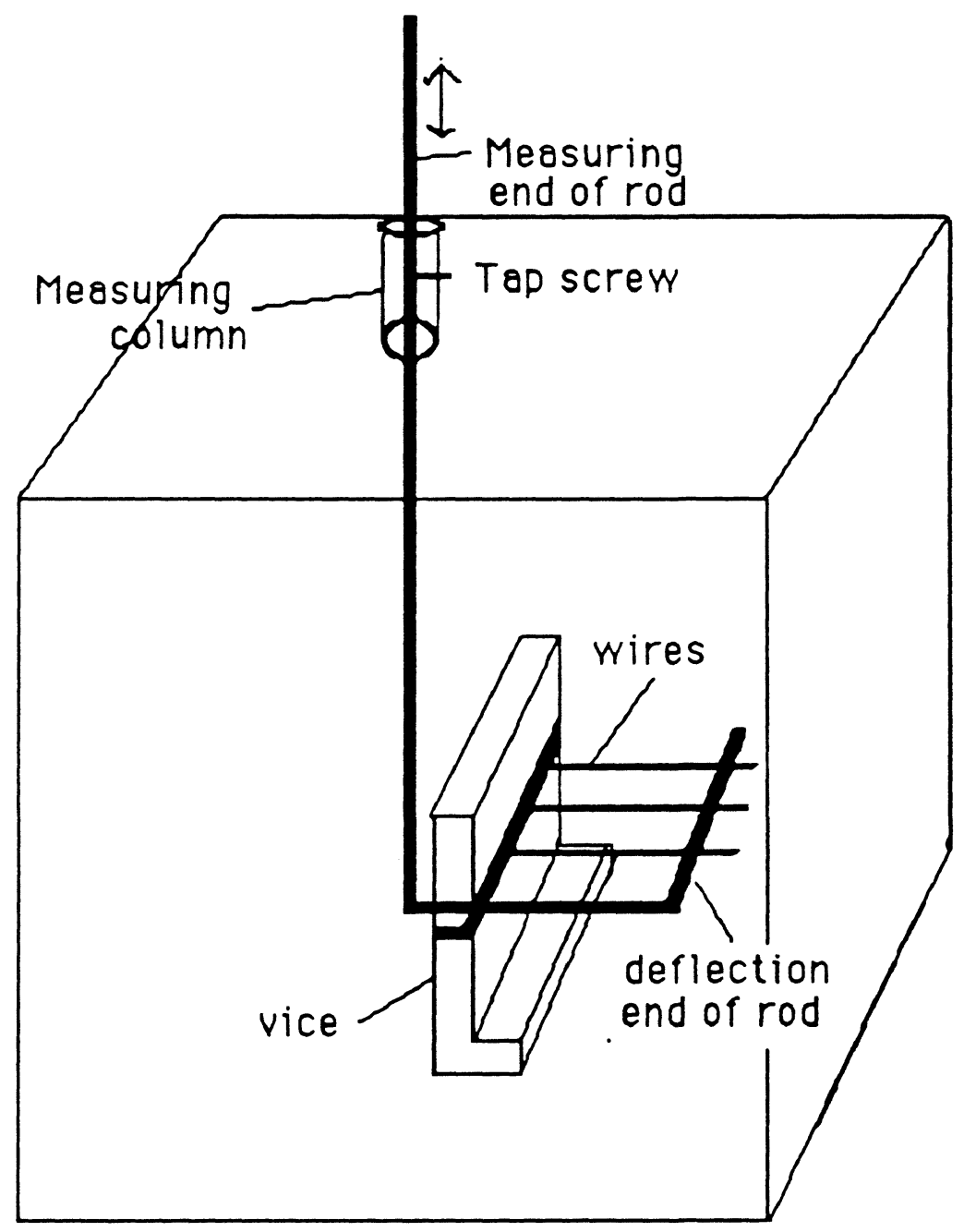

Fig. 5: Heating Chamber.

Instron environmental chamber/oven with accessories. 


\section{Other heating parameters}

\section{Duration and method of heating}

Material X10333A was used for these experiments. Four experimental groups, with three samples per group were tested. Each sample was initially tested to a deflection of 7.5 degrees to determine the flexural modulus (for details refer to section B.3.) prior to heating. This low deflection was well within the elastic limit of the wires, so there was no permanent deformation. The same samples were then heated at different temperatures. The approach of retesting the same samples provided a precise monitoring of the change in modulus before and after heating.

In order to minimize the variability, samples from the same batch and section of wire were taken.

Two of the experimental groups were heated as straight samples in the mold at $410 \mathrm{~F}$ for five and ten minutes, respectively. The remaining two groups were heated as straight samples $(0 \mathrm{~mm}$ deflection) in the oven at $410 \mathrm{~F}$ for five and ten minutes, respectively.

The temperature, duration and rate of heating were recorded using thermocouples connected to the HP 7090 Recorder via the TAC 80 
convertor as previously described, and shown in Figures 40 and 42 .

All samples were then tested to failure at room temperature, as 10 $\mathrm{mm}$ free-end cantilever beams, to determine the flexure modulus as previously described.

\section{Predrying and vacuum heating}

Straight samples of material $\times 10333 \mathrm{~A}$ were used for these experiments. Three experimental groups with three samples per group were tested. Each sample was initially weighed and tested to a deflection of 7.5 degrees to determine the flexural modulus (for details refer to section B.3.) prior to heating. This low deflection was well within the elastic limit of the wires, so there was no permanent deformation. The same samples were then heated at $400 \mathrm{~F}$ for 5 mins. as straight pieces under different conditions using an oven without a mold. The approach of retesting the same samples provided a precise monitoring of the change in modulus before and after heating.

In order to minimise the variability samples from the same batch and section of the wire were taken. The variability was further minimised by preselecting samples of similar original modulus. 
Group A was used as the control. Samples were heated at atmospheric pressure without prior predrying using the Instron environmental chamber.

Groups B and C, were predried under vacuum at $180 \mathrm{~F}$ for $24 \mathrm{hrs}$ in a vacuum oven. The samples were then reweighed to determine if loss of moisture or other compounds had occurred. Group C was heated at atmosheric pressure using the Instron environmental chamber. Group $B$ was heated and cooled under vacuum using a vacuum oven.

The temperature, duration and rate of heating were recorded using thermocouples connected to the HP 7090 Recorder via the TAC 80 convertor as previously described.

All samples were then tested to failure at room temperature, as 10 $\mathrm{mm}$ free-end cantilever beams, to determine the flexure modulus as previously described.

\section{Calibration of a warm-air gun and measurement of air}

temperatures during clinical forming of orthodontic retainers

Concurrent with this thesis, a pilot study had been initiated to evaluate the clinical efficacy of the FRC as an orthdontic retainer. Forming of the retainers in the past had been empirical. A warm-air 
gun (Unger 6966C) was used clinically to form orthodontic retainers. The gun provided convectional heating and had a dial that allowed regulation of the heat. It had been impossible to know what was the temperature of the heat generated by the gun, and of the study model that the retainer was formed on. Usage of this gun had been on an emperical basis. Operators had used different dial settings with large operator variability and different success rates. Calibration of the gun would quantitate what heat was generated and applied as well as define what dial setting should be used for proper fabrication of retainers.

Since forming of retainers had been on an emperical basis it was felt necessary to determine what temperature ranges were used when clinically acceptable retainers were formed. This information would allow comparison of differences that may exist between forming under clinical conditions and strict laboratory conditions such as that using the oven or mold. In addition, it would allow establishment of guidelines as to what the appropriate temperature range for forming may be under clinical conditions. 


\section{a. Calibration of heating nozzle of warm-air gun}

A thermocouple (Type T, Omega Co., CT. For details see Appendix C.) was placed at the nozzle tip of the warm-air gun (Unger 6966C) to allow measurement of the temperature of the air emitted by the gun. A second thermocouple was placed on the surface of a model which was previously at room temperature. The nozzle was kept one inch away from the surface of the model since this was the standard distance when retainers were made. The thermocouples were connected to the HP 7090 Recorder via the TAC 80 convertor as previously described.

The warm-air gun was kept on dial settings from \#5 to \#10 for two minutes each. Temperatures were recorded at both the nozzle of the gun and surface of model for these dial settings as shown in Figure 43.

b. Measuring the temperature range which is used clinically when forming retainers with the warm-air gun

For this part of the study thermocouples were placed on the lingual surfaces of lower canines and at the nozzle of the gun. A lingual bonded retainer was then formed from 110AZH tape with cross section dimension of 0.040 inch thickness and 0.060 inch width. 
$110 \mathrm{AZH}$ was identical to $113 \mathrm{AZH}$ except for the difference in thickness. The nozzle of the gun was held approximately one inch away from the retainer. Heat was applied with the dial setting at 5 , from one canine to the other until sufficient softening had occurred that the retainer could be adapted to the teeth. A second "sweep" with the heat gun was often needed to adapt the retainer further in some areas. Temperature differences are shown in Figure 44. 


\section{RESULTS}

\section{A. Heating experiments using straight lengths of FRC in mold and}

\section{heat press}

Results from the experiments conducted on straight lengths of wire, heated in the copper mold to maintain their cross sectional shape, are shown in Figures 7 to 34 and Tables 1 to 18. The figures and tables are divided into six groups according to the material tested as shown below:

* X10333A - Figures 7 to 12 and Tables 1 to 3.

* X10364 - Figures 13 to 18 and Tables 4 to 6.

* X10333B - Figures 19 to 22 and Tables 7 to 9.

* X10361 - Figures 23 to 26 and Tables 10 to 12.

* X10354 - Figures 27 to 30 and Tables 13 to 15.

* 113AZH - Figures 31 to 34 and Tables 16 to 18.

The figures and table show the effect of temperature on flexural modulus, maximum moment, maximum deflection, and moment vs deflection values at various temperatures, respectively. For the first two materials, $\mathrm{X} 10333 \mathrm{~A}$ and $\mathrm{X} 10364$, scanning electron 
micrographs of the specimens after the fracture test and optical micrographs of cross sections after heating are also included.

The line labelled "control", in the figures showing change in flexural modulus, is the mean value for the eight control groups. Values of the individual samples and the mean and standard deviation for each group are reported in their respective tables in Appendix B. There was no statistically significant difference between the eight control groups, so they are represented as a straight line in the figures for clarity. A pair wise students $t$ - test was performed for each experimental group before and after heating. Any statistically significant change $(p<0.01)$ in modulus is reported. For example, Table 1 shows the change in modulus for material X10333A. The mean modulus of the samples prior to heating at $200 \mathrm{~F}$ was $2.83 \mathrm{x}$ 106 psi. This is shown in the upper part of the table labelled modulus prior to heating and in the row with temperature indicated $200 \mathrm{~F}$ and column labelled mean. This was the control and was compared to the modulus after heating for the same temperature group in the lower part of the table. For $200 \mathrm{~F}$, this was $2.73 \times 10^{6}$ psi. The approach of retesting the same samples provided a precise monitoring of the change in modulus before and after heating. 
Results of the heating experiments using straight samples in the mold show that with increase in temperature there was a monotonic decrease in the modulus and maximum moment, but no change in maximum deflection.

Representative of these trends are the results for material $\mathrm{X} 10333 \mathrm{~A}$, shown in Figures 7-9. The difference in modulus between control and the heated samples was statistically significant at temperatures above $250 \mathrm{~F}$. At $250 \mathrm{~F}$ the decrease in modulus was $0.47 \times 106 \mathrm{psi}$ and at $450 \mathrm{~F}$ it was $1.93 \times 106 \mathrm{psi}$. The maximum moment decreased from $1478 \mathrm{gm}-\mathrm{mm}$ for samples which where not heated (control) to $852 \mathrm{gm}-\mathrm{mm}$ for samples heated at $400 \mathrm{~F}$. The maximum deflection was constant at $24.0+/$ - S.D. 4.0 degrees over the entire range of temperatures. The moment vs deflection curves (Fig. 10) were different for the various heating temperatures. The curves for those at RTP, $200 \mathrm{~F}$ and $250 \mathrm{~F}$ were linear to the yield strength with a moment-deflection rate of $75 \mathrm{gm}-\mathrm{mm} / \mathrm{degree}$ and little plastic deformation. For the higher temperatures, particularly $400 \mathrm{~F}$ to $450 \mathrm{~F}$, the curves shifted towards the lower moment. The material exhibited an apparent region of plastic deformation and 
was able to support a constant moment with increasing deflection but with decreased spring back.

Scanning electron fractographs for material X10333A with composition of $57 \%$ S2 glass in a PETG matrix (Tg. $165 \mathrm{~F}$ ) are shown in Figure 11.

Structural changes between the room temperature control specimens and those heated to elevated temperatures were observed. The changes were more dramatic with higher temperatures.

At room temperature the material apparently behaved homogeneously. The surface was smooth with no fiber pull out. Crack propagation was across the fibers and the matrix.

At higher temperatures the material behaved heterogeneously. Fibers were seen protruding from the surface. Crack propagation was different, and fiber pull out was seen at the fracture surface. Poor wetting of the fibers was also evident. The matrix morphology appeared different, the resin assuming a globular form.

Scanning electron fractographs for material $\times 10364$ with composition of $57 \%$ S2 glass in a PC matrix (Tg. $282 \mathrm{~F}$ ) are shown in Figure 17. Although similar structural changes were seen, the severity was less. Even at temperatures of $500 \mathrm{~F}$, little shredding of 
the material was evident. The matrix resin showed less morphological changes compared to the PETG resin at $400 \mathrm{~F}$. The differences are attributed to the higher $\mathrm{Tg}$ of Polycarbonate resin.

Changes in the cross sectional shape and dimension were also seen at elevated temperatures. This is illustrated in Figures 12 and 18 for $\mathrm{X} 10333 \mathrm{~A}$ and $\mathrm{X} 10364$, respectively. For material X10333A, at $300 \mathrm{~F}$ rounding of the edges was seen. At higher tempratures the changes were more significant, with shapes ranging from oval to trapiezoidal. In addition, at temperatures above $350 \mathrm{~F}$ "shredding" of the material was evident. Both of these factors made determination of the cross section difficult. Material X10361 (PCTG) resin showed less dimensional changes than $\mathrm{X} 10333 \mathrm{~A}$. The least change was seen with $\times 10364$ due to the high glass transition temperature of polycarbonate resin.

As regards the flexural properties and morphological changes with heating, all materials showed a similar trend to X10333A. However the temperature at which the decrease in modulus became significant was different. For material $\times 10364$ this began at $300 \mathrm{~F}$ with a decrease of $0.55 \times 106 \mathrm{psi}$ and at $500 \mathrm{~F}$ the decrease was $1.44 \times 106 \mathrm{psi}$. For $\times 10361$ the rate of change in modulus with 
temperature was low so that the drop between $200 \mathrm{~F}$ and $400 \mathrm{~F}$ was insignificant, being $0.15 \times 106 \mathrm{psi}$ and $0.73 \times 106 \mathrm{psi}$ respectively. For $\mathrm{X} 10354$ significancant decrease was seen at $250 \mathrm{~F}$ with a decrease of $1.23 \times 106 \mathrm{psi}$ and at $350 \mathrm{~F}$ the difference was $1.93 \times 106 \mathrm{psi}$. For $\mathrm{X} 10333 \mathrm{~B}$ significant decrease was seen at $250 \mathrm{~F}$ with a decrease of $0.46 \times 106 \mathrm{psi}$ and at $400 \mathrm{~F}$ the difference between before and after heating was $0.91 \times 106 \mathrm{psi}$. Thus the least significant decrease with heating temperatures was with matrial $\times 10361$ and the most with $\times 10354$.

The maximum moment also decreased with increase in heating temperature for all materials, although the temperature where significant drop was first seen was different, as was the rate of change.

The maximum deflection remained constant for all heating temperatures, but at the higher temperatures there was less spring back. Material X10364 and X10361 showed the least decrease in the spring back at temperatures above $350 \mathrm{~F}$. Material X10354 with the Kevlar fibre-reinforcement showed the most significant decrease in spring back. 
B. Forming experiments using the Instron heating chamber and material X10333A

Results of the change in modulus in the forming experiments for material $\times 10333 \mathrm{~A}$ are shown in Figures 35 to 37 and Tables 19 to 22.

The line labelled "control", in the figures showing change in flexural modulus, is the mean value for the eight control groups. Values of the individual samples and the mean and standard deviation for each group are reported in their respective tables in Appendix B. There was no statistically significant difference between the control groups, so they are represented as a straight line in the figures for clarity. A pair wise students $t$ - test was performed for each experimental group before and after heating. Any statistically significant change $(p<0.01)$ in modulus is reported. For example, Table 19 shows the change in modulus at $0 \mathrm{~mm}$ deflection. The mean modulus of the samples prior to heating at $250 \mathrm{~F}$ was $2.76 \times 106 \mathrm{psi}$. This is shown in the upper part of the table labelled modulus prior to heating and in the row with temperature indicated $250 \mathrm{~F}$ and column labelled mean. This was the control and was compared to the modulus after heating for the same temperature group in the lower 
part of the table. For $250 \mathrm{~F}$, this was $1.97 \times 106 \mathrm{psi}$. The approach of retesting the same samples provided a precise monitoring of the change in modulus before and after heating.

The flexural modulus is a reliable and accurate parameter for evaluating the general physical and structural properties of a material and was thus used as the primary measurement. While the flexural modulus measurements were consistent, there was great variability in the maximum moment and deflection. Plastic deformation of the material made the point of maximum deflection ill-defined. Consequently the latter two measurements are not reported in this part of the study.

For both the straight samples $(0 \mathrm{~mm}$ deflection) and formed samples (10 $\mathrm{mm}$ deflection), the apparent modulus increased from $175 \mathrm{~F}$ to $300 \mathrm{~F}$ and then dropped linearly with further increase in temperature, as shown in Figures 35 and 36.

It should be noted that both the groups $(0 \mathrm{~mm}$ and $10 \mathrm{~mm}$ deflection) which were heated at $300 \mathrm{~F}$ have a higher modulus than comparable groups which were heated at other temperatures. This difference was attributed to a change in the specimen geometry. Visual observation of the samples showed that at tempearatures above 
$175 \mathrm{~F}$, buckling of the material occurred. This was primarily in the horizontal plane but also in the vertical plane. Some twisting of the wire was also present. This buckling was most evident at $175 \mathrm{~F}$ and at $250 \mathrm{~F}$ only a slight rippling of the surface was observed. At temperatures above $300 \mathrm{~F}$, changes in the cross section were seen from mild rounding to tapiezoidal and oval shapes.

In addition, the cross sectional dimensions of the wire were different along its length. Where the wire was held in the vice it was wider but thinner. At the other end it was more rectanular. This is illustrated schematically in the figure below. These geometrical changes, specifically the buckling, cause an apparent decrease in modulus.

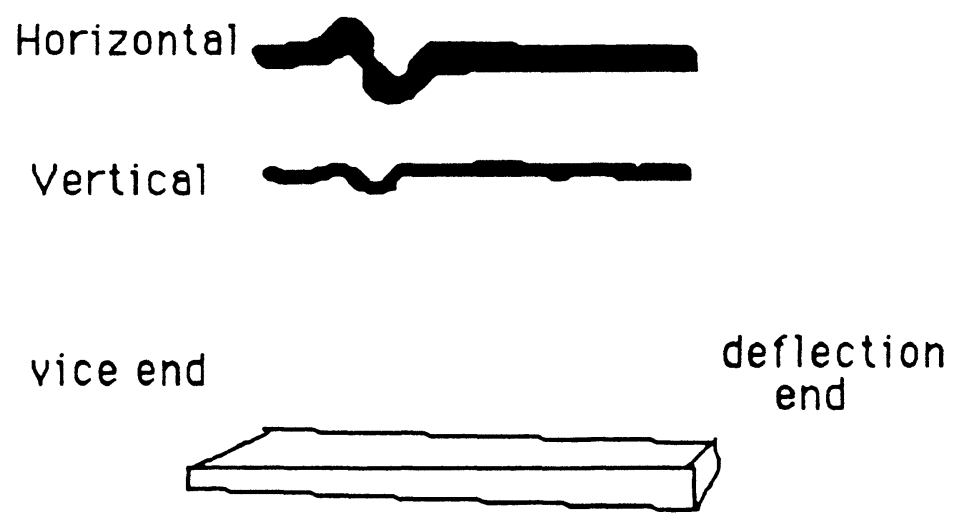

Fig. 6: Shape of wire after heating in oven. No forming was done. 
The effects of forming alone can clearly be demonstrated by the histogram in Figure 37 which has been replotted from the data above. The data are summarized in Table 21. Results of $0 \mathrm{~mm}$ deflection (no forming) or $10 \mathrm{~mm}$ deflection (forming) at three temperatures, $250 \mathrm{~F}, 300 \mathrm{~F}$ and $350 \mathrm{~F}$, are shown. At $250 \mathrm{~F}$, an intermediate curvature of $7 \mathrm{~mm}$ was also tested. Columns representing the modulus before forming (control) and after forming are shown. Standard deviations are also indicated.

A 3-factor repeated measures Anova was done to determine any statistical differences in modulus. The summary data is presented in Table 22 and shows the effects of temperature, deflection and the repeated measure (before and after treatment). A statistically significant difference $(p<0.0001)$ was seen between the before and after groups. Temperature had a significant effect $(p<0.0002)$. Forming appeared to have an effect $(p<0.0155)$. However it was likely that the buckling of the specimens that happened in both $0 \mathrm{~mm}$ and $10 \mathrm{~mm}$ def groups was responsible for this statistical value. In addition forming as a factor could be eliminated since the forming group also consisted of a control sub-group ( $0 \mathrm{~mm}$ deflection). A 3way interaction $(p<0.0221)$ between temperature, deflection, and the 
before and after experimental groups was present. This is explained by the geometrical changes of the specimen and the fact that the modulus of all the pretest groups was not similar.

In summary, although there was a statistically significant decrease in modulus with forming at elevated temperatures, it was independent of the degree of forming.

It is concluded that the change in modulus was due to the heating and not forming since the modulus was similar to the control samples (heated in the chamber but not deflected i.e. not formed).

\section{Other heating parameters}

1. Duration and method of heating

The effect of duration of heating at $410 \mathrm{~F}$ in the mold and oven is shown in Table 23 and as a histogram in Figure 38. Columns representing the modulus before (control) and after treatment are shown. Standard deviations are also indicated.

A 3-factor repeated measures Anova was done to determine any statistical differences in modulus. The summary data is presented in Table 24 and shows the effects of the method and duration of heating, and the repeated measure (before and after treatment). A 
statistically significant difference $(p<0.0001)$ was seen between the before and after experimental groups. Neither the method of heating $(p<0.5663)$ nor the duration $(p<0.4311)$ had a significant effect on the modulus.

It is concluded that the change in modulus was due to the heating of samples and was independent of the method and duration of heating. It was interesting to note that when the effect of either using the mold or the oven for similar duration of heating is compared, there was a lesser decrease in modulus with the oven experiments. This difference is due to a change in specimen geometry as discussed earlier.

Quantification of the time versus temperature curves shows major differences between the mold, for both rapid cooling by quenching and bench cooling to room temperature, and the environmental chamber. This is clearly illustrated in Figures 40, 41 and 42.

When the mold was heated to a temperature of $410 \mathrm{~F}$ using the heat press, it heated linearly at a rate of $32 \mathrm{~F} / \mathrm{min}$. The total time it took to reach $410 \mathrm{~F}$ from $70 \mathrm{~F}$ was 9.75 mins. The time taken to reach the Tg of PETG (165 F) from room temperature $(70 \mathrm{~F})$ was 2.25 mins. and from $\mathrm{Tg}$ to $410 \mathrm{~F}$ was 7.5 mins. 
The cooling characteristics for the mold depended on the method of cooling. When the temperature was held at $410 \mathrm{~F}$ for approximately 5 mins. and was then allowed to bench cool to room temperature (Fig. 40), the temperature drop from $410 \mathrm{~F}$ to the $\mathrm{Tg}$ was exponential taking 29.75 mins. The temperature decrease from $20 \mathrm{~F}$ above $\mathrm{Tg}$ to $20 \mathrm{~F}$ below $\mathrm{Tg}$ occured in about 5.5 mins. The total time that the mold with the samples was above the $\mathrm{Tg}$ was 45.5 mins.

When the mold was quenched in room temperature water (Fig. 41), the temperature drop from $410 \mathrm{~F}$ to the $\mathrm{Tg}$ took less than 10 seconds. The temperature decrease from $20 \mathrm{~F}$ above $\mathrm{Tg}$ to $20 \mathrm{~F}$ below Tg occured in about 2 seconds. The total time that the mold with the samples was above the $\mathrm{Tg}$ was 12 mins.

A one factor ANOVA-Repeated measures test showed no difference $(p<0.8369)$ between bench cooling to room temperature or quenching.

The rate of heating for the environmental chamber was different as seen in Figure 42. It heated exponentially at an average rate of 5 $\mathrm{F} / \mathrm{min}$. The total time it took to reach $410 \mathrm{~F}$ from $70 \mathrm{~F}$ was 61 mins. The time taken to reach the $\mathrm{Tg}$ of PETG (165 F) from room temperature $(70 \mathrm{~F})$ was 5.5 mins. and from $\mathrm{Tg}$ to $410 \mathrm{~F}$ was 55.5 mins. 
When the temperature was held at $410 \mathrm{~F}$ for approximately 10 mins. and the chamber door opened to cool, the temperature drop from $410 \mathrm{~F}$ to the $\mathrm{Tg}$ was almost instantaneous, taking less than 10 seconds. The temperature decrease from $20 \mathrm{~F}$ above $\mathrm{Tg}$ to $20 \mathrm{~F}$ below Tg occured in about 2 seconds. The total time that the samples in the chamber were above the $\mathrm{Tg}$ was 62.5 mins. It was $57.5 \mathrm{mins}$ if the temperature at $410 \mathrm{~F}$ was held for 5 mins.

\section{Predrying and vacuum heating}

The effect of predrying and vacuum heating using the oven is shown in Table 25 and as a histogram in Figure 39. Columns representing the modulus before (control) and after treatment are shown. Standard deviations are also indicated.

A 2-factor repeated measures Anova was done to determine any statistical differences in modulus. The summary data is presented in Table 26 and shows the effect of pre-drying and the repeated measure (before and after treatment). A statistically significant difference $(p<0.0001)$ was seen between the before and after groups. However there was no difference $(p<0.24)$ between the various treatments. 
It is concluded that the effect of heating is the most significant factor. Predrying and heating under vacuum had no significant effect.

\section{Calibration of a warm-air gun and measurement of air}

temperatures during clinical forming of orthodontic retainers

Figure 43 illustrates the relation between the dial setting, the nozzle temperature and the surface temperature one inch away. It was noted that the surface temperature on the model was significantly less than the nozzle temperature for all dial settings. For example, at a dial setting of \#5, the difference was $154 \mathrm{~F}$.

Figure 44 shows that there was a large temperature variation when forming retainers with the warm-air gun. The temperature was between $176 \mathrm{~F}$ and $309 \mathrm{~F}$, even when care was exercised to maintain a constant temperature. The nozzle temperature was steady for any given dial setting as shown by the top line in Figures 43 and 44 . The temperature of the air emitted by the gun was much higher than that at the working surface of the study model. 


\section{DISCUSSION}

In order to study the effects of thermoforming on the flexural properties of composite wires, it was first necessary to distinguish between factors which may be important. These included the temperature of heating, method of heating, amount of forming, material composition, duration of heating and predrying samples before heating. Experiments were conducted to identify the importance of each of these factors.

The effect of temperature was considered to be the most important factor. This was examined by heating straight samples without forming at different temperatures under controlled conditions, as that obtained by using a custom made copper mold in a heat press. It was felt the mold would also hold the shape of the wire and restrict any change in geometry that might occur as a result of previous stresses introduced during processing. Also, in industry many fabrication methods involve the use of molds, so that it could be related to a practical method. It was found that at temperatures up to $350 \mathrm{~F}$, the samples held their shape, even if the original sample had a curvature to begin with. At higher temperatures of $400 \mathrm{~F}$ and 
above, the material would stick to the mold even if a mold releasing silicone lubricant spray was used. Thus some distortion occured from handling, even if great care was exercised.

The method of heating was considered to be an important factor, since both the mold and chamber have different rates of heating and cooling. Results of the heating experiments in the oven were similar to the mold experiments at temperatures higher than $300 \mathrm{~F}$ but different at lower temperatures. With oven heating there was an increase in modulus between $150 \mathrm{~F}$ and $300 \mathrm{~F}$. At $300 \mathrm{~F}$ a peak in modulus was seen. However at temperatures above $300 \mathrm{~F}$ a progressive drop in modulus with temperature was observed.

It is hypothesized that there were essentially three mechanisims contributing to this behavior. The first factor, which is felt to play only a minor role, is the release of thermal stresses and strains. At heating temperatures near or above its $\mathrm{Tg}$, the heat energy put into the material caused the release of thermal strains and stresses that were introduced during pultrusion processing. Confirmational changes occurred in the matrix as the material tried to move to a more stable state. This resulted in changes within the structure of the material. It is possible that when the material was restrained as 
in the mold, the effect of these thermal stresses and strains within the material caused structural deterioration.

The second factor is the geometrical change of the sample. At lower temperatures (175 F-250 F) this was manifested as buckling of the specimen and caused an apparent decrease in modulus with the oven experiments. This buckling decreased with increase in temperature and at temperatures above $250 \mathrm{~F}$ was not observed. Of course when the mold was used the system was restrained so that the buckling was not evident.

At temperatures above $350 \mathrm{~F}$, the geometrical change was seen as a rounding of the edges, change in cross sectional shape and dimension etc.. This became more pronounced at higher temperatures and caused an apparent decrease in modulus. The effect of this was more significant with the oven experiments, rather than the mold experiments, where geometrical changes are restricted.

The third factor is polymer degradation which increased with temperature and became a very significant factor. Polymer degradation, as determined from SEM examination, lead to both matrix and interfacial break down. The system could no longer behave homeogeneously or function properly. This was also seen in 
the moment vs. deflection curves where there was a plastic region (plateau) indicating that the spring back of the material was decreased. The load distribution was not efficient and this was reflected as a drop in modulus and maximum moment. In the mold experiments the same was true, but only that the contained stresses apparently had a more significant effect of fiber pull out "shredding" of the material so that visually the samples looked worse and made determination of the cross section more difficult.

In conclusion, the decrease in modulus and deterioration in flexural properties that was seen with heating was primarily due to polymer degradation and geometrical changes.

The effect of forming alone was examined using the heating chamber and material $\times 10333 \mathrm{~A}$. Results indicated that there was no significant effect of the actual forming of bends of different curvatures compared to the straight samples. The main effect appeared to be heating in the temperature range used in this study.

The composition of composites will have an effect on its properties. It was felt necessary to determine how much of the change in flexural properties with heating was related to composition. When findings for materials with different composition are compared for 
heating as straight samples in a mold it was found that the trend of decrease in modulus with temperature was similar although the amount was different. Comparision of X10333A and X10333B where the materials have the same PETG matrix but fiber contents of $57 \%$ and $54 \%$, respectively were comparable. As expected, changing the matrix resin influenced the softening point of the composite. This was related to the glass transition temperatures of the different resins. Both $X 1033 \mathrm{~A}$ and $\mathrm{X} 10333 \mathrm{~B}$ have PETG (Tg=165 F/74 C) as the matrix resin. When the fiber content was kept the same at $57 \%$ but the matrix was changed to $P C(T g=282 F / 139 \mathrm{C})$, the curves moved towards the higher temperature so that the softening and working temperature range was higher. With PCTG ( $T g=174 \quad F / 79 \quad \mathrm{C})$, the softening and working temperature was not significantly different from PETG. When the fiber was Kevlar instead of the $S 2$ glass, with PETG as the matrix, the composite had very poor properties. The sample variation was very large and the material behaved in an inconsistent manner. One of the explanation for this is Kevlar itself is a polymer with chains which are in a mesh work. As a result it is unable to support compressive forces which occur on the concave surface of the flexure specimens, as well as glass reinforcement. 
Also Kevlar itself may undergo degradation by oxidation upon heating. However this has been reported in the literature as occurring only at long term temperatures of $300 \mathrm{~F}(150 \mathrm{C}) .41$

The uniformity of the fiber distribution was also examined. This was important since in a composite if the fiber distribution is not uniform, than different regions will behave differently and exhibit different physical properties. Wire samples of material $113 \mathrm{AZH}$ with a cross section $0.021 \times 0.025$ inch were cut and used. This material was supplied as a tape 0.021 inch thick and 4.0 inch wide, with a composition of $40 \% E$ glass in a PETG resin matrix. It was found that the samples had large variations in both the fiber distribution and physical properties as seen by microscopic examinations and the large standard deviations within the before and after tested groups. Since the material is not truly homogeneous it would be erroneous to extrapolate findings from a large dimension sample to a smaller dimension sample. In wires which were proccesed to the dimensions of $0.021 \times 0.025$ inch there was greater homogeneity amongst the samples in both composition and structure. Sample to sample variation was small as seen by the small deviation within the before and after tested groups. 
The duration of heating should influence the structure and properties of composities. In industry, during processing this factor is taken into consideration and is controlled. Generally the duration of high heating temperatures is kept to a minimum since it deteriorates the properties. No statistically significant difference was found between the heating times or the method of heating in the experiments conducted. One of the explanations for this may be that since the wires are of such small dimensions it was rapidly and uniformly heated. Thus the duration of heating may not have a significant effect unless it was for considerably longer durations than the time and temperatures used in this study.

Analyses of the heating cycles for the mold with the heat press and the oven showed a difference in the duration and the rate of heating/cooling (Figs. 40, 41, 42). The mold using the heat press heated up rapidly from room temperature at a rate of $32 \mathrm{~F} / \mathrm{min}$. The cooling to room temperature was less rapid. The total time that the mold with the samples was above the $\mathrm{Tg}$ of PETG was 45.5 mins for heating temperature of $410 \mathrm{~F}$ at $5 \mathrm{mins}$. It was also noted that the mold got heated uniformly and to the same temperatures as that of the heating platens. The temperature fluctuations of the heating 
platens was +/- $4 \mathrm{~F}$ from the mean, and was considered to be acceptable. The oven heated up gradually at a rate of $5 \mathrm{~F} / \mathrm{min}$. The cooling was more rapid since the chamber door was opened to allow the influx of room temperature air, being more rapid than the mold. The total time that the mold with the samples was above the $\mathrm{Tg}$ of PETG was 57.5 mins for heating temperature of $410 \mathrm{~F}$ at 5 mins. The temperature fluctuations were negligible. Thus the duration of the heating cycle of the oven was twelve minutes longer than that of the mold with heat press. The data obtained also showed that for comparable experiments the method of heating did not influence the properties and also reinforced the finding that the duration of heating did not affect the properties for the time and temperatures examined in this study.

Another factor which is important is moisture contamination. This is known to cause a deterioration in the physical properties and structural breakdown of the composite. In order to study this factor experiment D.2. was conducted. It was anticipated that any affect of moisture would become apparant. However no change in weight was noted with predrying. Neither was there any change in physical properties compared to the control where samples were neither 
dried nor heated under vacuum. Thus moisture contamination did not appear to be an important factor with these composites, under the test conditions. A useful experiment that would reinforce these findings would be to reverse the conditions by hydrating the samples until saturation prior to testing.

In calculating the flexural modulus and other flexural properties, the standard formula used has some inherent problems. There is an assumation that the length of the beam does not change. In fact the length is not constant and changes as the specimen is deflected. The formula is also strictly applicable to small deflections only. In addition, if the sample is not straight, the formula does not hold true and a correction has to be made. Therefore for samples which were formed (curvature placed into the wire) the numbers obtained for the change in modulus, moment and deflection after forming can only be used in a qualitative sense for relative comparision. In addition during forming it is assumed that the amount of curvature for all samples in one group are similar. This may not really be the case due to technical difficulties of the method.

Samples were kept to the standard dimension of $0.021 \times 0.025$ inch as much as possible since for composites where the material may 
not be truly homogeneous and the microstructure different from the macrostructure, comparing a sample of a different dimension to the standard even after correction may not be appropriate. One of the results of heating the samples was a change in the cross section. This was more apparant at higher temperatures and with heating in the oven where there was not a mold to retain the shape. Thus although the new dimension was measured it was assumed for the calculation that the wire was still rectangular. However in fact it was a range of shapes from trapiezoidal to oval.

With the forming experiments there was a change in cross section from one end where the wire was held to the deflecting end. Where the wire was held the material was wider and thin like a fan. At the deflecting end the wire was rounded. Obviously the averaging of the cross section was not strictly valid since during flexure the point where the wire was held experiences the maximum bending moment. Thus in summary although the changes and trend seen in the flexural properties are real the inherent problems of the formula and measurement techniques suggest that the actual numerical values should be analysed with care, particularly those of the forming experiments. 
One of the questions asked was what was the temperature range that was applied when retainers were clinically formed on study models. Also what was the actual temperature at the nozzle of the heat gun and how did it relate to the dial temperature setting on the heat gun? Such questions are important since what is done clinically may be different than theoretically. Experiments D.3.a. and D.3.b. were conducted to answer these questions. Results indicated that even under relatively controlled conditions the forming temperature was varied. Therefore if a fiber-reinforced composite was going to be used clinically for forming retainers it should have a relatively wide "working temperature range" without significant deterioration in properties. It is recommended from the results that a temperature of $460 \mathrm{~F}$ at the nozzle be used when the nozzle is one inch away from the model. This corresponds to a dial setting of \#5 on the instrument used and will allow the most efficient heating of the retainer clinically.

The following modifications to the warm-air gun are proposed in order to make it more suitable for forming retainers. The nozzle tempearature should be restricted to temperatures between $400 \mathrm{~F}$ and $600 \mathrm{~F}$. This would prevent over or under heating of the material. 
The nozzle tips should be of various openings from $2.0 \mathrm{~mm}$ to $5.0 \mathrm{~mm}$ diameter. This would allow the operator to apply heat only to the desired area. In addition the warm-air gun should be more compact in size to make it easier to maneuver.

In summary, forming in itself, or other variable factors such as duration of heating, predrying to remove any moisture contamination did not have a significant effect on the flexural properties or structure. The most significant factor appeared to be the temperature of heating. 


\section{SUMMARY AND CONCLUSIONS}

Advances in material science and technology continue to have a large impact on the practice of dentistry. This has resulted in appliances and restorations with superior properties and better performance. This has usually meant more accessibility and choice of services for the patient as well as making the fabrication or placement of such appliances less demanding for the operator.

Fiber-reinforced composites are an emerging new class of engineering materials. The ability to tailor make composite materials and structures offers exciting opportunities for a broad spectrum of applications including orthodontic wires and appliances. To date little or no information is available on the dental applications. It is thus important to learn about the relations among processing, forming, structure, and performance.

In general our objectives were to develop a methodology and apparatus to evaluate various parameters of thermoforming on the structure and flexural properties of composite wires.

Composite wires of cross section $0.021 \times 0.025$ inch and $10 \mathrm{~mm}$ span length were tested. The compostion was varied with the matrix 
resin being PETG, PCTG or PC and the fiber reinforcement being either S2 glass of various quantity or Kevlar $57 \%$ by weight. Most of the examination was done using $\times 10333 \mathrm{~A}$ with $57 \%$ S2 glass in a PETG resin matrix.

For samples which where only heated without forming (straight samples), either a mold with a heat press or an oven was used. Results indicated that for the mold experiments where the wire was constrained, that for all materials there is a progressive reduction in the flexural modulus and maximum moment with increasing temperature. The temperatures at which softening and significant decrease were seen was different for various compositions. This is primarily due to the different glass transition temperatures of the various resins. Varying the amount of fiber content from $57 \%$ to $55 \%$ resulted in no significant differences in flexural properties. Kevlar had the worst properties and deterioration in structure. For X10333A at temperature above $250 \mathrm{~F}$ a significant $(p<0.01)$ reduction in flexural modulus and maximum moment occurred, reaching a maximum reduction at $450 \mathrm{~F}$. Structural changes seen in the scanning electron micrographs collaborate with the detrioration in the mechanical properties that was seen with higher heating 
temperatures. Mild disintegration in the structure was seen even at low temperatures of $200 \mathrm{~F}$ and became more pronounced with higher heating temperatures.

When the heating experiments were in the oven without a constraining effect of a mold so that the wire was free to change its morphology, a progressive increase in modulus was seen from $170 \mathrm{~F}$ (near softening point of the material $\times 10333 \mathrm{~A}$ ) to about $300 \mathrm{~F}$. From $300 \mathrm{~F}$ to the higher temperatures a progressive drop in modulus was observed comparable to that using the mold. It is hypothesized that there are essentially three mechanisms contributing to this behavior. Upon heating the material near or above its $\mathrm{Tg}$, thermal stresses within the material are released and strains manifest as changes in the morphology of the wire. This mechanism predominates at the lower temperatures. The second factor is the geometrical change of the sample. At lower temperatures (175 F$250 \mathrm{~F})$ this is manifested as buckling of the specimen during forming. At temperatures above $350 \mathrm{~F}$, the geometrical change is seen as a rounding of the edges, change in cross sectional shape and dimension etc.. and the buckling is less pronounced. This becomes more pronounced at higher temperatures. Using the mold as a 
constraint both the buckling and gross changes in the cross section of the samples is prevented. The third factor is polymer degradation. This increases with temperature and becomes a more important factor. Polymer degradation leads to interfacial breakdown and structural deterioration of the material.

Although an attempt was made to take the geometrical changes into account when calculating flexural properties, it is impossible to do so without complex mathematical formulas and more sophisticated instumentation. Thus this "under correction" of the geometrical changes also manifests as a progressive drop in properties with temperature.

Results of the forming experiments in the oven with $\times 10333 \mathrm{~A}$ indicate that the actual forming of curves of different degrees in the wire had no significant effect. The only influencing factors was heating. It should be noted that apart from the curve geometry that was placed in the wires, there was an additional change in the cross section along the length of the wire. This made computation of the numerical values difficult. Thus the numerical values reported should not be taken as absolute, but rather as a means of comparing changes from one sample to another. When results of all the 
experiments are taken together it can be concluded that for forming we should use a temperature above the $\mathrm{Tg}$ of the material so that sufficient softening and release of thermal strains can occur without distortion in geometry of the wire. At the same time the temperature should not be very high otherwise significant structural disintegration of the wire will occur. Thus for every material there is a temperature range or "working range" where the material can be properly formed with minimal changes in the physical properties. For $\mathrm{X} 10333 \mathrm{~A}$ (PETG resin matrix) this range appears to be from $250 \mathrm{~F}$ to $350 \mathrm{~F}$.

Effect of pre-drying the samples under vaccum, heating under vacuum and duration of heating relationships were also studied but do not appear to be critical factors.

Thus it appears that the FRC may have an important role as orthodontic wires and other dental applications when used with a proper technique and controlled forming conditions. More work in this field of research is warrented. Other methods, such as differential scanning calorimetry (DSC) and infrared spectroscopy would allow us to more completely characterize the microstructural and chemical changes. A more sophisticated mathematical formula 
and measuring technique would be useful in allowing us to more accurately take the effect of dimensional changes into account.

Other physical properties which would be clinically important and warrant further study are the effects of stress relaxation and hydrolitic stability. The synergism between body temperature and saliva may have a pronounced effect in the plastic region of the material.

As processing techniques improve, materials with better physical and handling properties should become available in the future.

It is anticipated that the findings reported in this thesis will help establish guidelines for potential uses of thermoplastic fiberreinforced composites in dental, specifically orthodontic, applications.

It is further hoped that these findings and methodology will be useful in directing future research in this field. 


\section{BIBLIOGRAPHY}

1. Combe, E.C. : Notes on dental materials, 3rd edition, Churchill Livingston, 1977.

2. Burstone, C.J.: Applications of bioengineering to clinical orthodontics. In Graber, T.M. (editor): Current orthodontic concepts and techniques. I, ed. 2, Philadelphia, 1975, W.B. Saunders Company, pp. 23-258.

3. Drake, S.R., Wayne, D.M., Powers, J.M., and Asgar, K.: Mechanical properties of orthodontic wires in tension, bending, and torsion, Am. J. Orthod. 82: 206-210, 1982.

4. Asgharnia, M.K., and Brantley, W.A.: Comparision of bending and tension tests for orthodontic wires, Am. J. Orthod. 89: 228236, 1986.

5. Andreasen, G.F., and Morrow, R.E.: Laboratory and clinical analyses of nitinol wire, Am. J. Orthod. 73: 142-151, 1978.

6. Burstone, C.J., and Goldberg, A.J.: Beta titanium: A new orthodontic alloy, Am. J. Orthod. 77: 121-132, 1980.

7. Burstone, C.J., Qin, B., and Morton, J.Y.: Chinese Niti wire- A new orthodontic alloy, Am. J. Orthod. 87: 445-452, 1985.

8. Schaus, J.G., and Nikolai, R.J.: Localized, transverse, flexural stiffnesses of continuous arch wires, Am. J. Orthod. 89: 407414, 1986.

9. Brantly, W.A., Augut, W.S., Myers, C.L., and Winders, R.V.: Bending deformation studies of orthodontic wires, J. Dent. Res. 57: 609 615,1978 .

10. Brantly, W.A.: Comments on stiffness measurements for orthodontic wires, J. Dent. Res. 55: 705, 1976. 
11. New A.D.A. specification no.32 for orthodontic wires not containing precious metals, J. Am. Dent. Assoc. 95: 11691171, 1977.

12. Nielsen, L.E.: Mechanical properties of polymers and composites.

13. Bever, M.B. (editor-in-chief): Encyclopaedia of Materials Science and Engineering, 1st edition, Pergamon Press Ltd,1986.

14. Mullarky, R.H.: Aramid fiber reinforcement of acrylic appliances J. Clin. Orthod. 19: 655-658, 1985.

15. Bjork, N., Ekstrand, K., and Ruyter, I.E.: Implant fixed, dental bridges from carbon/graphite fibre reinforced poly (methyl methacrylate), Biomaterials. 7: 73-75, 1986.

16. Grave, A.M.H., Chandler,H.D., and Wolfaardt, J.F.: Denture base acrylic reinforced with high modulus fiber, Dent Mater.1: 185187, 1985.

17. Levenson, M.F.: The use of a clear, pliable film to form a fiberglass-reinforced splint, J. Am. Dent. Assoc. 112: 7980,1986 .

18. Diamond, M.: Resin fiberglass bonded retainer, J. Clin. Orthod. 21:182-183, 1987.

19. Beardmore, P., Harwood, J.J., Kinsman, K.R., and Robertson, R.E.: Fiber- reinforced composites - Engineered structural materials,Science. 208: 833-840, 1980.

20. Hillig, W.B.: New materials and composites, Science. 191:733739,1976 .

21. English, L.K.: The expanding world of composites, Material Eng. Pg. 27-, April, 1986.

22. Stinchcomb, W.W.: Technology of composite materials - An overview, ASTM Standardization News, 12-15, Dec. 1983. 
23. Hunston, D., Dehl, R., and Wen-Li Wu.: Polymer compositeschallenges and research trends, Mech. Eng. 56: 52-56, March 1986.

24. English, L.K.: Fabricating the future with composite materials, Material Eng.

Part 1. The basics, ME. 29-35, Nov. 1986.

25.

Part 2. Reinforcements, ME. 37-41, Jan. 1987.

26.

Part 3. Matrix resins, ME. 33-37, Feb. 1987.

27.

Part 4. The interface, ME. 43-47, March. 1987.

28. Charrier, J.M.: Basic aspects of structure-property relationships for composites, Polymer Sci. \& Eng. 15: 731-746, 1975.

29. Gore, C.R., Cuff, G., and Cianelli, D.A.: Long/short-fiber reinforced thermoplastics, Material Eng. 47-50, March 1986.

30. Brady, D.G.: Aerospace discovers thermoplastic composites, Material Eng. 41-44, Sept. 1986.

31. Newaz, G.M.: Comparing performance of unidirectional composites, Material Eng. 99:21-24, May 1984.

32. Krone, J.R., and Walker, J.H.: Processing thermoplastic advanced composites, Plastics Technology 32: 61-65, Nov 1986.

33. Technology News: Advanced composites - more processing options, Plastics Technology 32: 13-17, Nov. 1986.

34. Crosby, J.M., and Drye, T.R.: How fibers affect fracture behavior of nylon-66 composites, Modern Plastics 63: 74-84, Nov. 1986. 
35. Kelleher, P.G., Wentz, R.P., Hellman, M.Y., and Gilbert, E.H.: The hydrolytic stability of glass fiber reinforced Poly(butylene terephthalate), Poly(ethylene terephthalate) and Polycarbonate, Polymer Eng. \& Sci. 23: 537-542, July 1983.

36. Jabarin, S.A., and Lofgren, E.A.: Effects of water absorption on physical properties and degree of molecular orientation of Poly (ethylene terephthlate), Polymer Eng. \& Sci. 26: 620-625, midMay 1986.

37. Tolunay, M.N.: Heating and bonding mechanisms in ultra sonic welding of thermoplastics, Polymer Eng. \& Sci. 23: 726- , Sept.1983.

38. Bowman, J., and Barker, M.B.: A methodology for describing creep-fatigue interactions in thermoplastic components, Polymer Eng. \& Sci. 26: 1582-1590, Dec. 1986.

39. Kretis, G.: A review of the tensile, compressive, flexural and shear properties of hybrid fiber reinforced plastics, Composites 18: $13-23,1987$.

40. Yoshikawa, D.K.: Flexural modulus of orthodontic stainless steel wires J. Dent. Res. 60: 139, 1981.

41. Reinhart, T.: Vol 1, Composites, Engineered Materials Handbook, ASM International, 1988. 


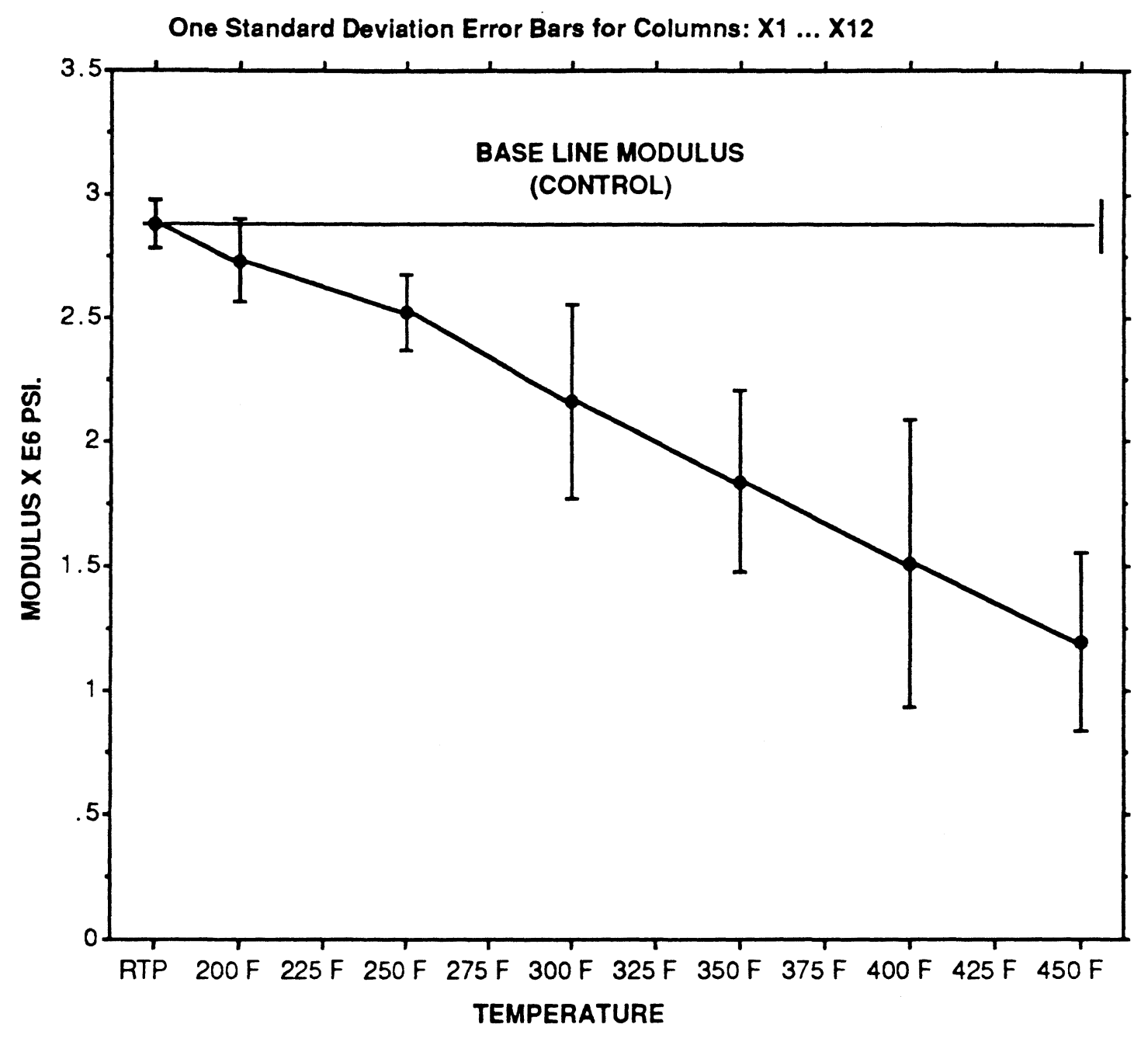

Fig. 7: Change in modulus with heating using mold - X10333A. 


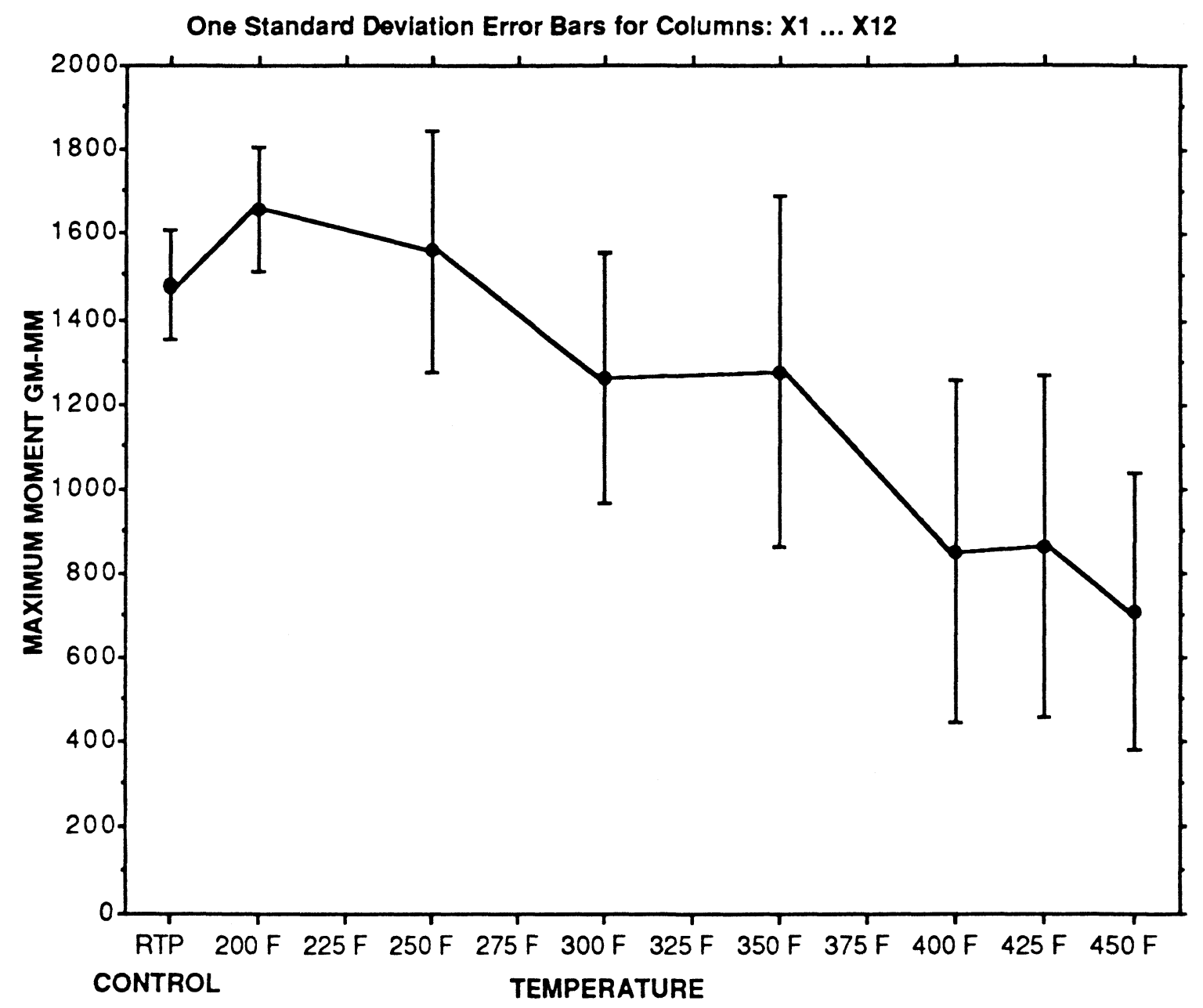

Fig. 8: Maximum moment vs. heating temperature using mold - X10333A. 


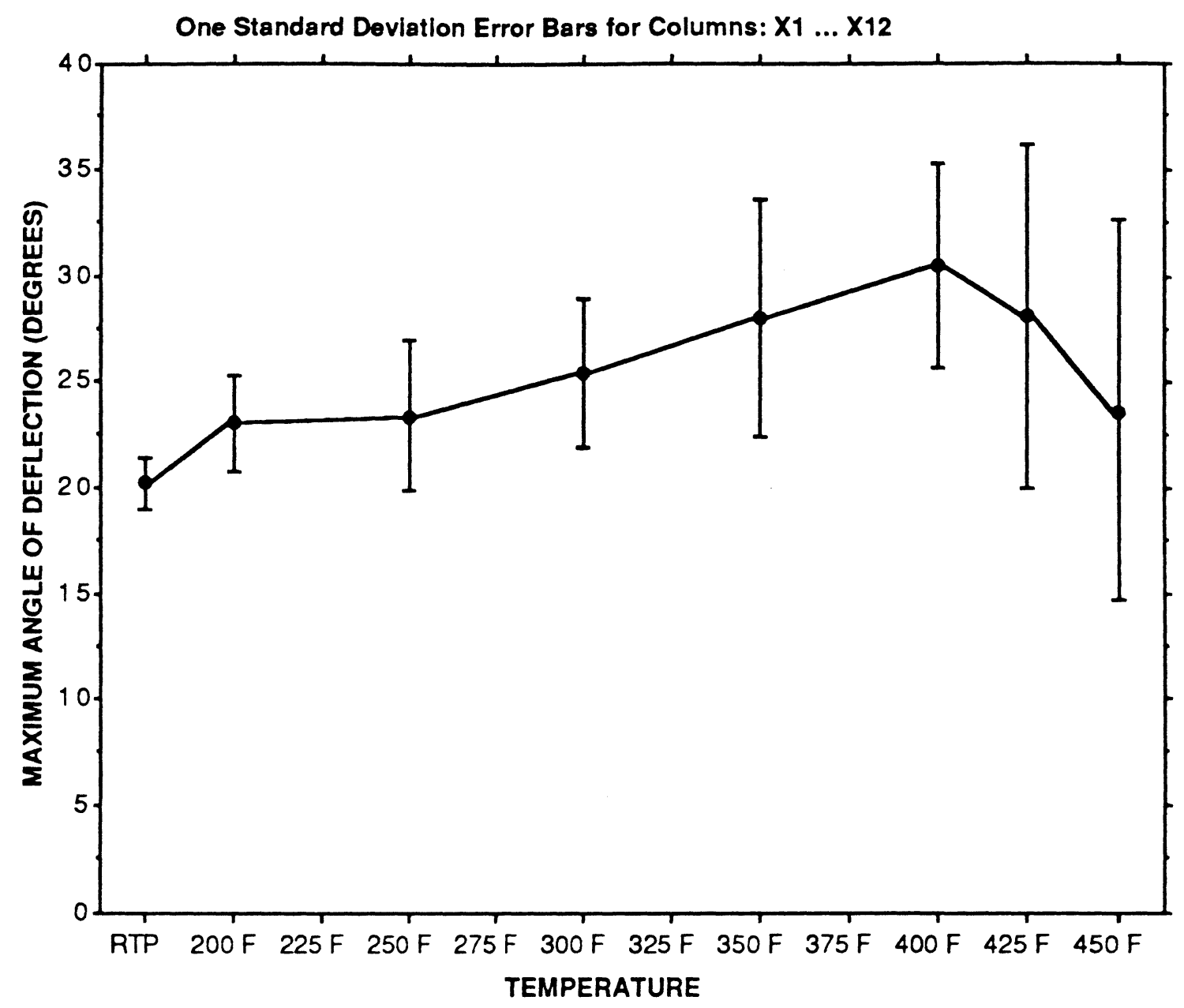

Fig. 9: Maximum deflection vs heating temperature using mold - X10333A. 


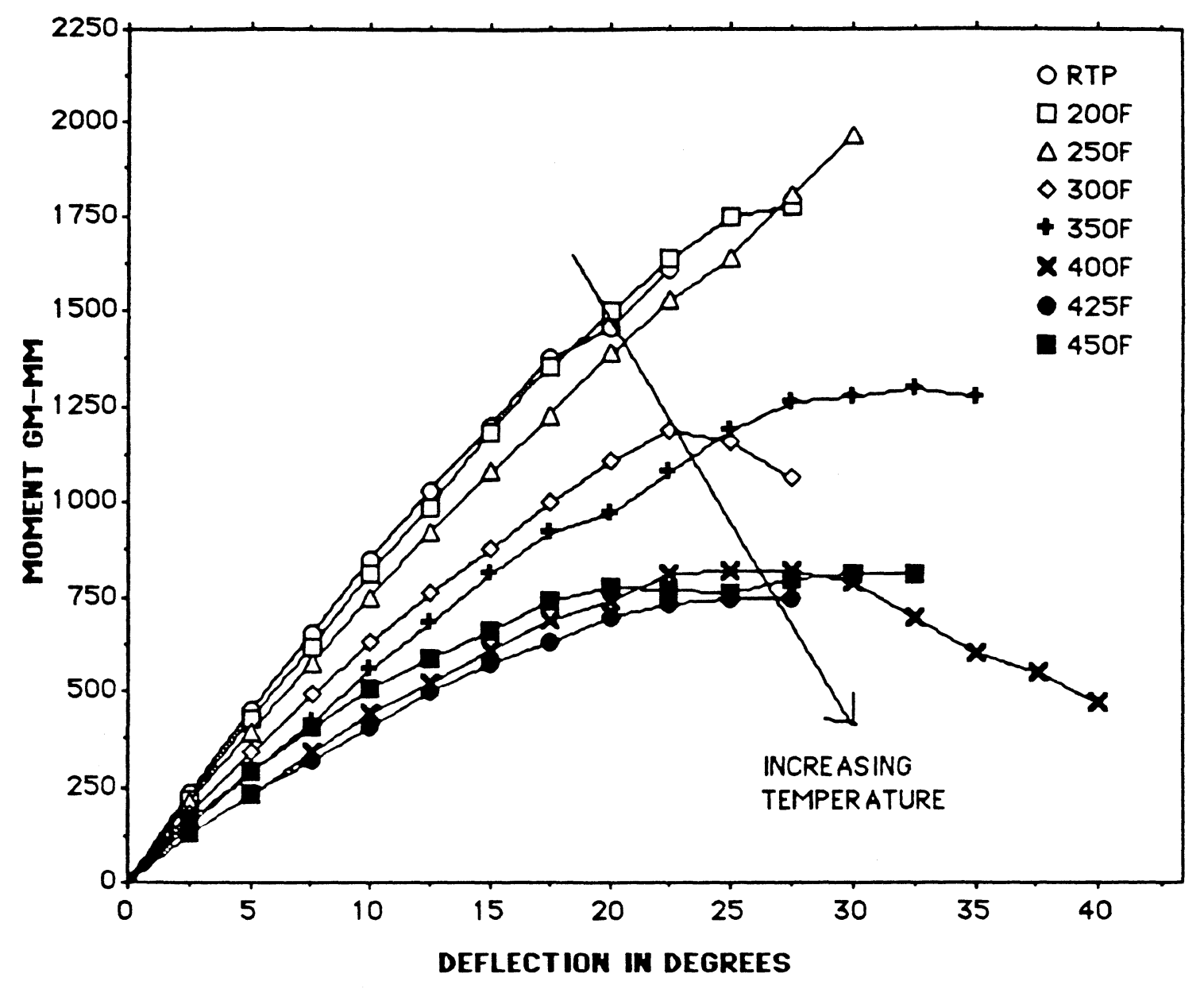

Fig. 10: Moment vs Deflection curves using mold -X10333A. 


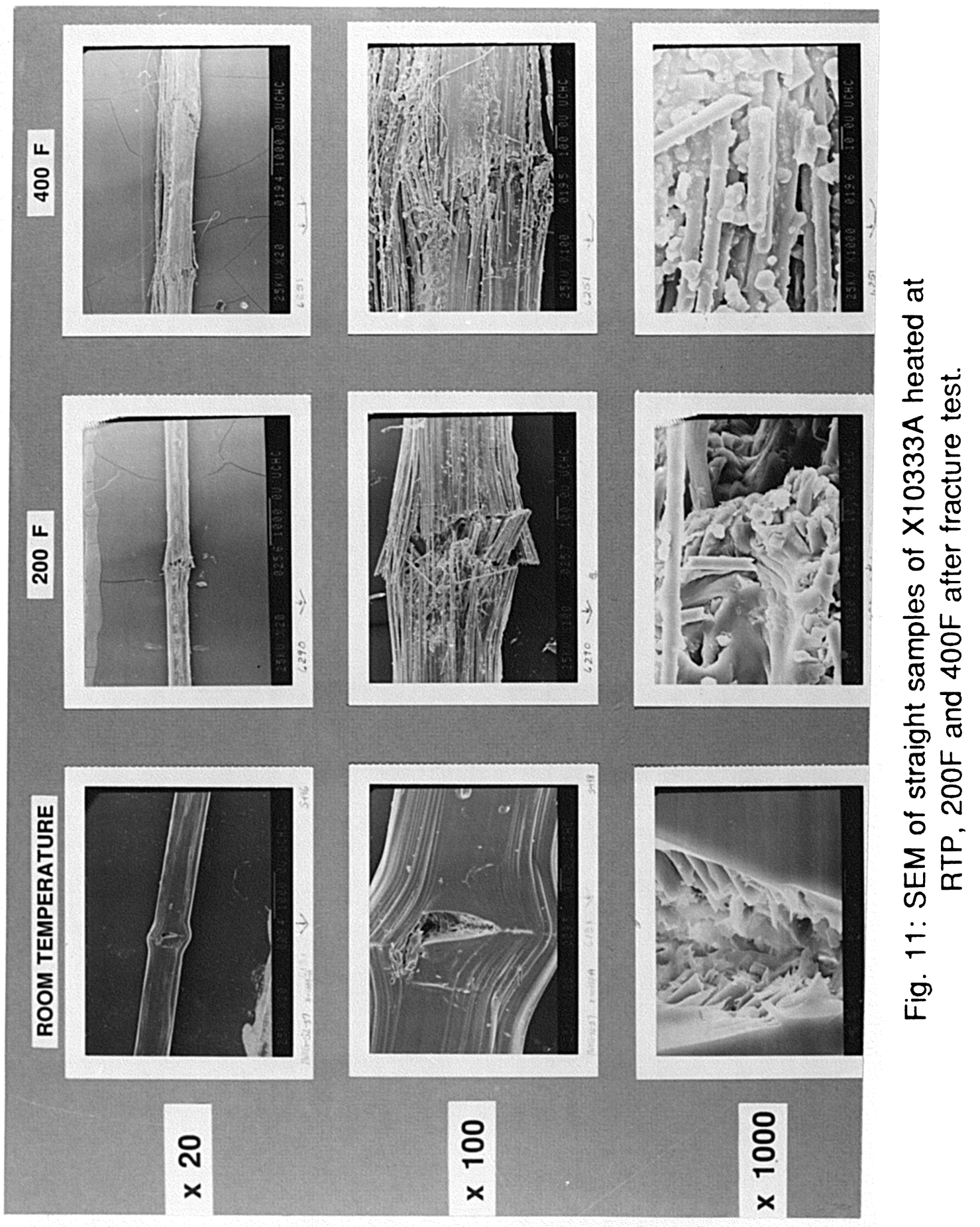




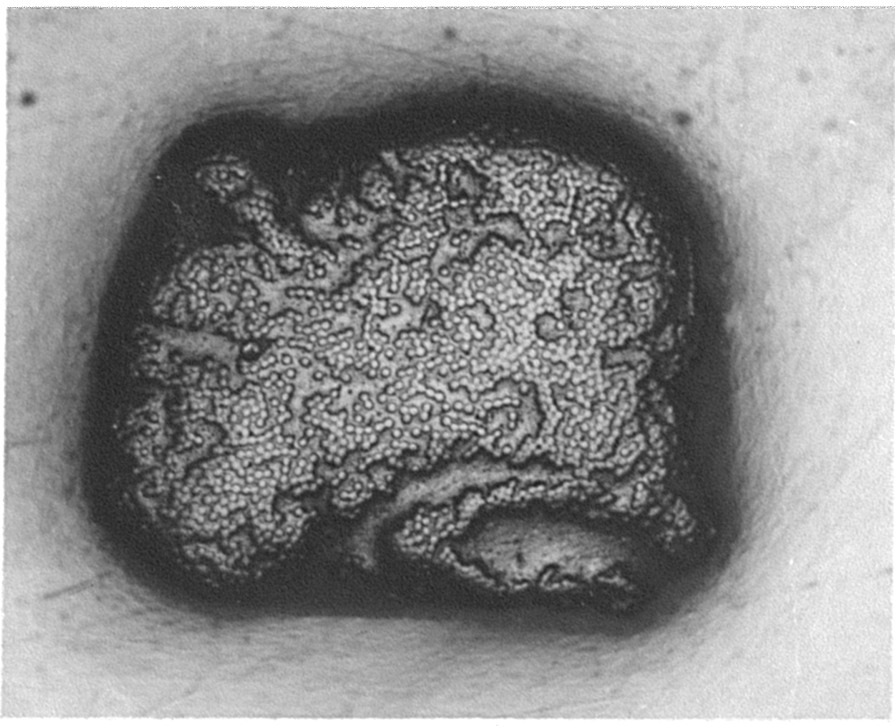

\section{BTP}

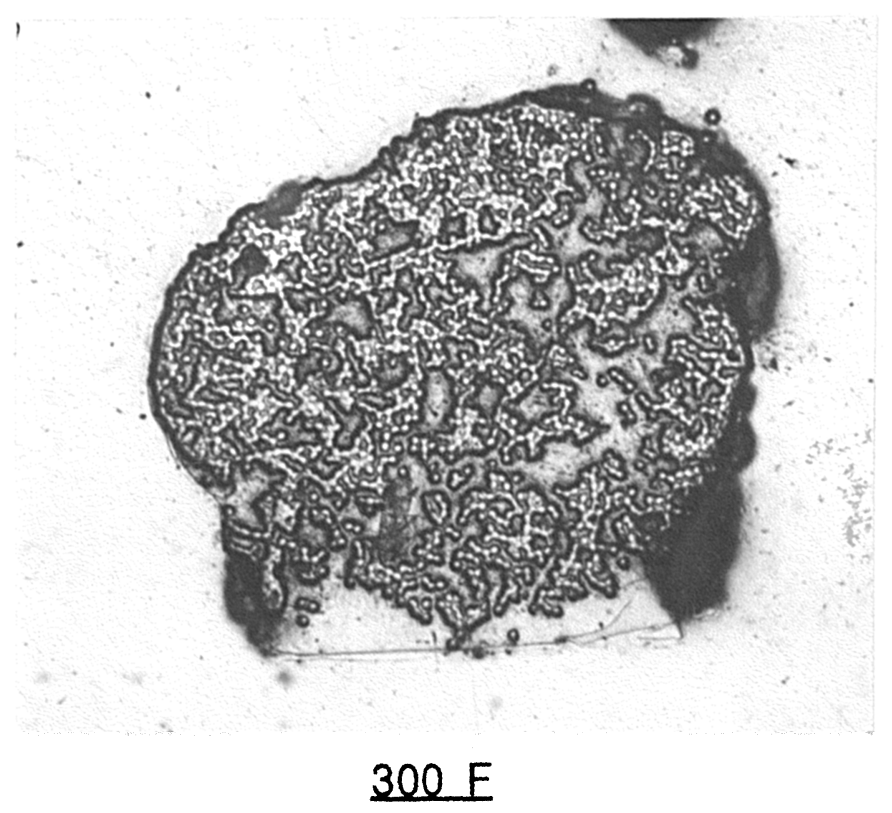

Fig. 12: Optical micrographs of cross-sections of straight samples of X10333A after heating to RTP and 300 F. Mag: 100X. 
One Standard Deviation Error Bars for Columns: X1 ... X14

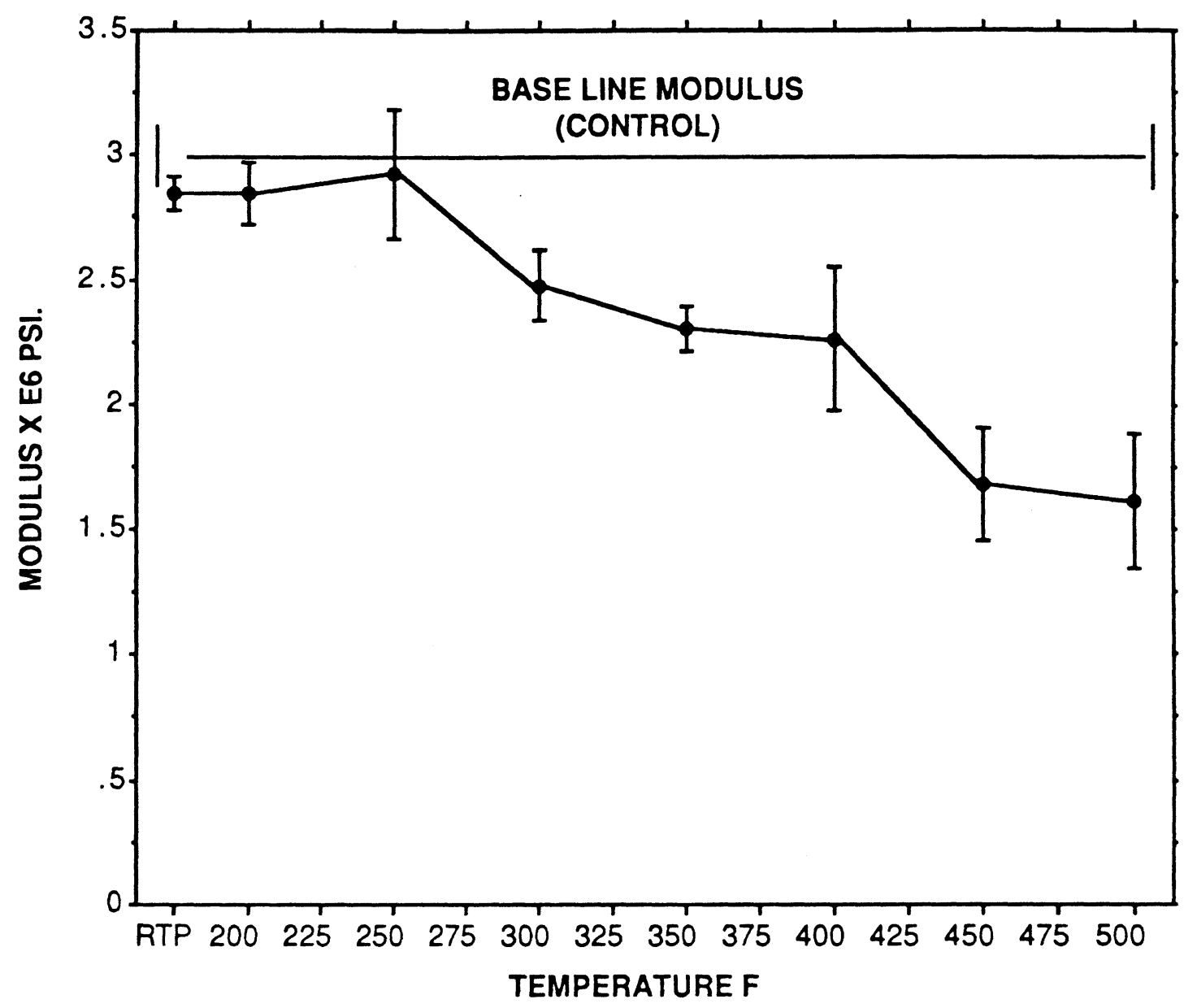

Fig. 13: Change in modulus with heating using mold - X10364. 
One Standard Deviation Error Bars for Columns: X1 ... X14

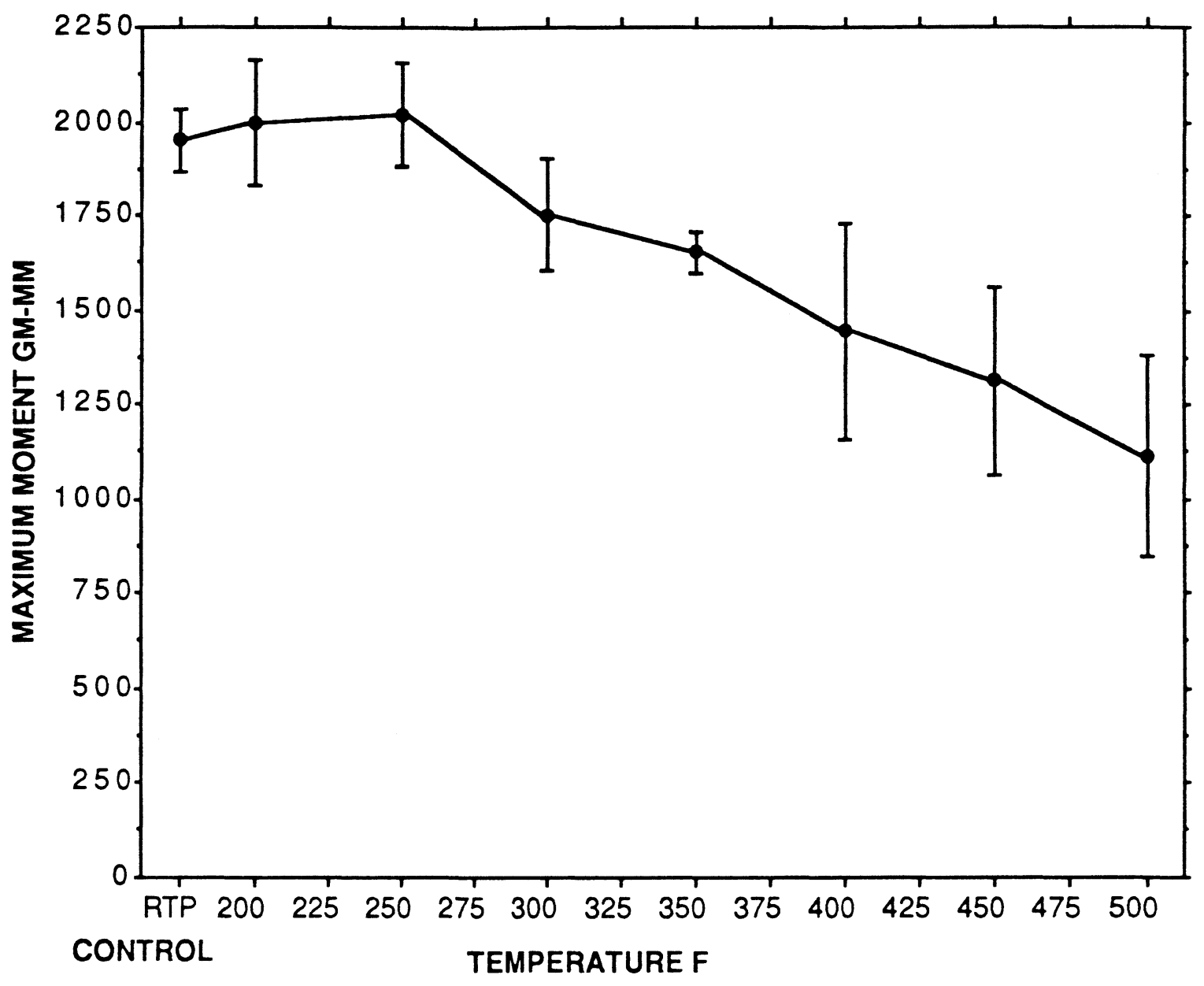

Fig. 14: Maximum moment vs heating temperature using mold - X10364. 
One Standard Deviation Error Bars for Columns: X1 ... X13

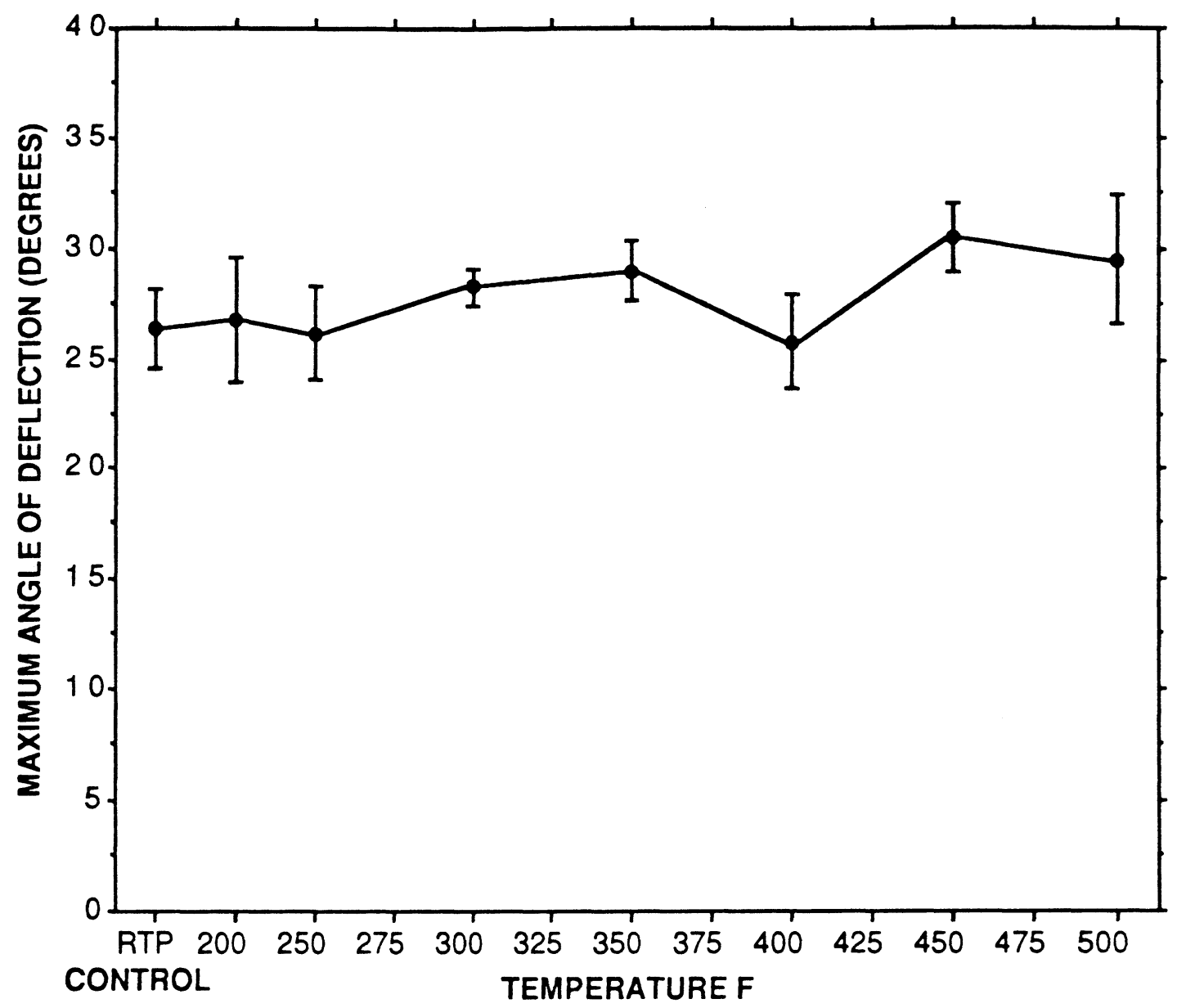

Fig. 15: Maximum deflection vs heating temperature using mold - X10364. 


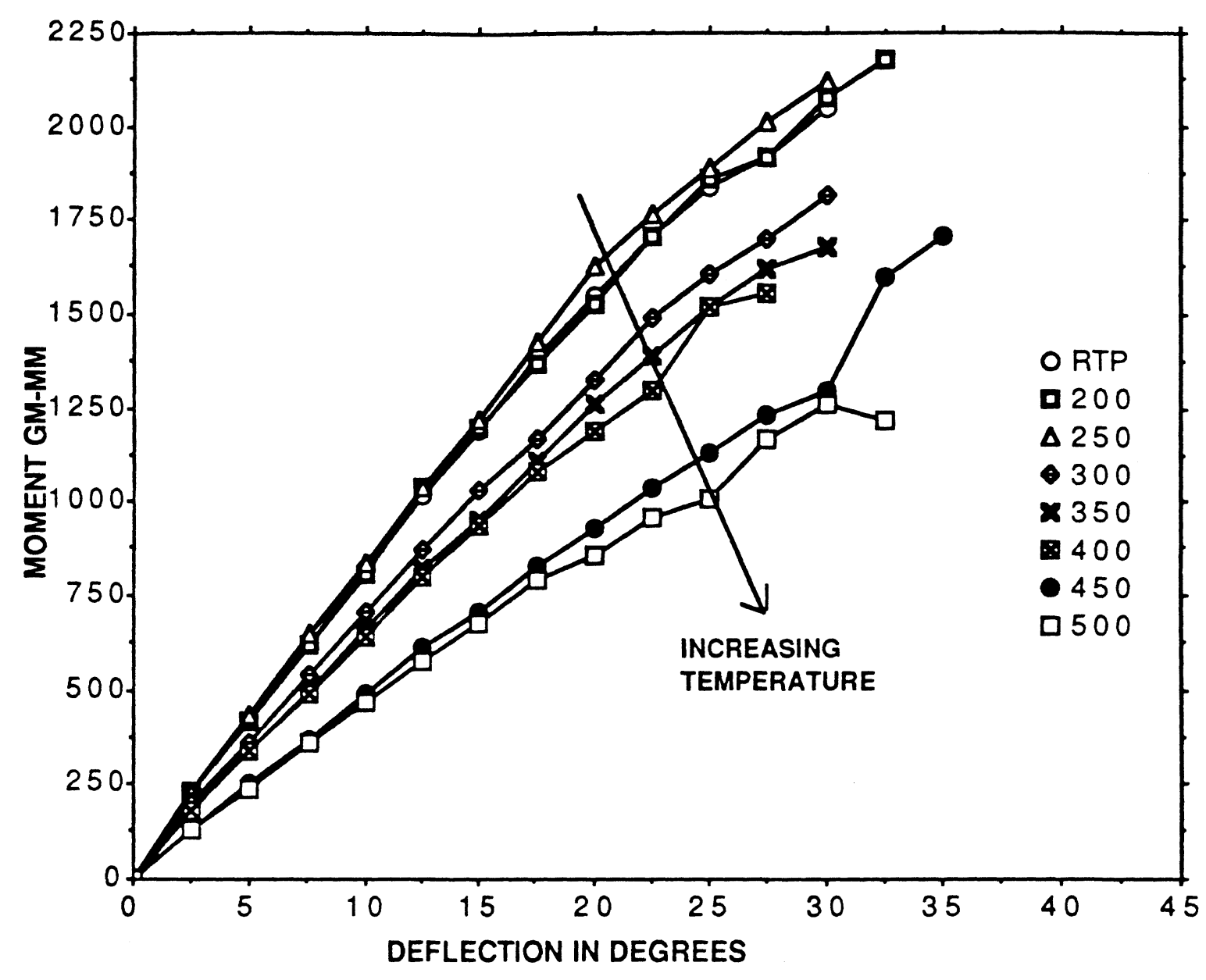

Fig. 16: Moment vs Deflection curves using mold - X10364. 


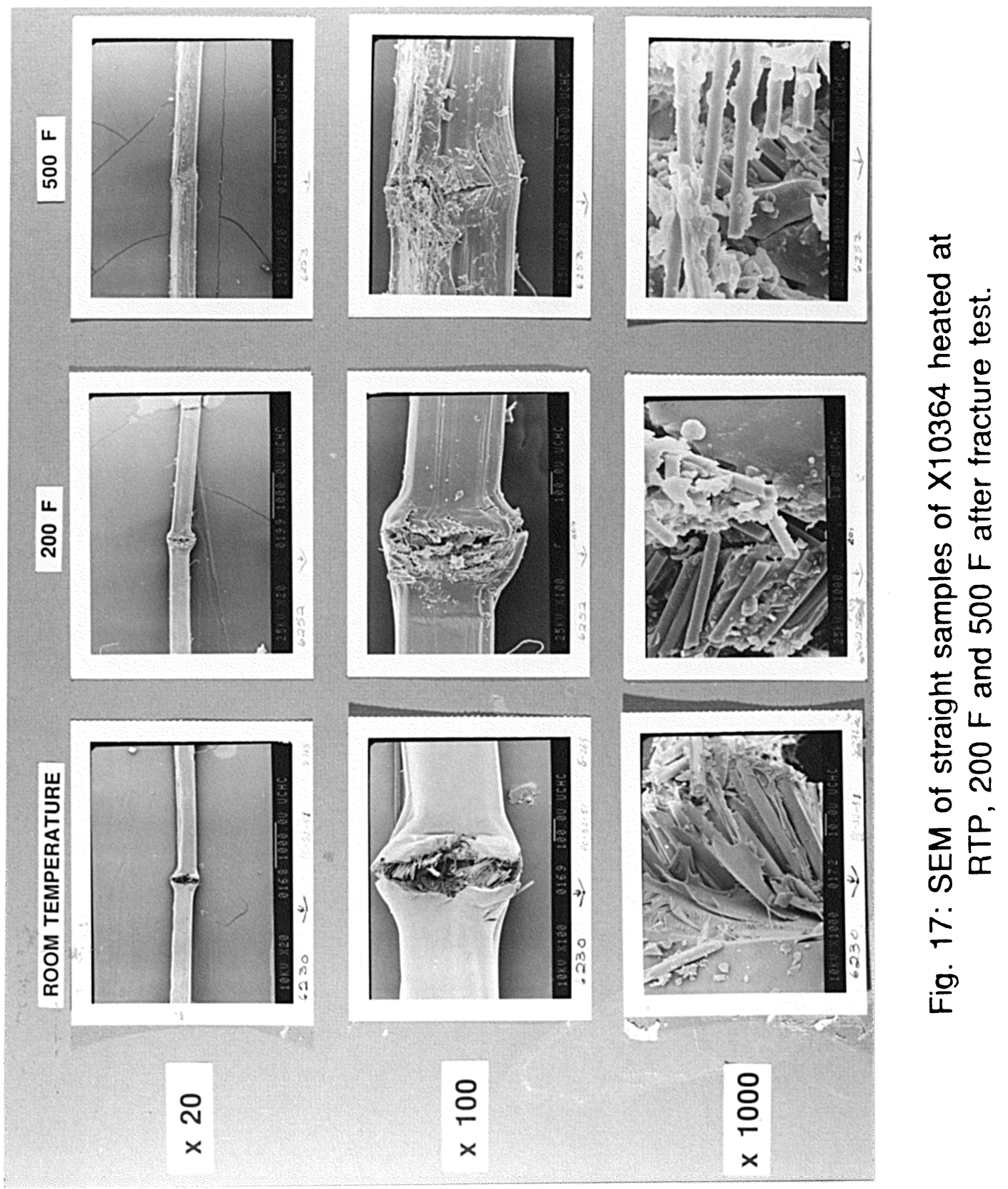




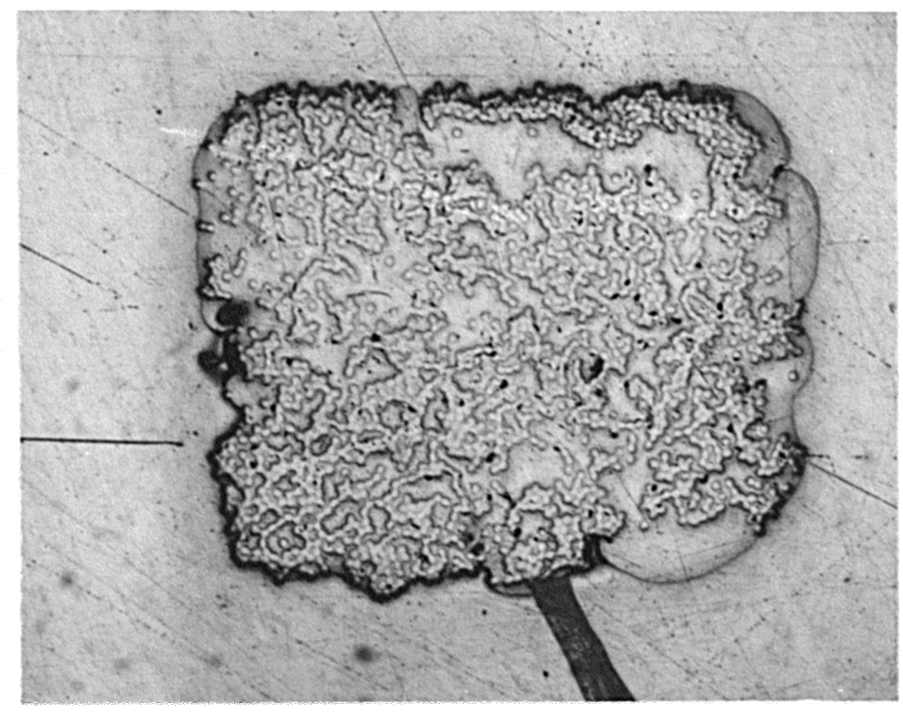

RTP

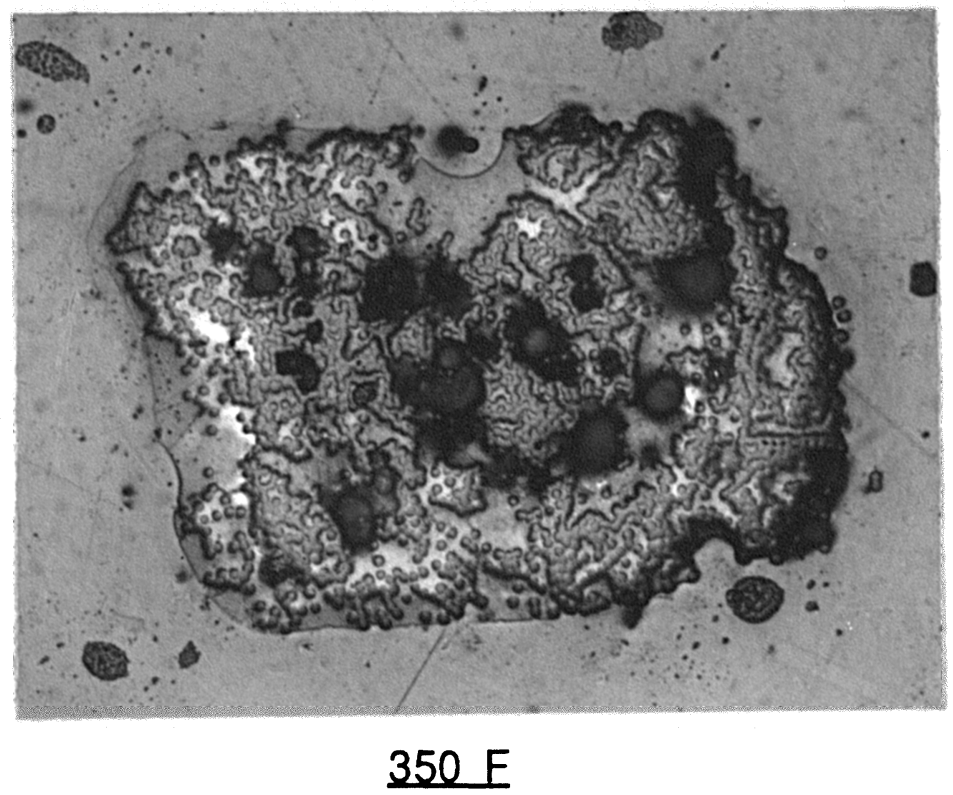

Fig. 18: Optical micrographs of cross-sections of straight samples of X10364 after heating to RTP and 350 F. Mag: $100 X$. 
One Standard Deviation Error Bars for Columns: X1 ... X12

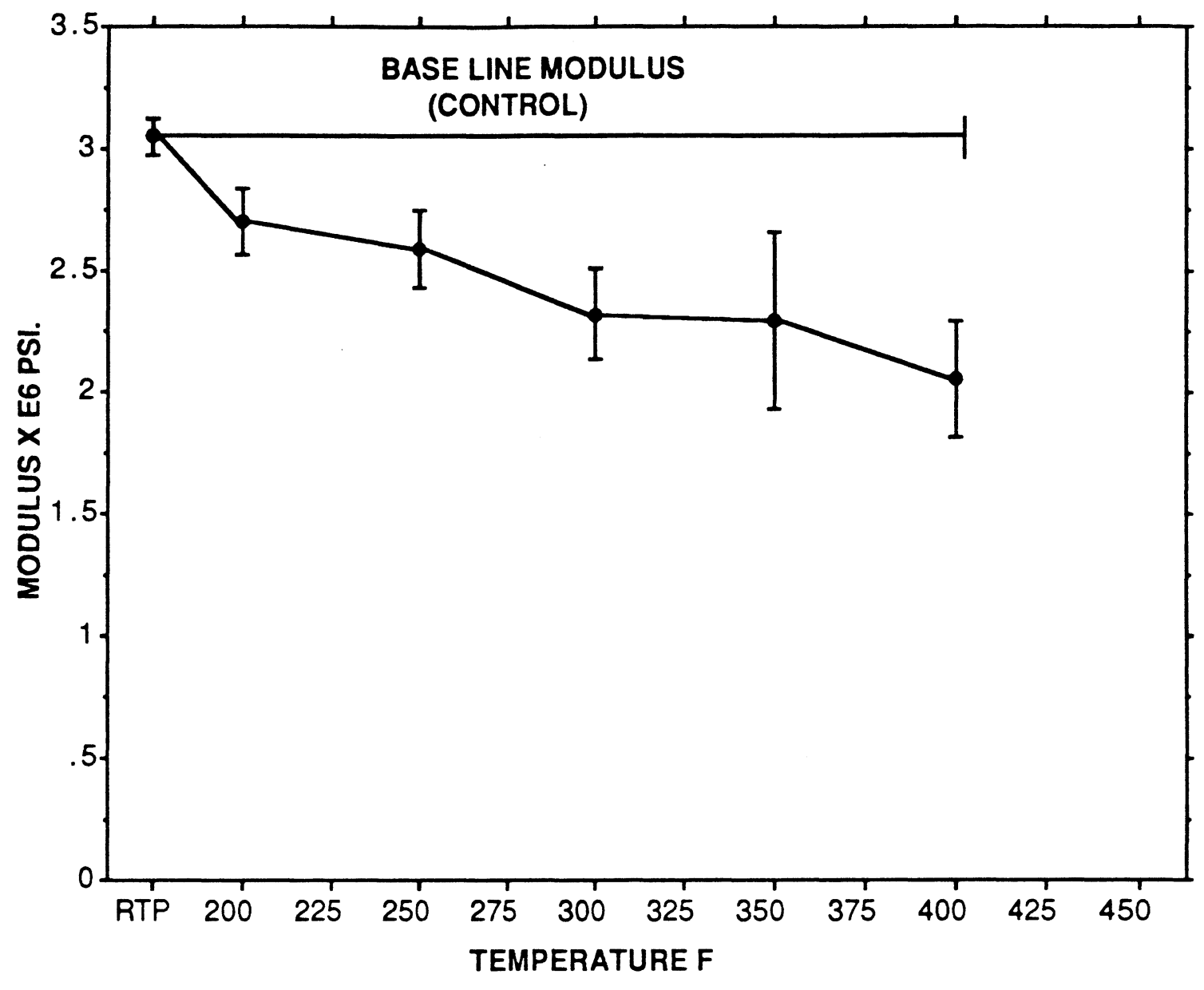

Fig. 19: Change in modulus with heating using mold - X10333B. 


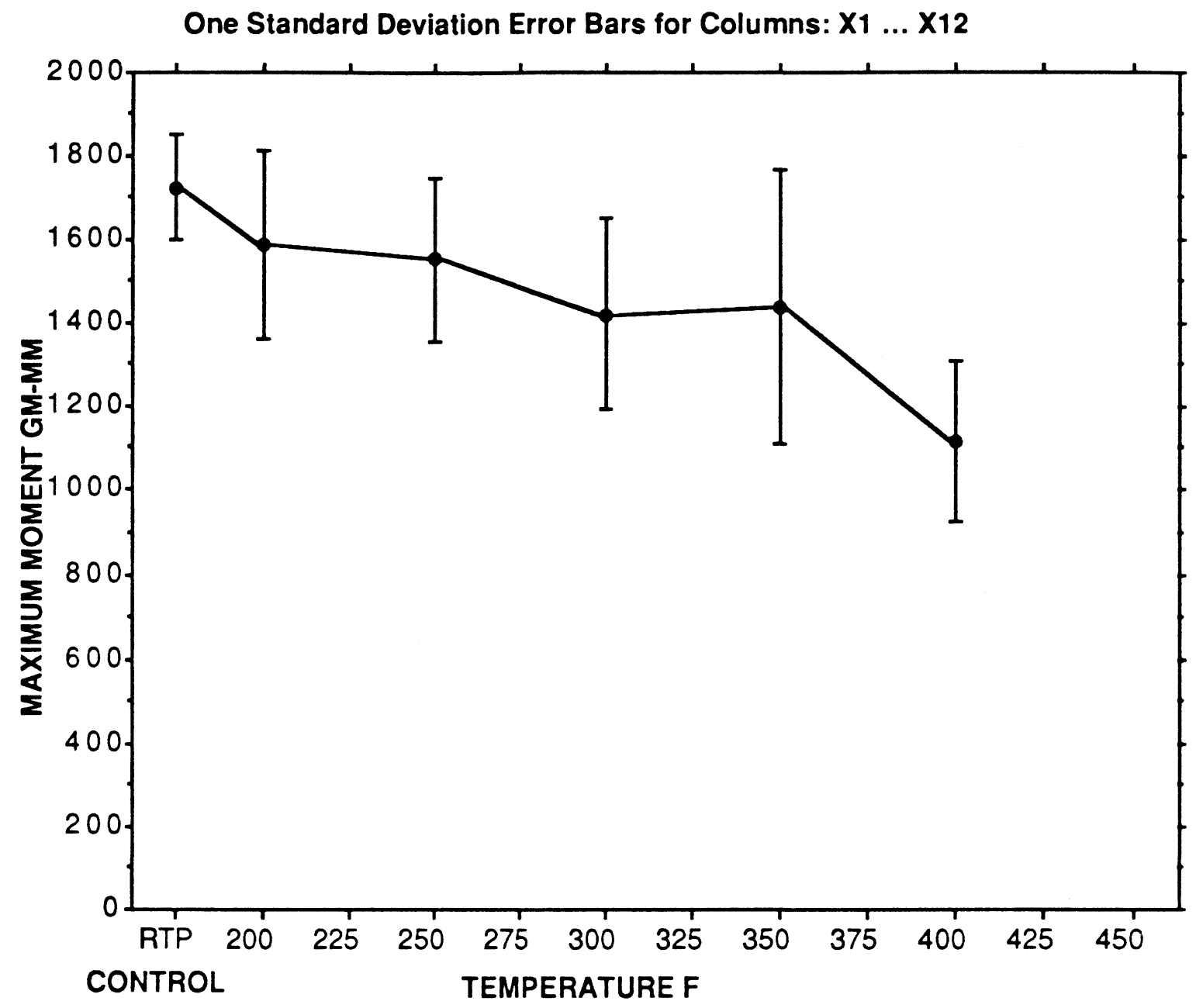

Fig. 20: Maximum moment vs heating temperature using mold - X10333B. 


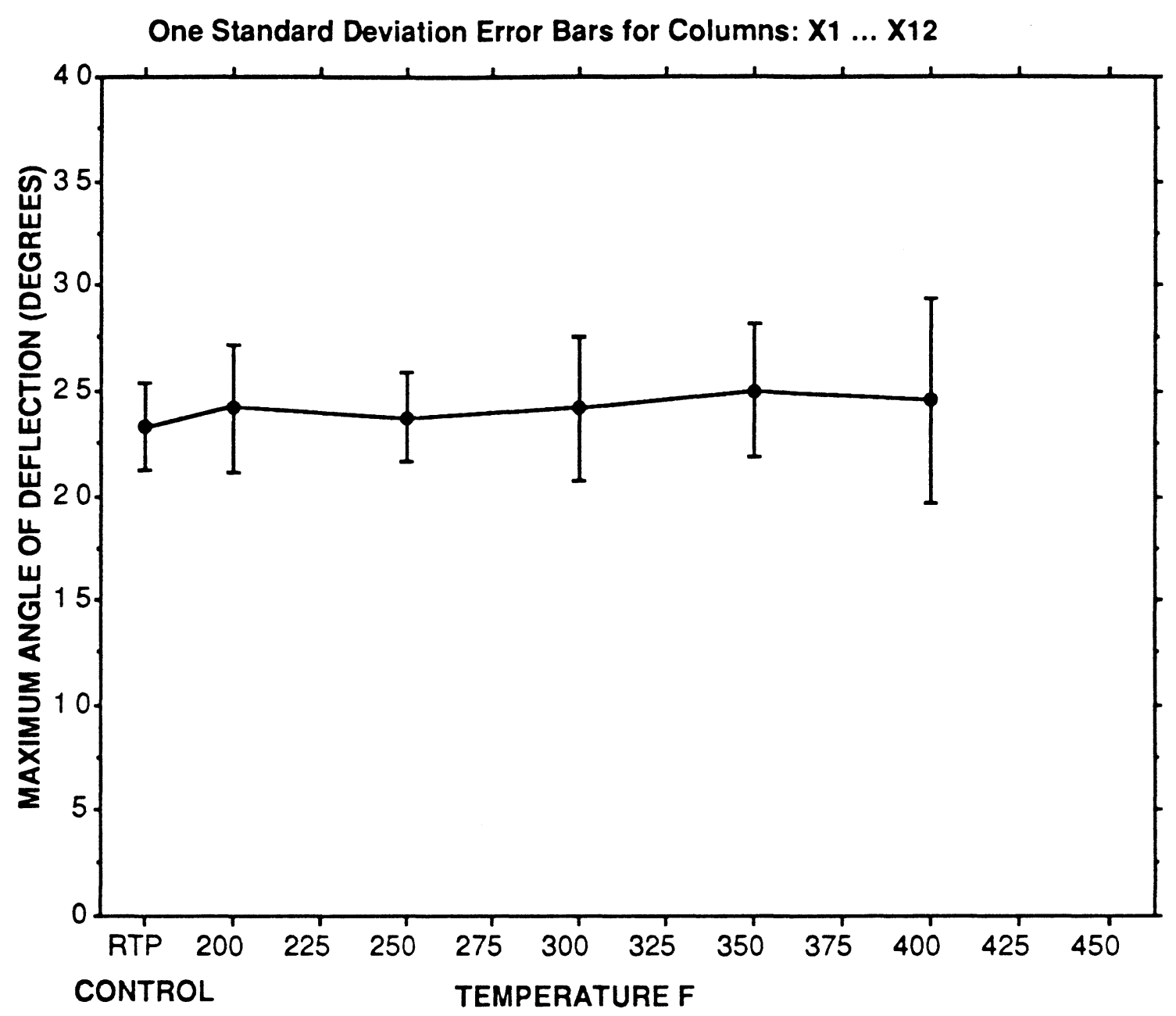

Fig. 21: Maximum deflection vs heating temperature using mold - X10333B. 


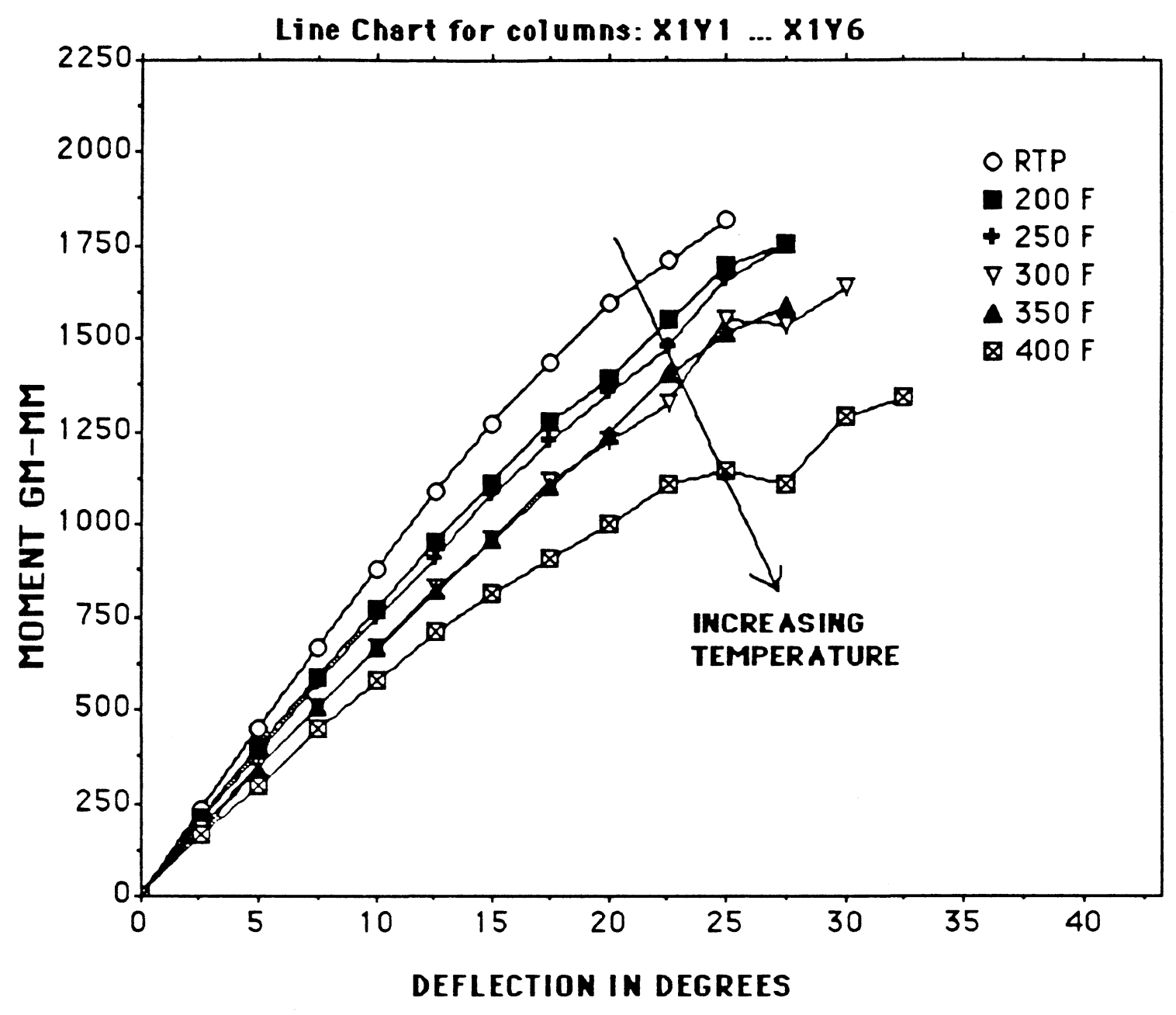

Fig. 22: Moment vs Deflection curves using mold - X10333B. 


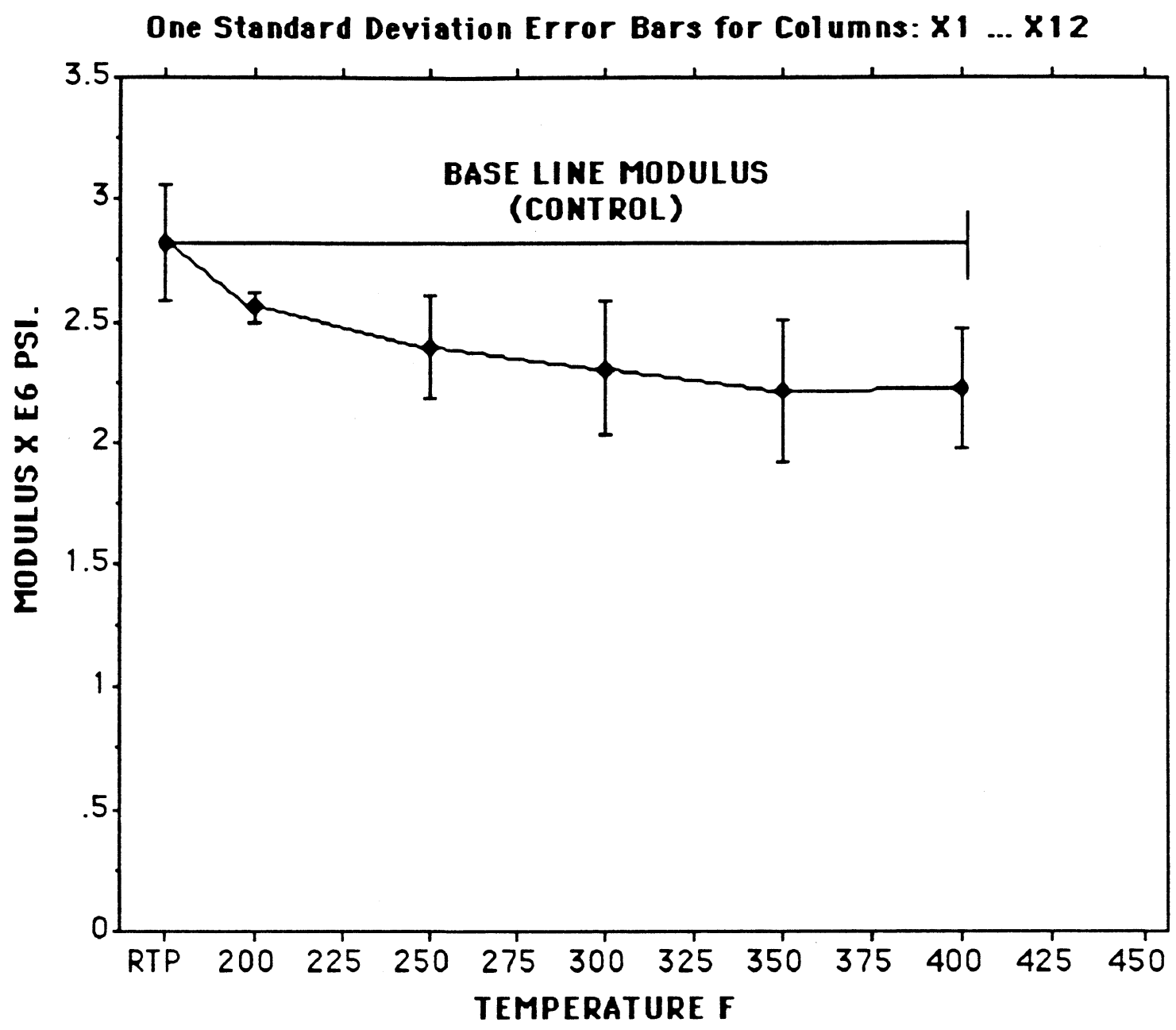

Fig. 23: Change in modulus with heating using mold - X10361. 
One Standard Deviation Error Bars for Columns: $\times 1 \ldots$... $\times 12$

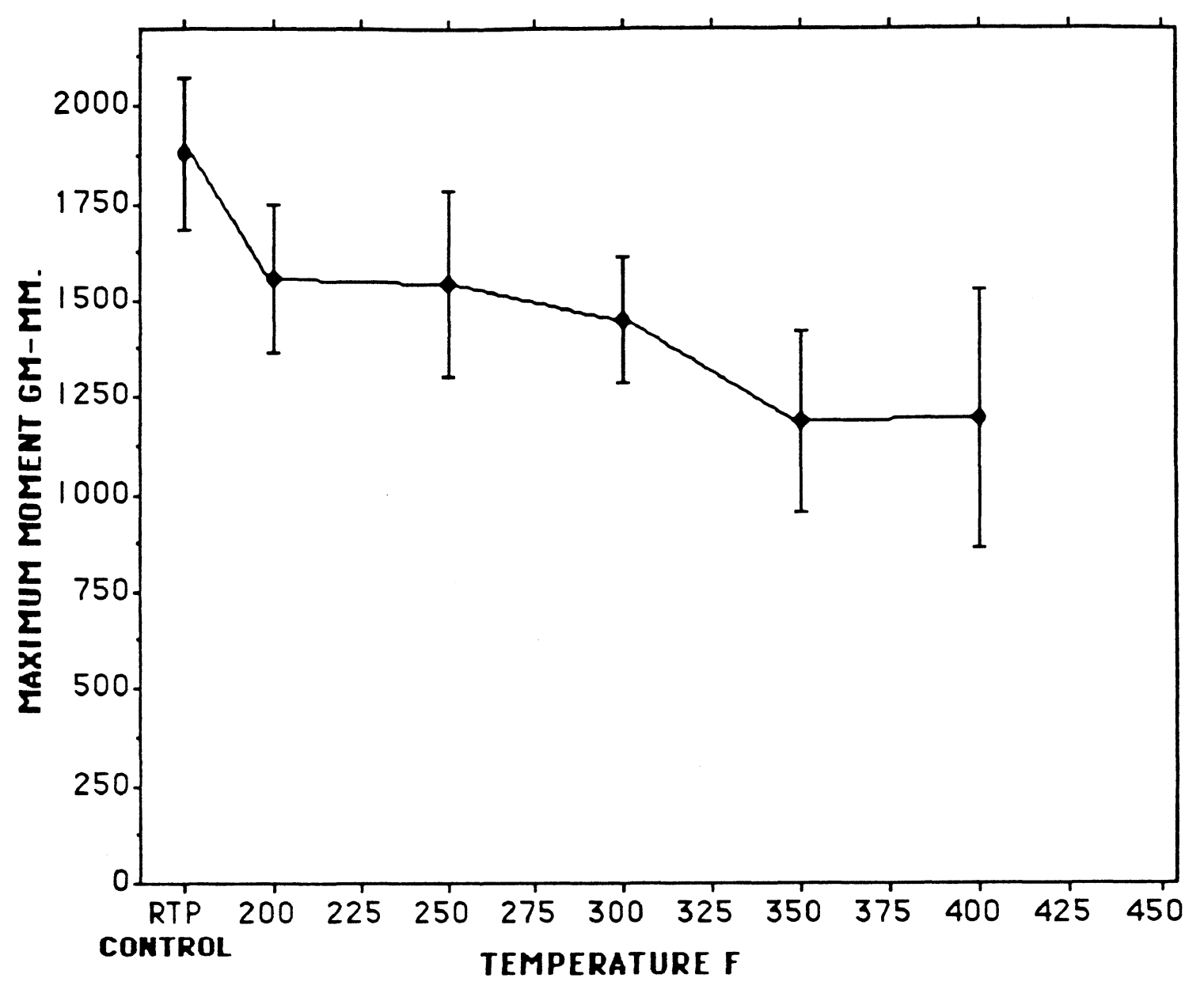

Fig. 24: Maximum moment vs heating temperature using mold - X10361. 


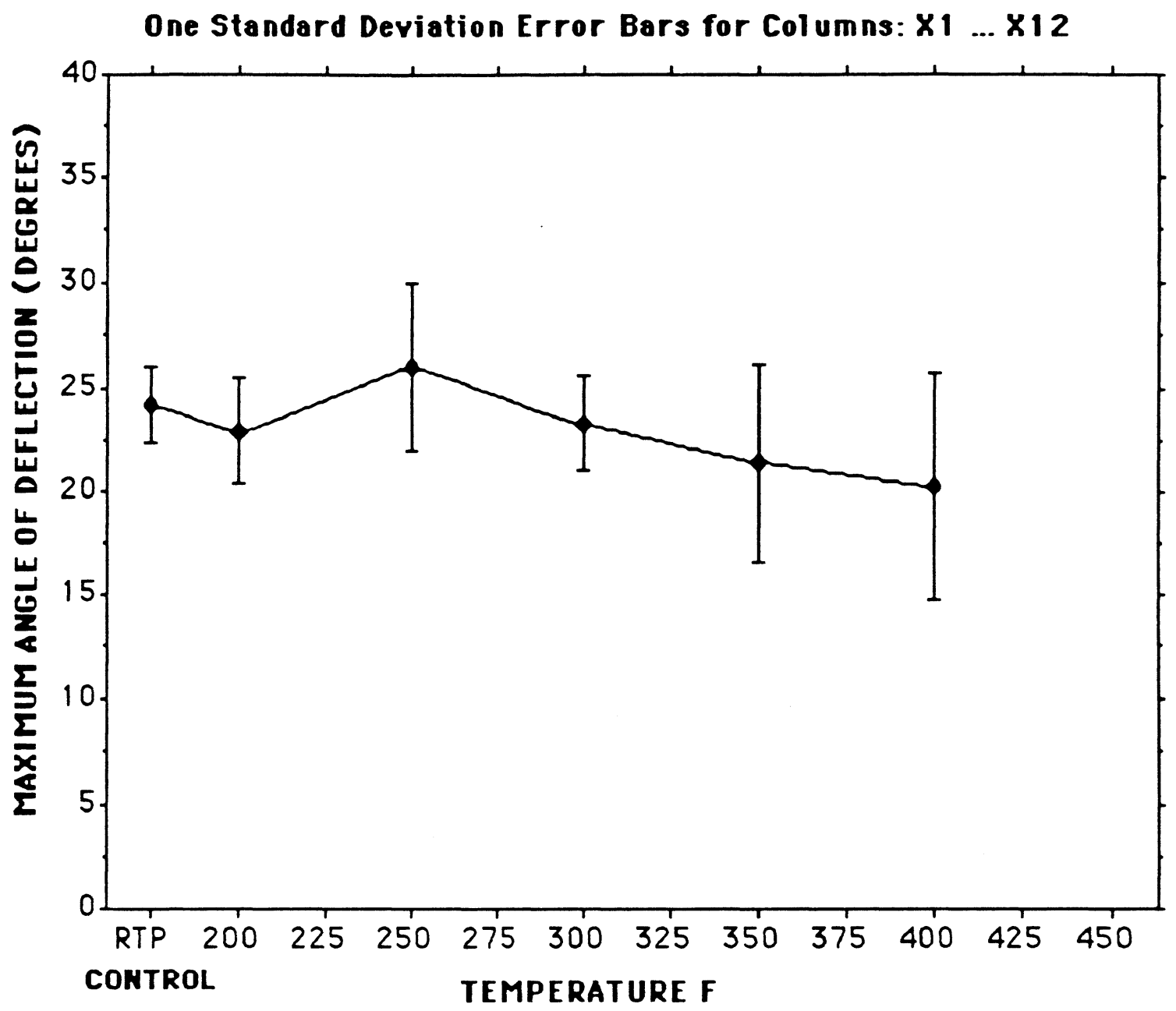

Fig. 25: Maximum deflection vs heating temperature using mold $-\mathrm{X} 10361$. 


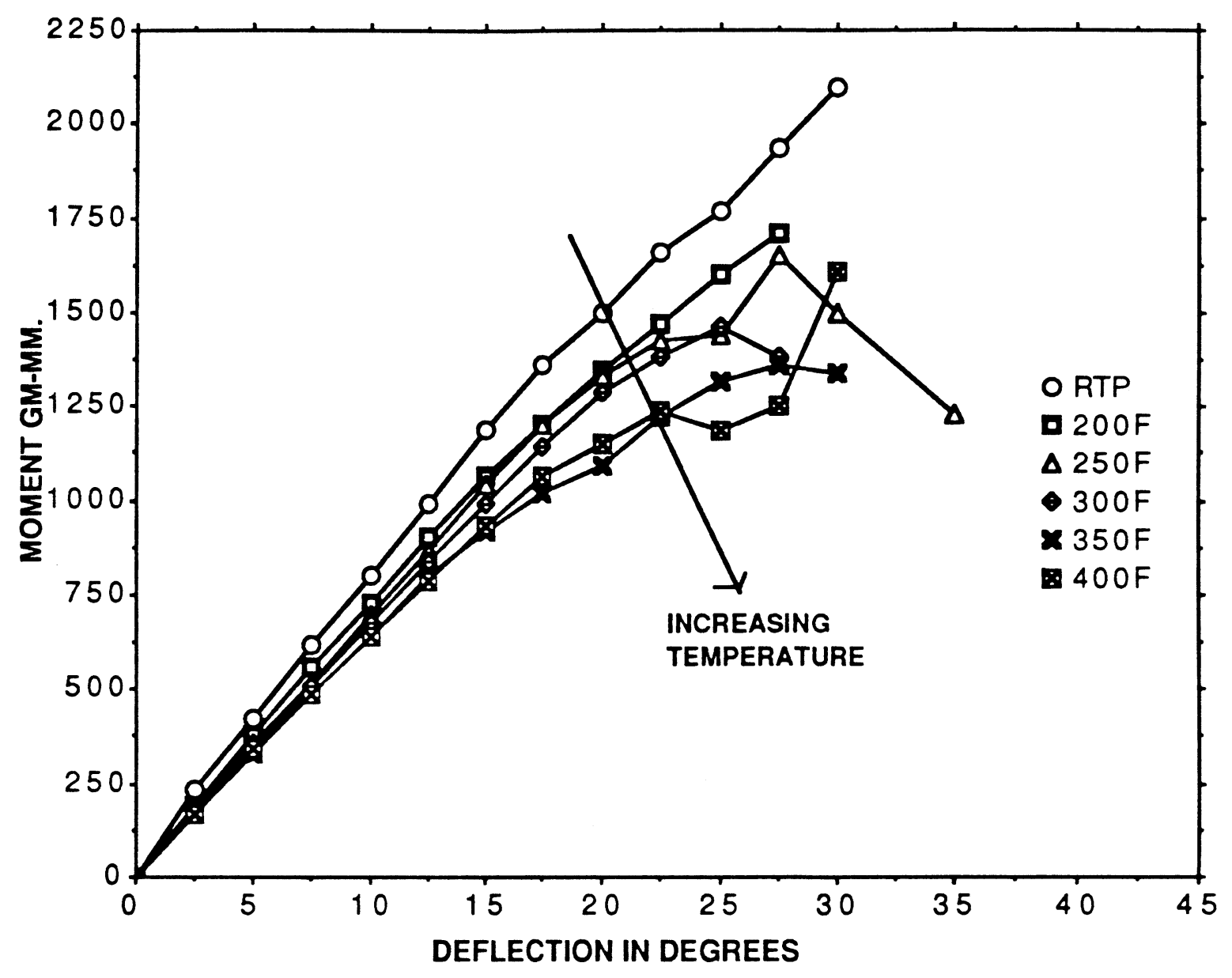

Fig. 26: Moment vs Deflection curves using mold - X10361. 


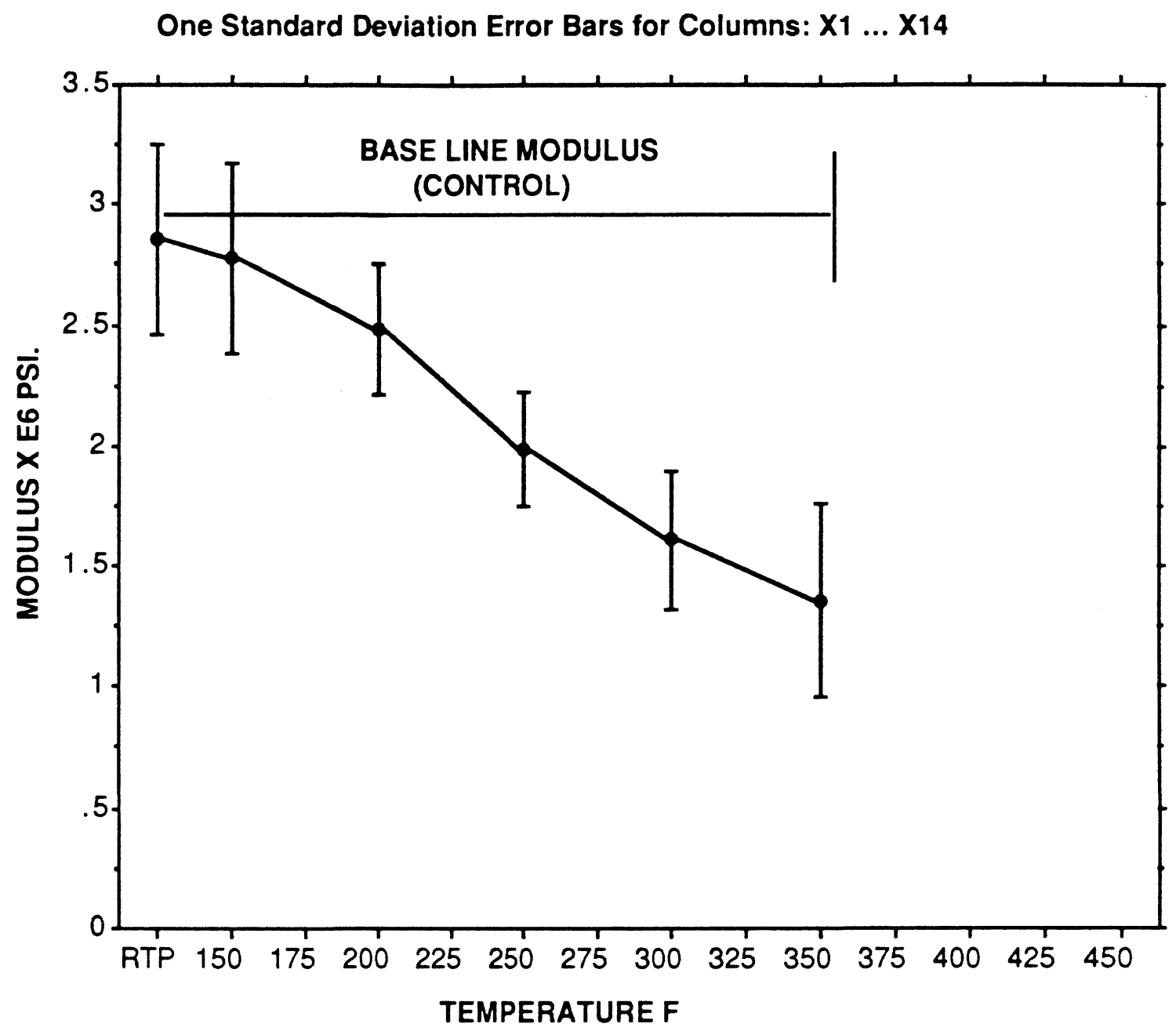

Fig. 27: Change in modulus with heating using mold - X10354. 


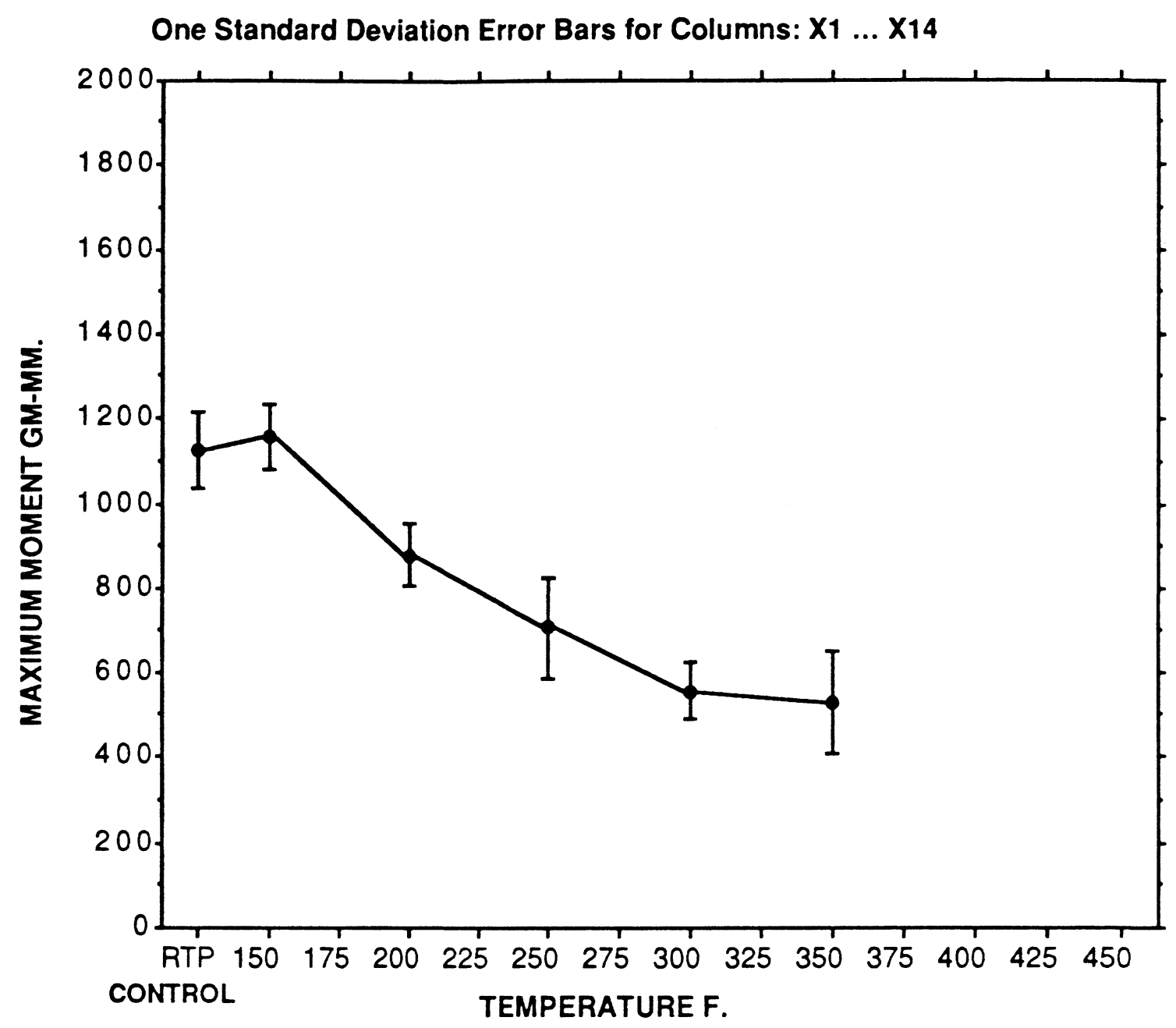

Fig. 28: Maximum moment vs heating temperature using mold - X10354. 
One Standard Deviation Error Bars for Columns: X1 ... X14

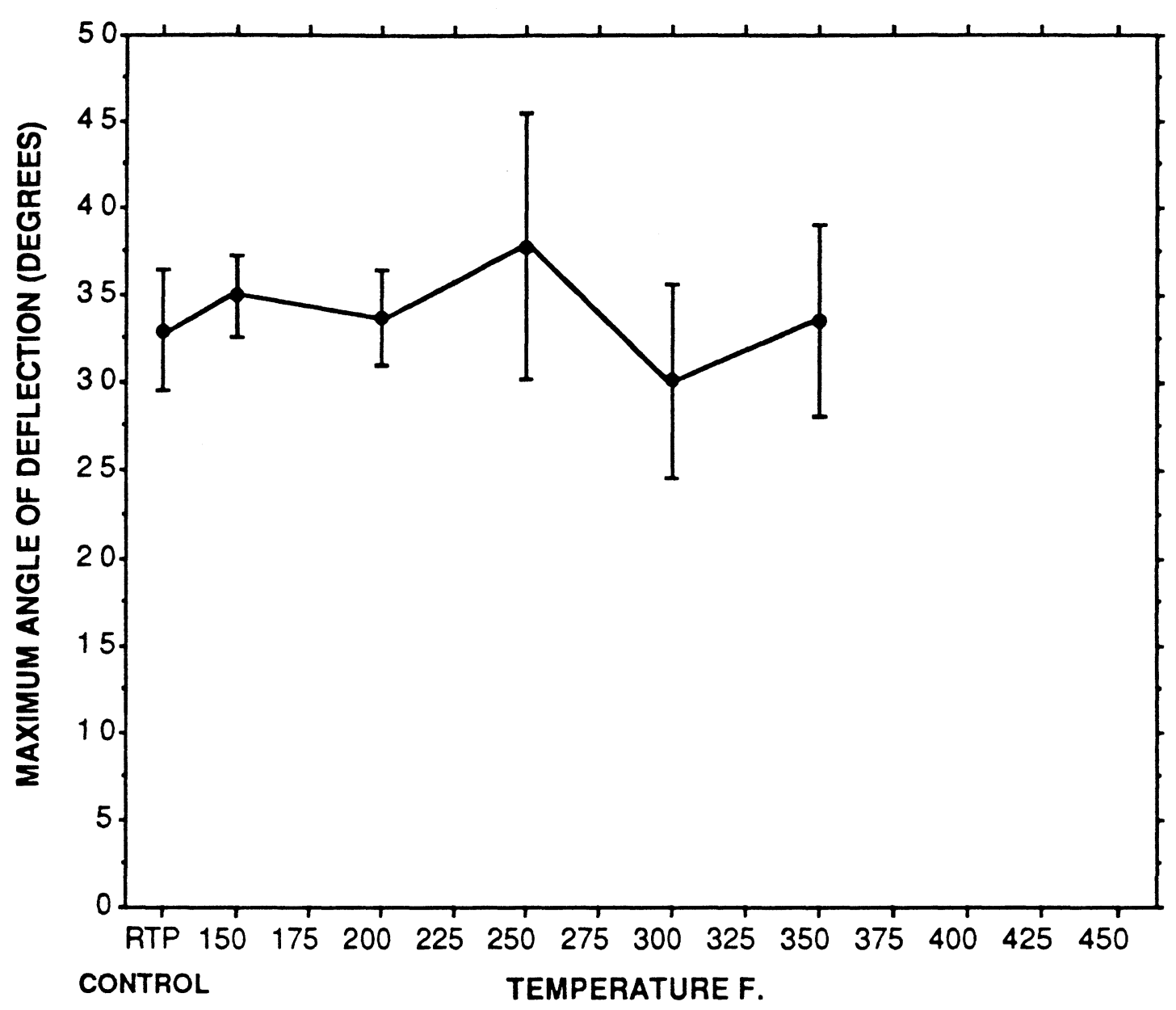

Fig. 29: Maximum deflection vs heating temperature using mold - X10354. 


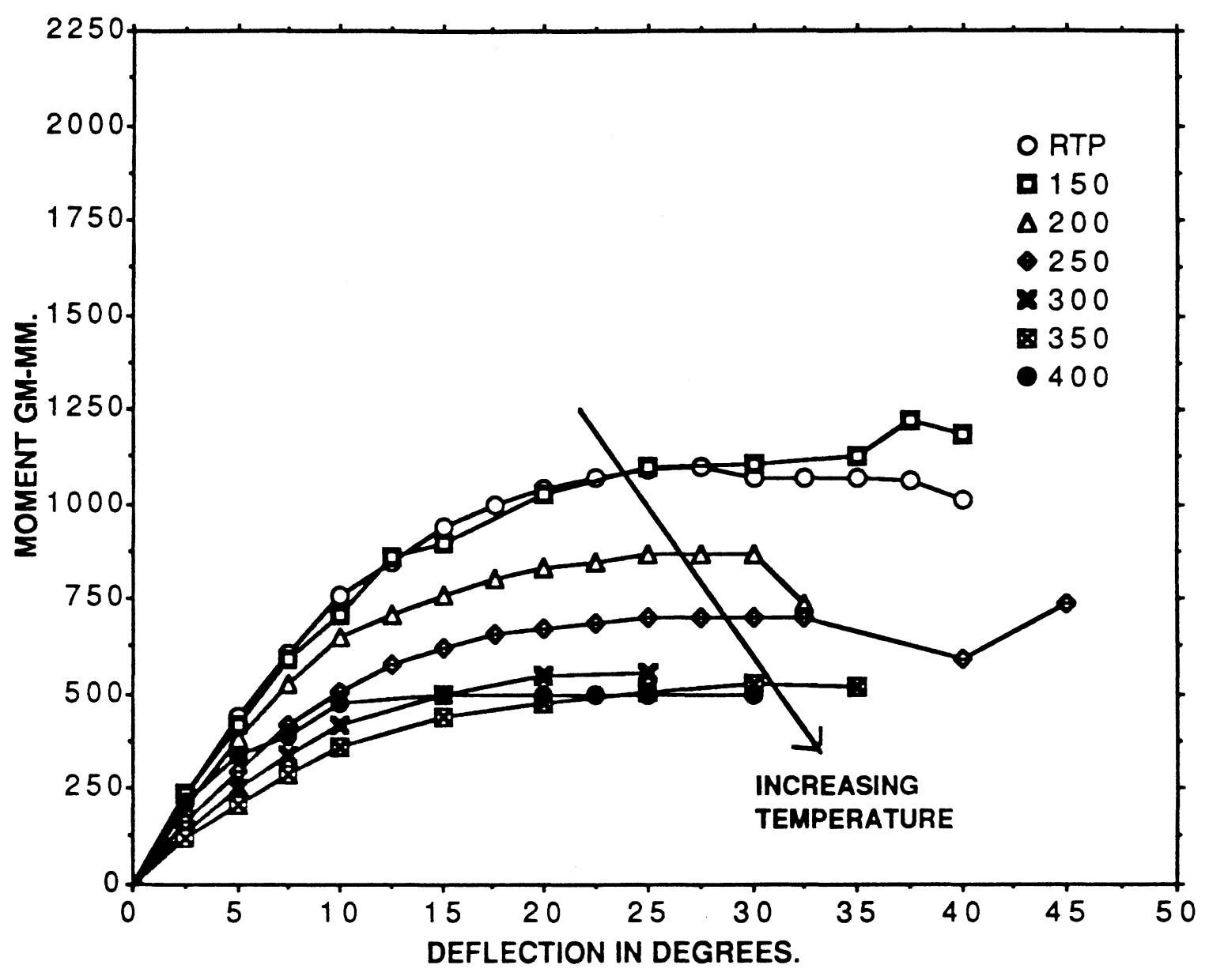

Fig. 30: Moment vs Deflection curves using mold - X10354. 


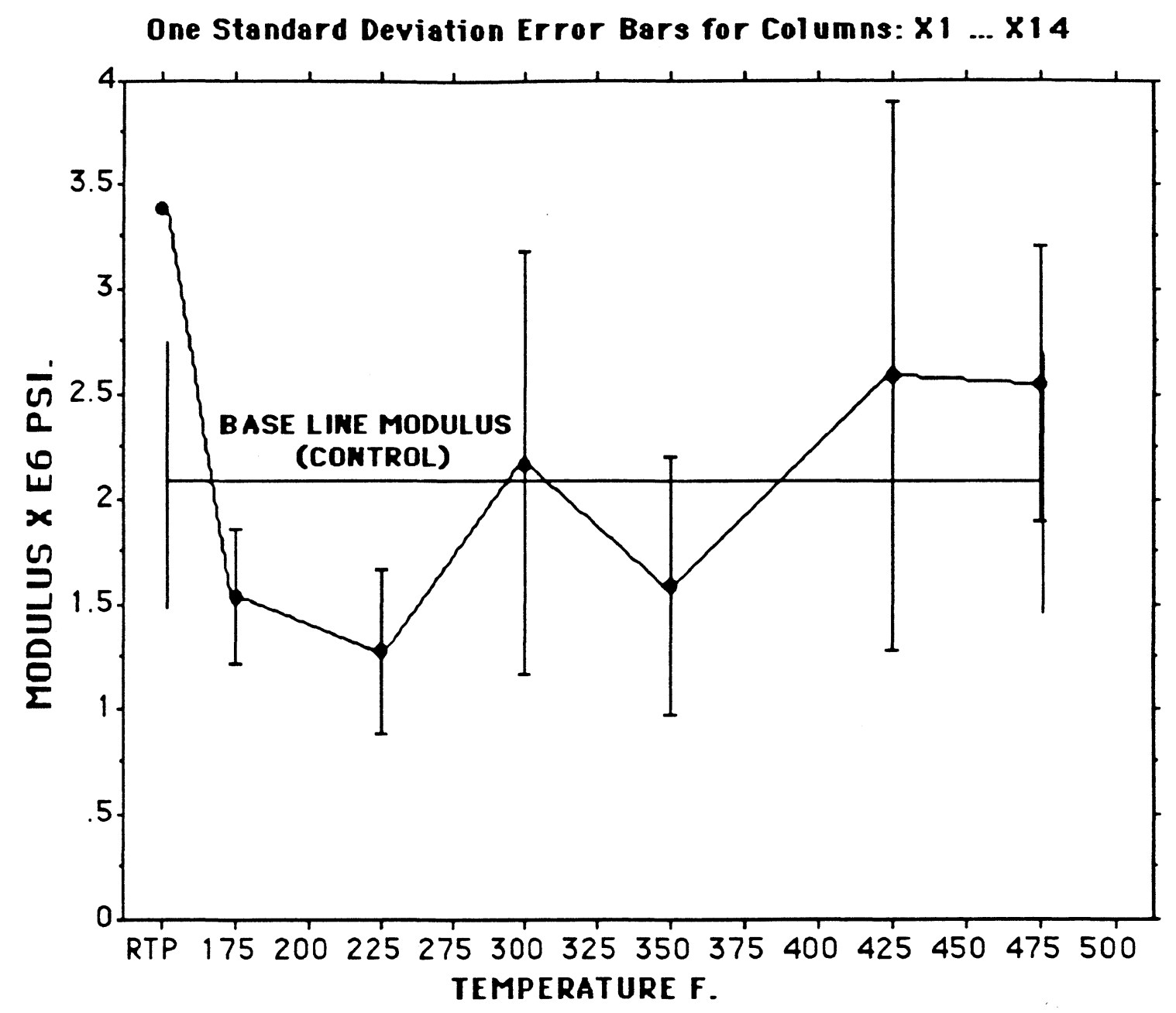

Fig. 31: Change in modulus with heating using mold $-113 \mathrm{AZH}$. 


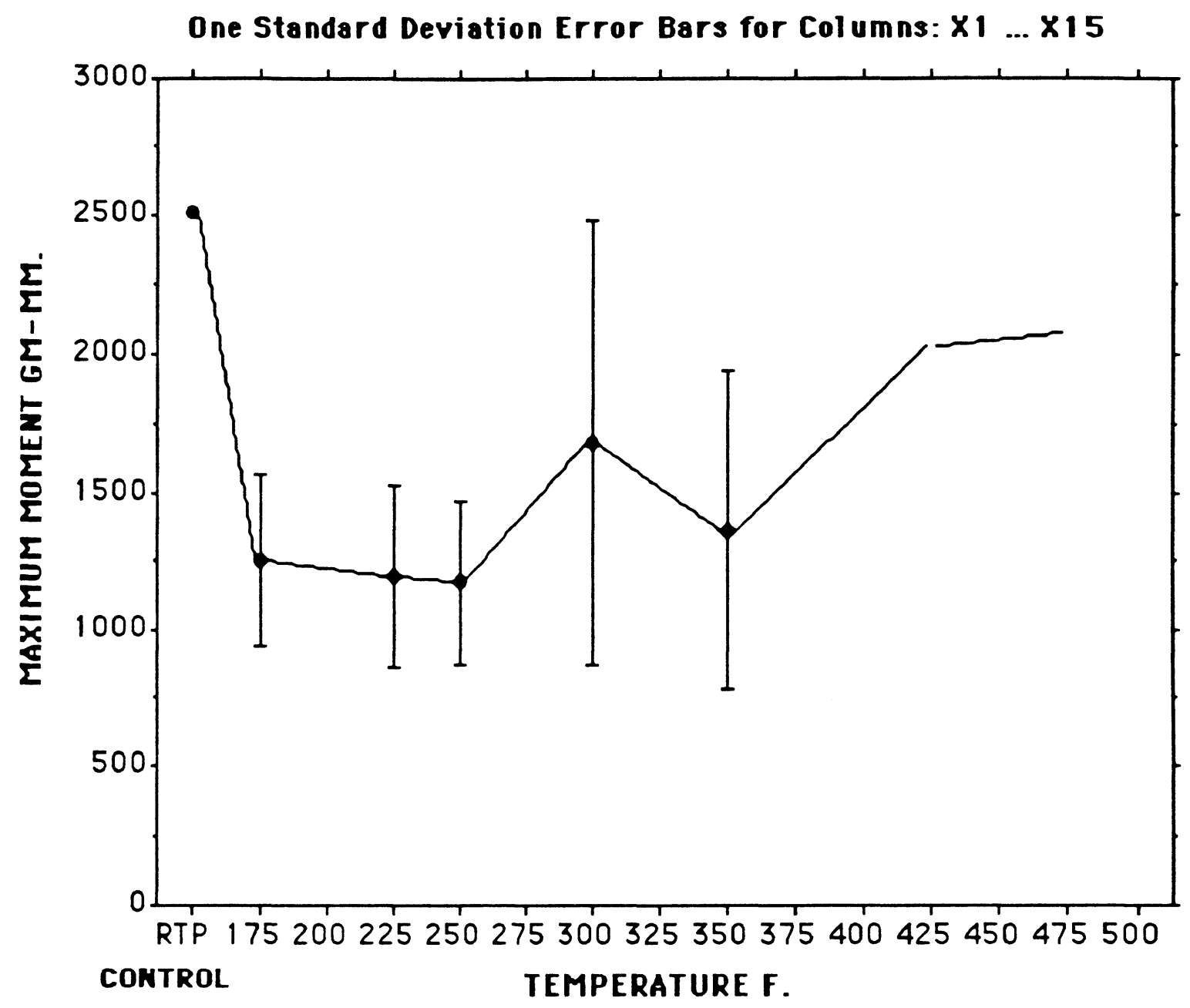

Fig. 32: Maximum moment vs heating temperature using mold $-113 A Z H$. 
One Standard Deviation Error Bars for Columns: X1 ... X15

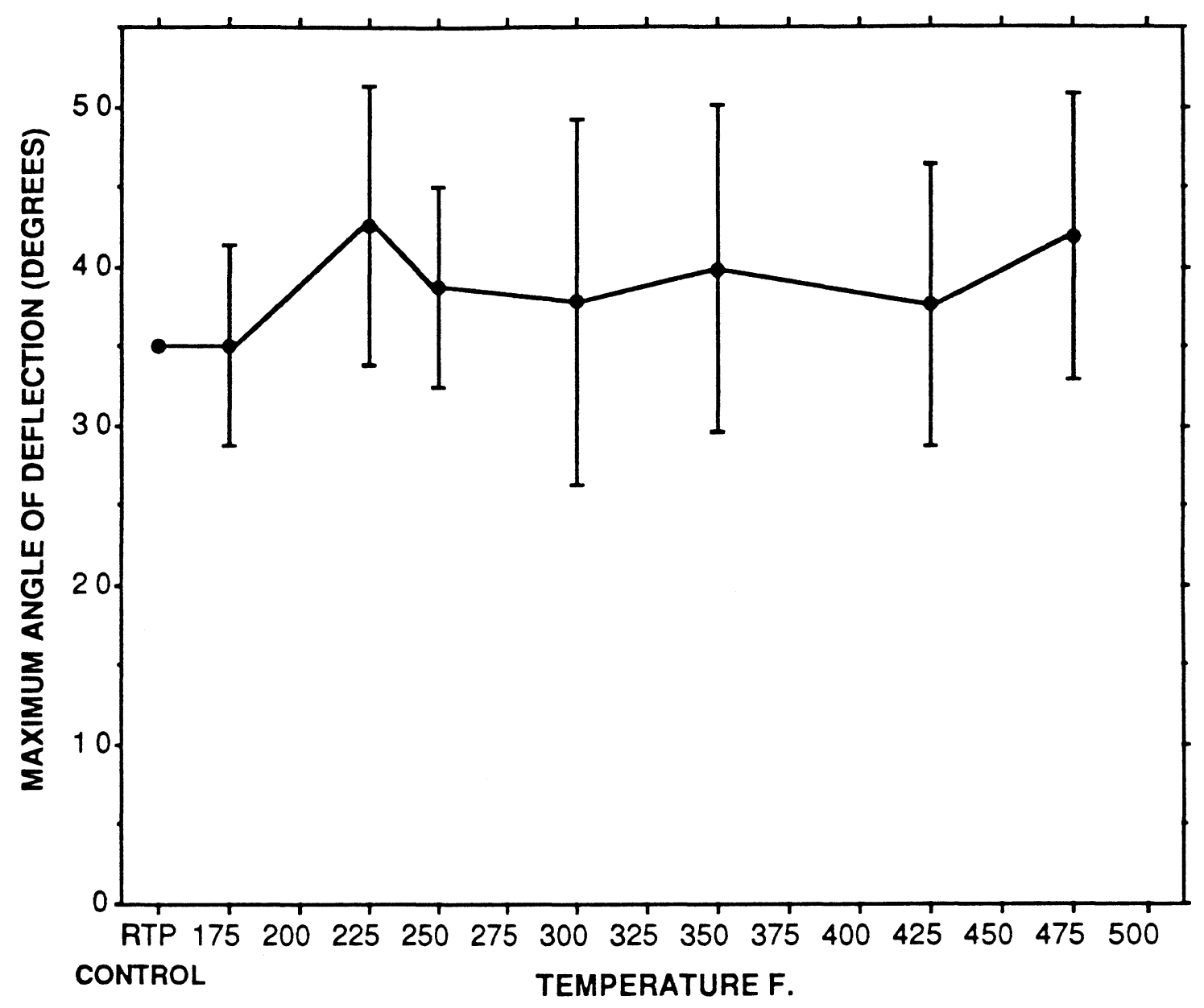

Fig. 33: Maximum deflection vs heating temperature using mold $-113 \mathrm{AZH}$. 


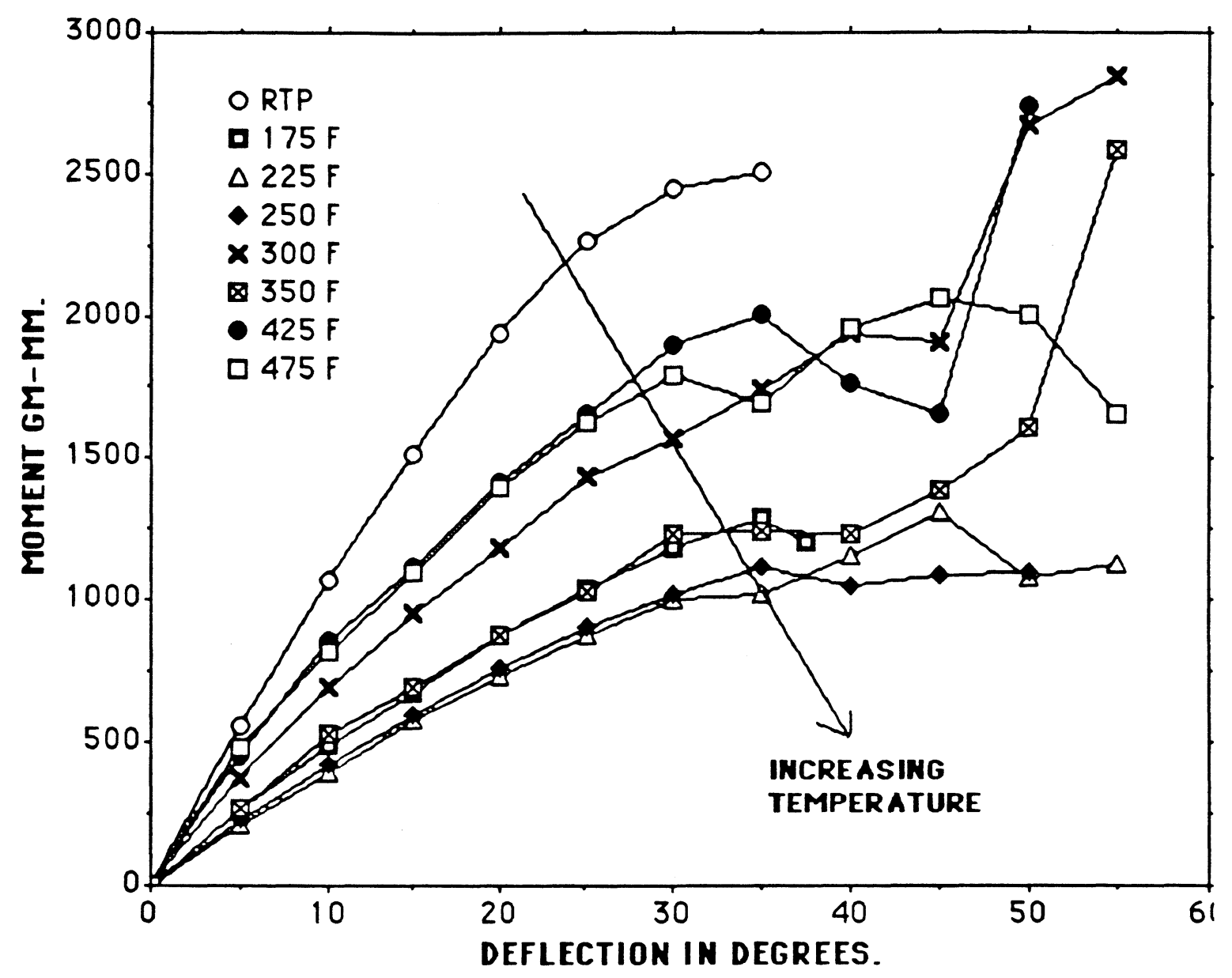

Fig. 34: Moment vs Deflection curves using mold -113AZH. 
One Standard Deviation Error Bars for Columns: X1 ... X13

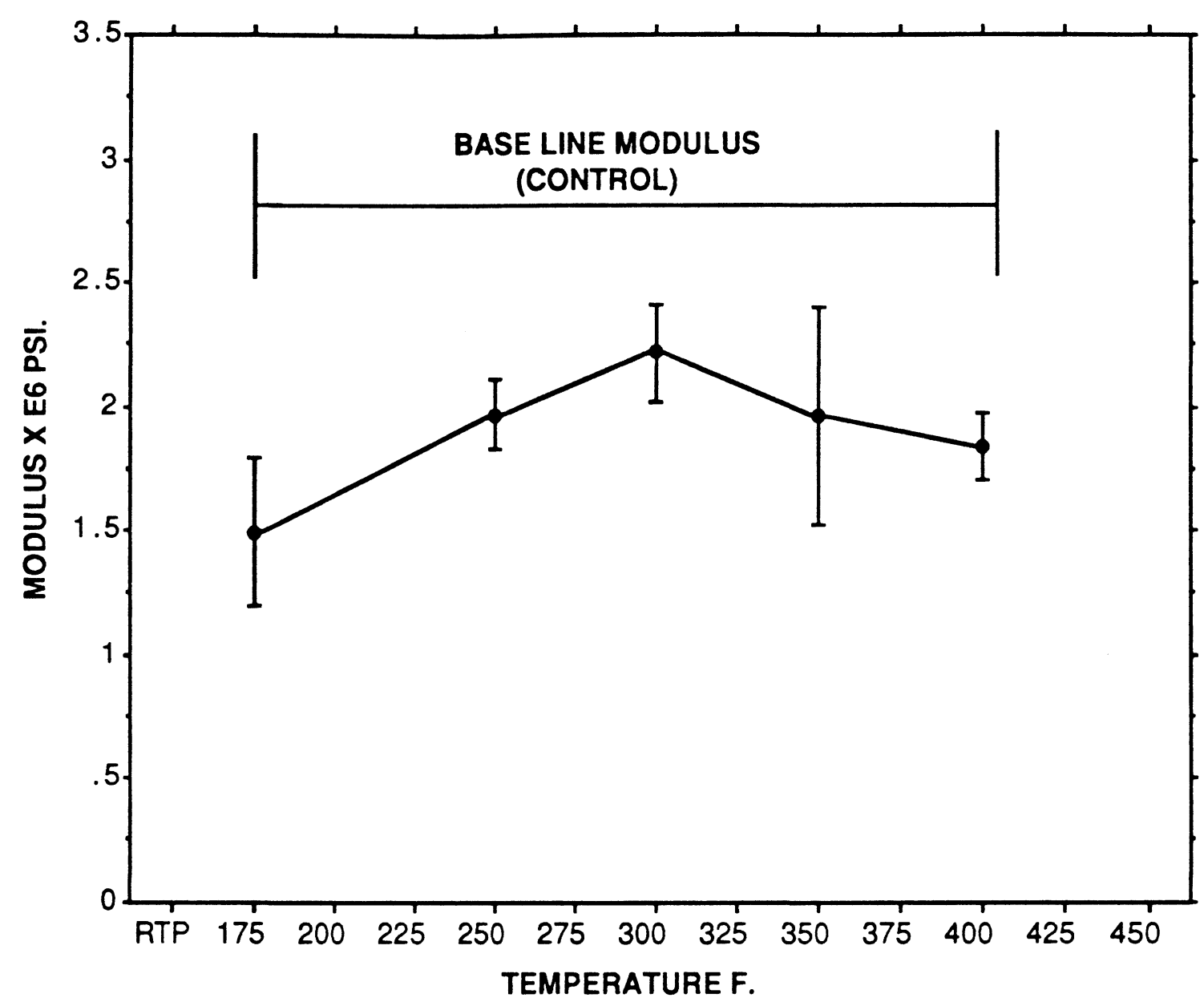

Fig. 35: Change in modulus with heating using oven $-0 \mathrm{~mm}$ deflection - X10333A. 
One Standard Deviation Error Bars for Columns: X1 ... X13

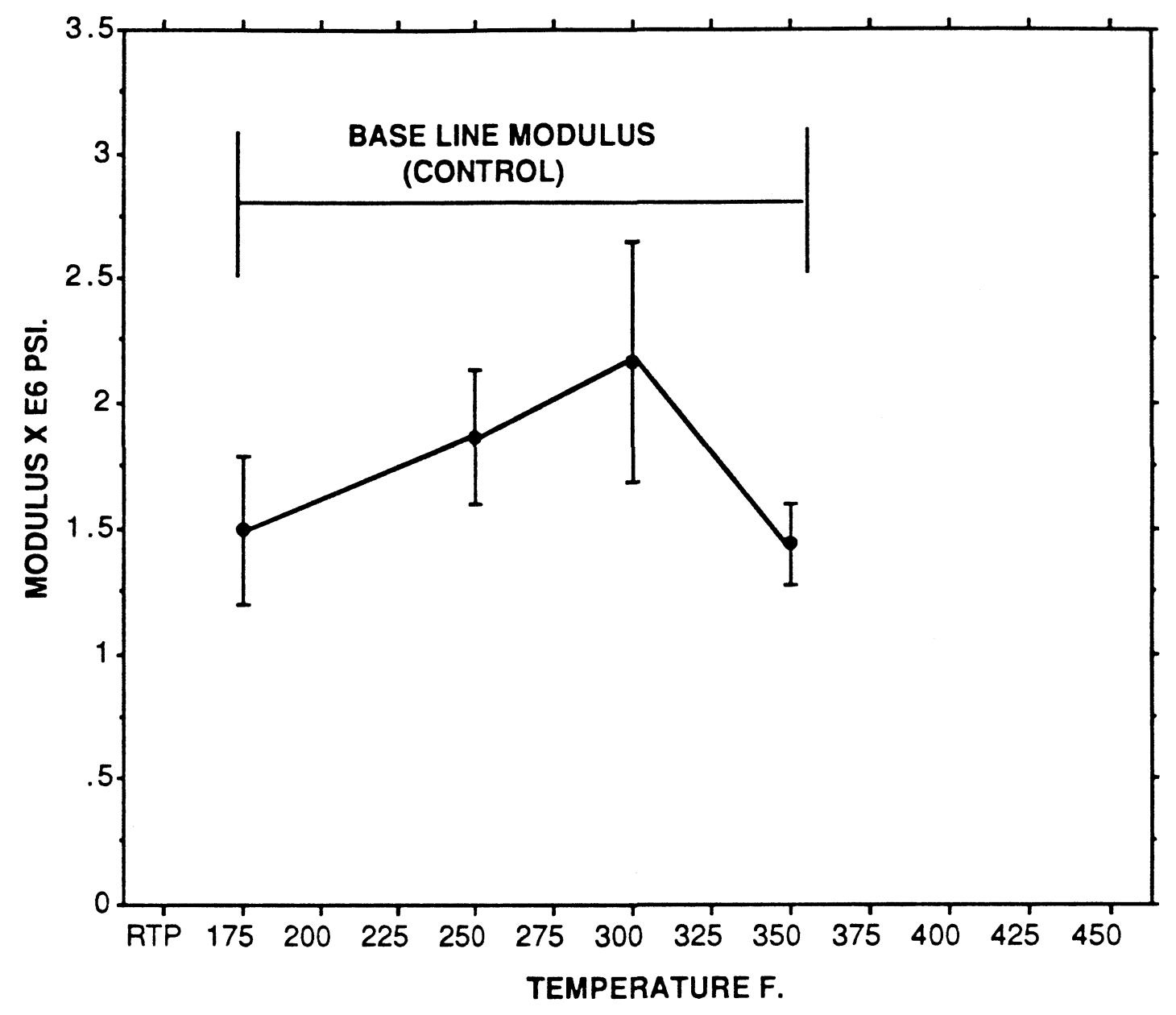

Fig. 36: Change in modulus with heating/forming using oven $-10 \mathrm{~mm}$ deflection - X10333A. 


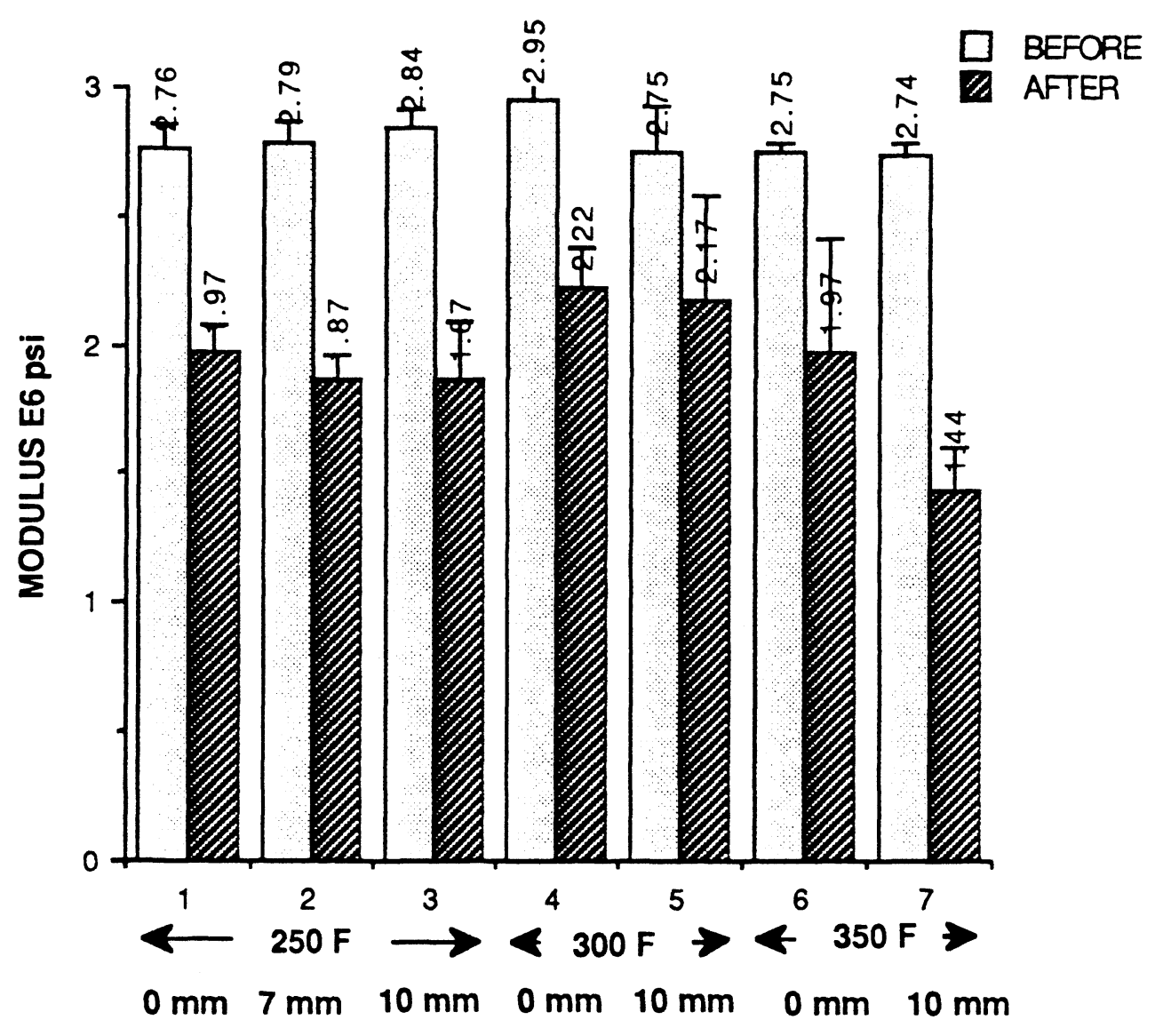

Fig. 37: Change in modulus with forming/temperature- X10333A. 


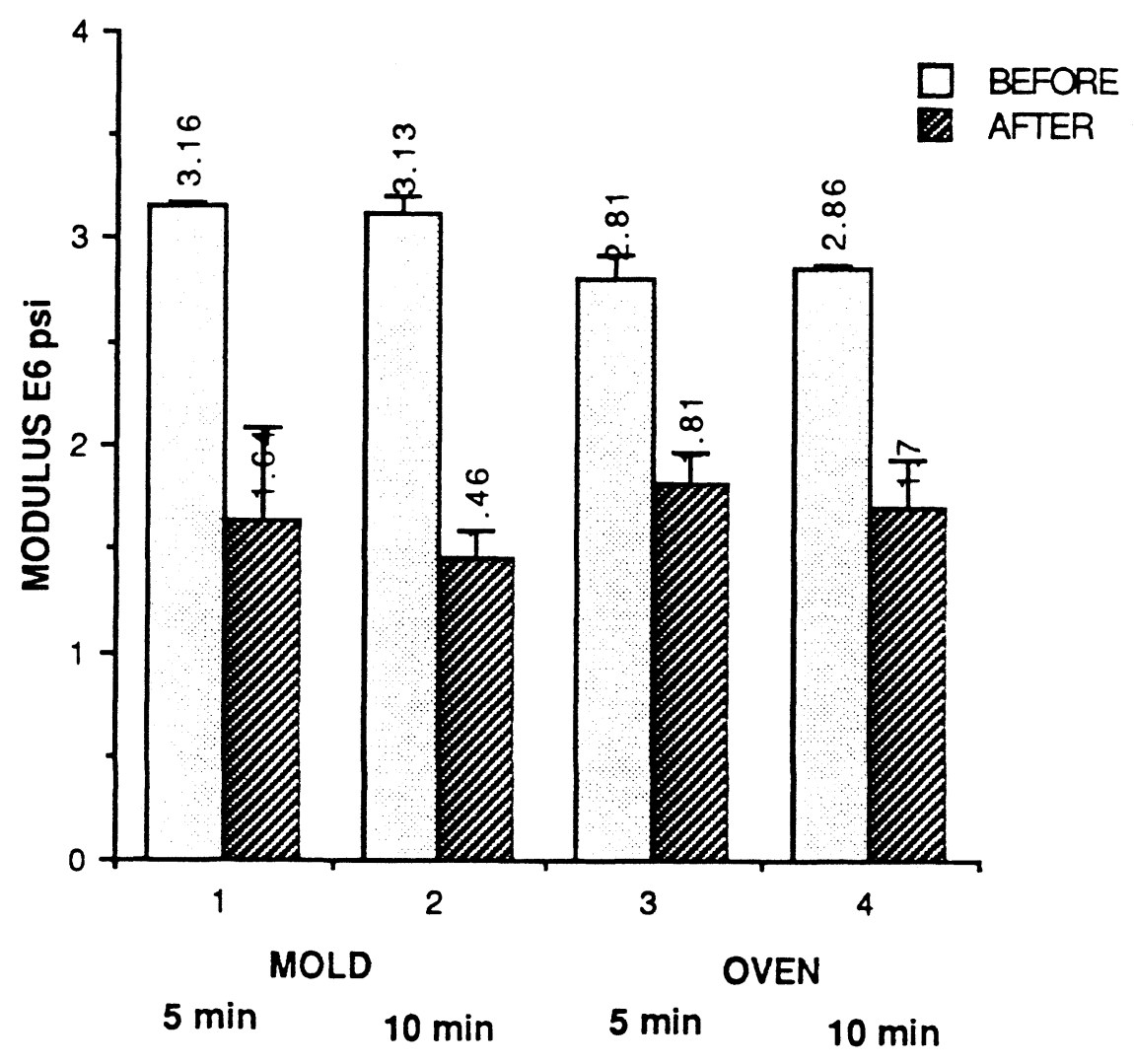

FIG. 38: Effect of method and duration of heating at $410 \mathrm{~F}$. 


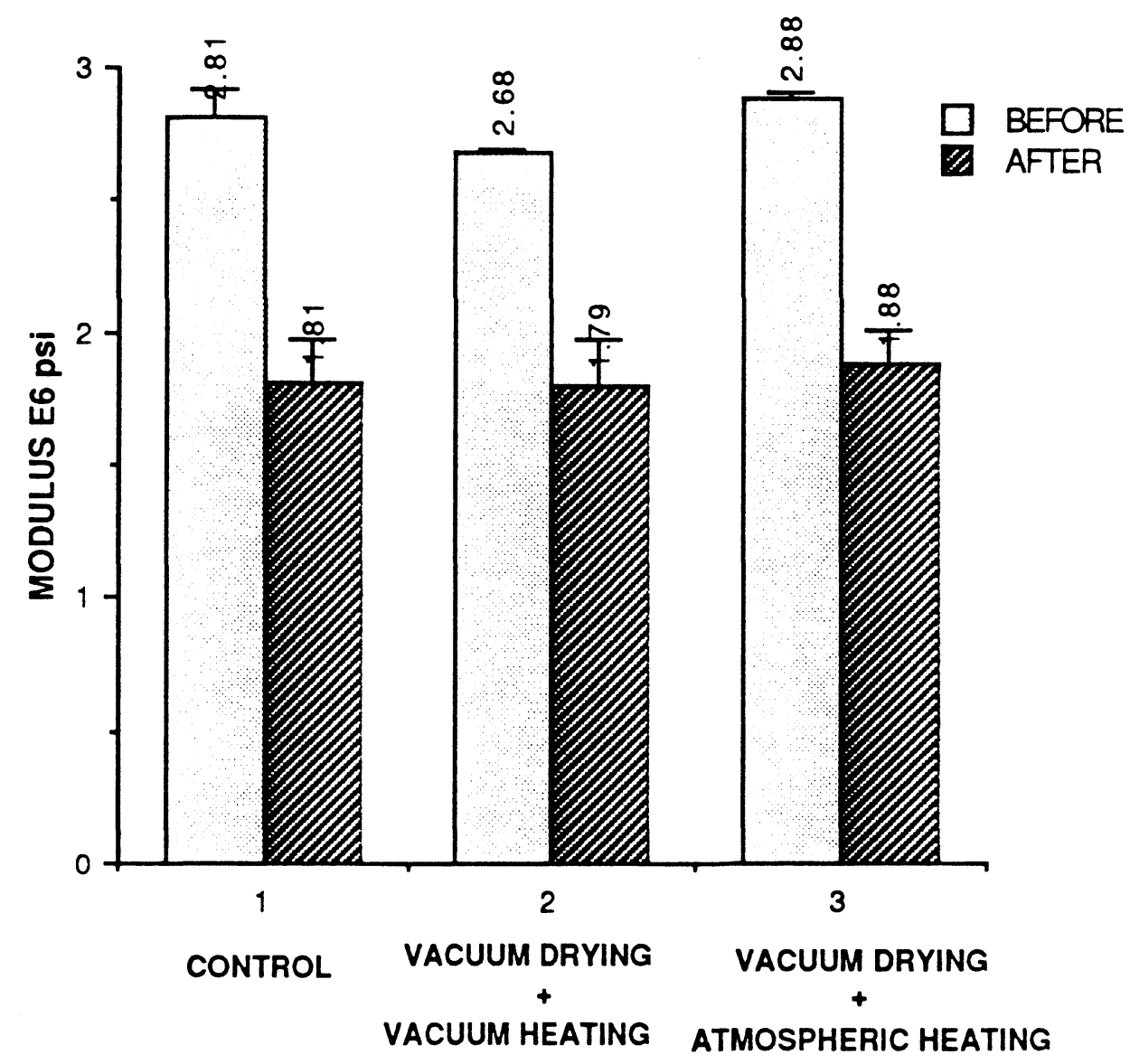

Fig. 39: Effect of pre-drying and vacuum heating at $400 \mathrm{~F}$. 


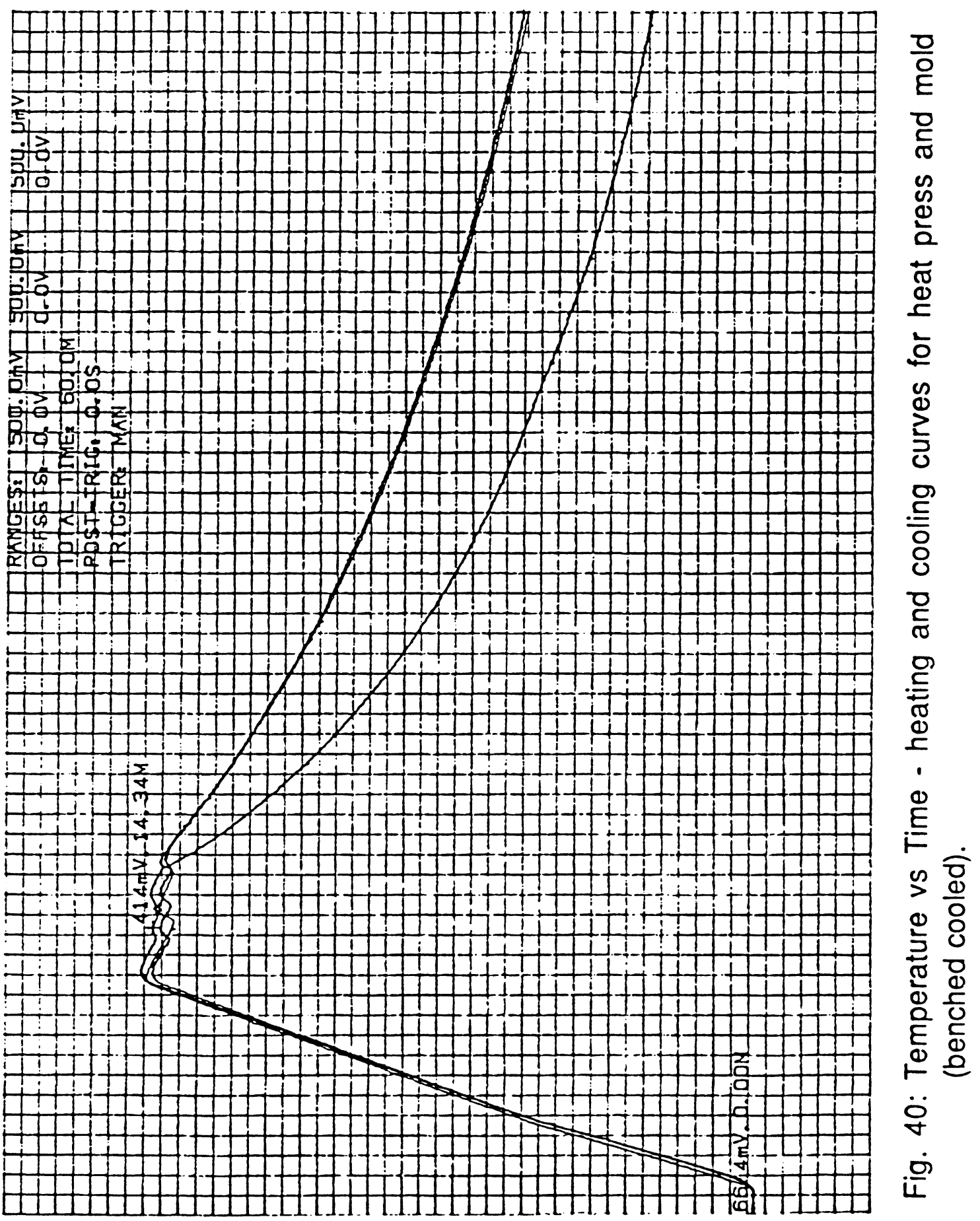




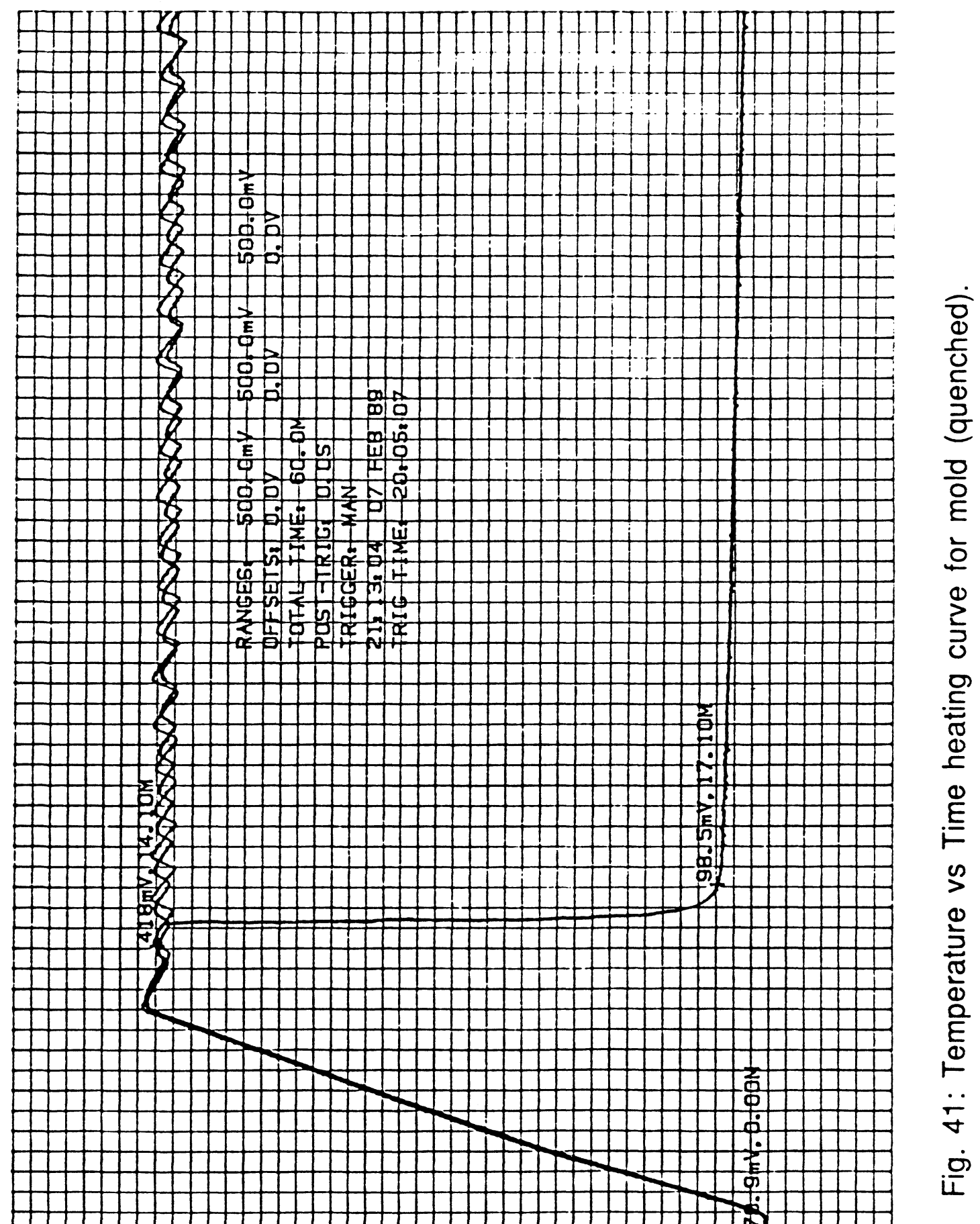




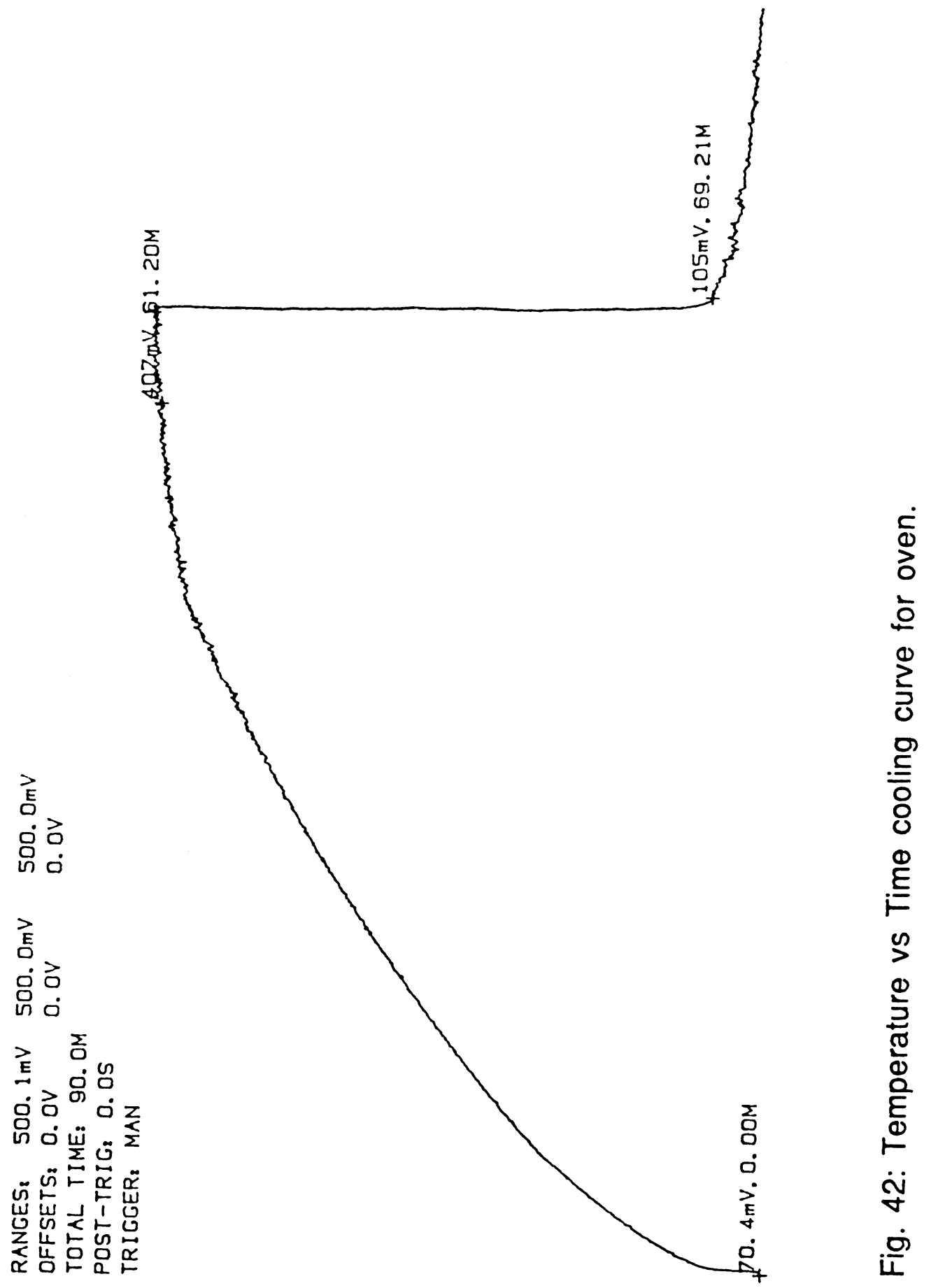




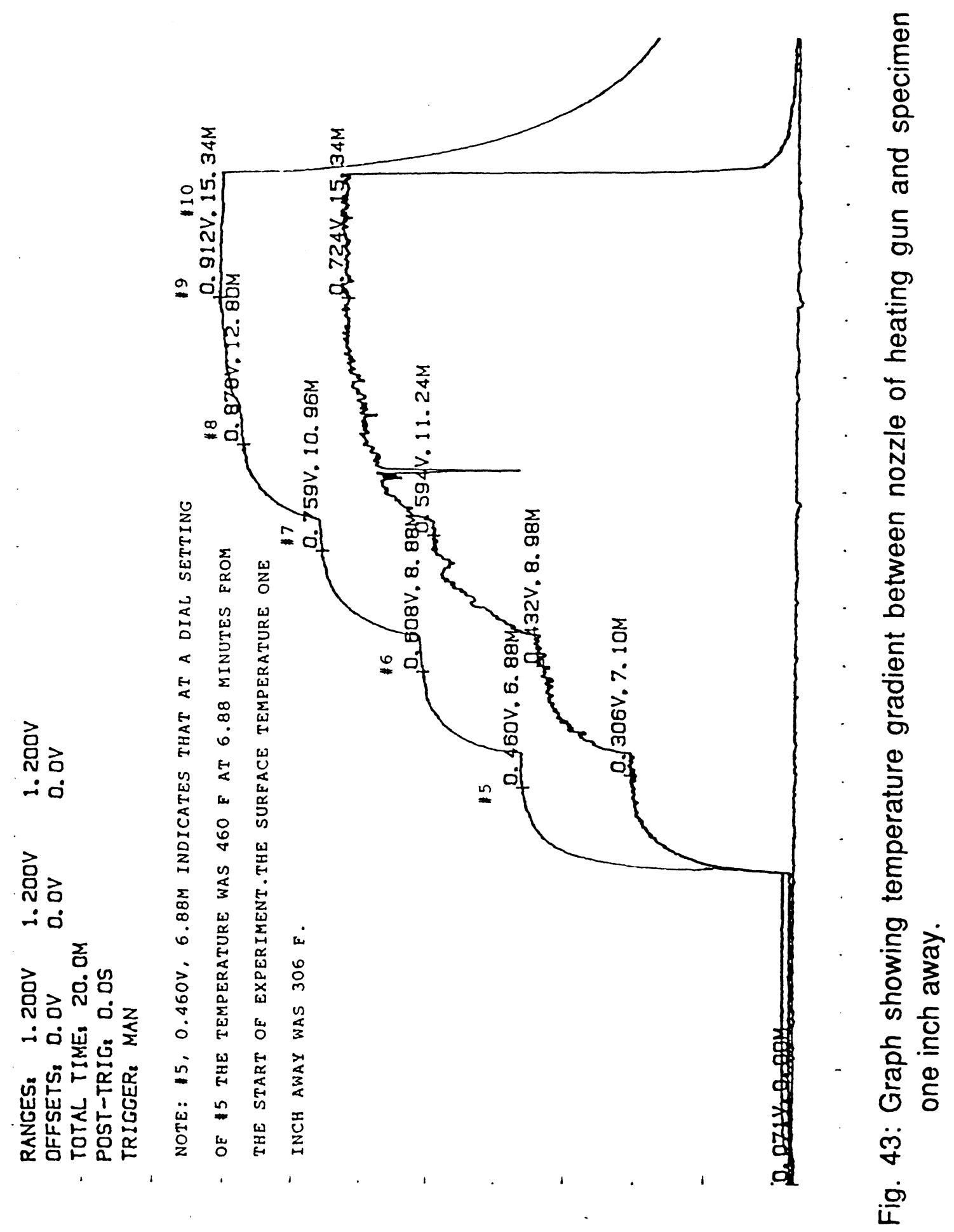




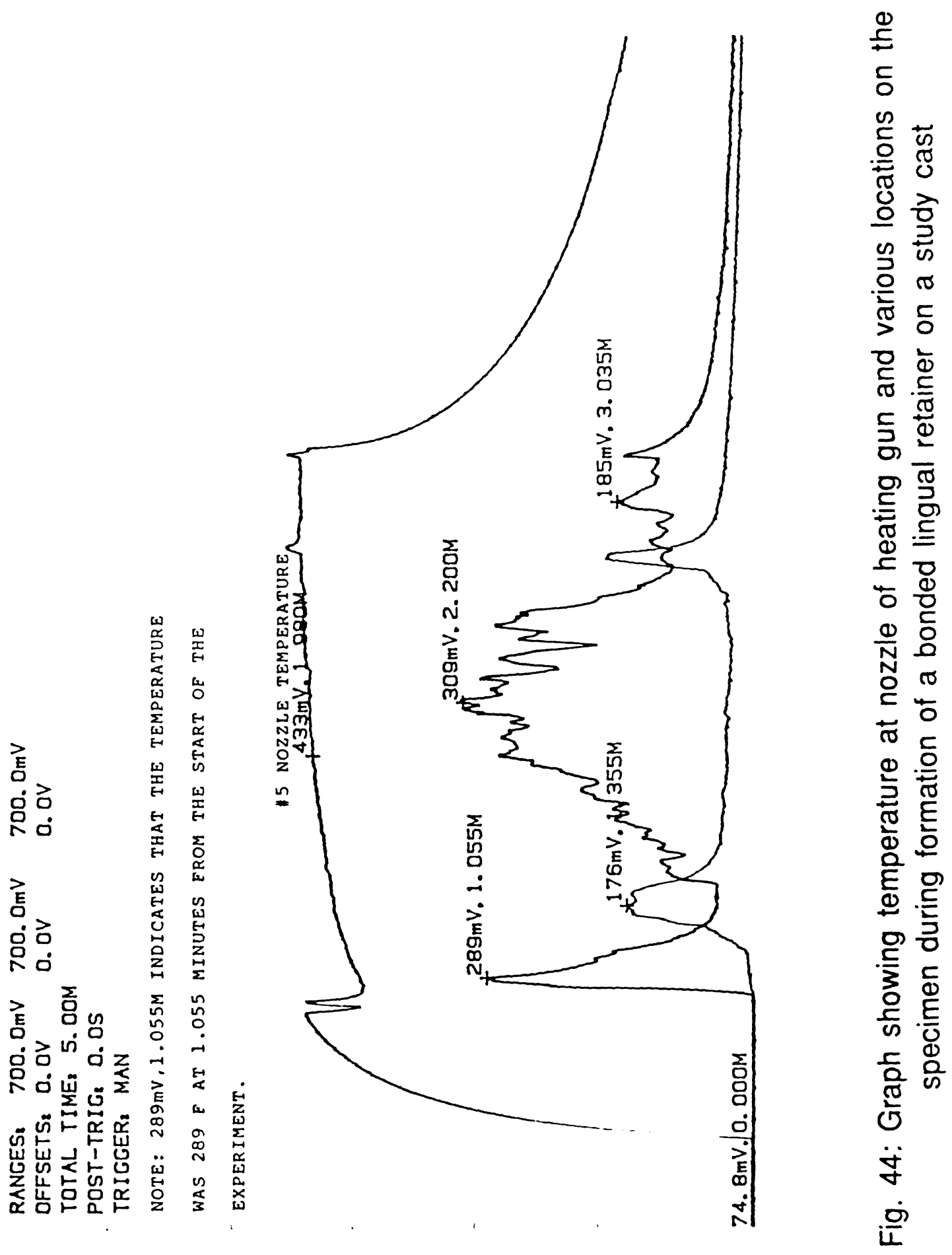


MODULUS PRIOR TO HEATING

\begin{tabular}{|r|rrrrrrr|r|r|}
\hline TEMP & \multicolumn{7}{|c|}{ SAMPLE } & MEAN & S.D. \\
\hline F & 1 & 2 & 3 & 4 & 5 & 6 & 7 & & \\
\hline RTP & 2.80 & 2.76 & 2.86 & 2.99 & 2.86 & 3.04 & 2.85 & 2.88 & 0.10 \\
250 & 3.02 & 2.83 & 2.87 & 2.77 & 2.83 & 2.68 & & 2.83 & 0.11 \\
300 & 3.10 & 2.92 & 2.99 & 3.14 & 3.05 & 2.74 & & 2.99 & 0.15 \\
350 & 2.73 & 2.86 & 2.75 & 2.91 & 2.64 & 2.67 & & 2.76 & 0.11 \\
400 & 2.85 & 2.64 & 2.87 & 2.65 & 2.80 & 2.62 & & 2.74 & 0.11 \\
450 & 2.83 & 2.95 & 2.89 & 2.84 & 2.47 & 2.83 & & 2.80 & 0.17 \\
& 2.82 & 2.85 & 3.26 & 3.05 & 3.00 & 3.23 & 3.13 & 0.18 \\
& & & & & & MEAN OF TOTAL & 2.89 & 0.19 \\
\hline
\end{tabular}

MODULUS AFTER HEATING

\begin{tabular}{|r|rrrrrrr|r|r|}
\hline TEMP & \multicolumn{7}{|c|}{ SAMPLE } & MEAN & S.D. \\
F & 1 & 2 & 3 & 4 & 5 & 6 & 7 & & \\
\hline RTP & 2.80 & 2.76 & 2.86 & 2.99 & 2.86 & 3.04 & 2.85 & 2.88 & 0.10 \\
200 & 2.93 & 2.53 & 2.86 & 2.80 & 2.54 & 2.74 & & 2.73 & 0.17 \\
250 & 2.53 & 2.41 & 2.52 & 2.81 & 2.38 & 2.47 & & 2.52 & 0.15 \\
300 & 1.75 & 2.07 & 2.10 & 2.75 & 2.50 & 1.80 & & $* 16$ & 0.39 \\
350 & 1.38 & 2.23 & 1.73 & 1.52 & 2.28 & 1.91 & & $* 1.84$ & 0.37 \\
400 & 1.93 & 1.04 & 1.43 & 0.90 & 2.26 & & & $* 1.51$ & 0.58 \\
450 & 2.66 & 1.96 & 2.55 & 0.72 & 2.21 & 1.07 & & $* 1.20$ & 0.36 \\
& & & & & & & & & \\
\hline
\end{tabular}

- Indicates groups which were statistically different $(p<0.01)$ from the paired control shown above.

TABLE 1. CHANGE IN MODULUS WITH HEATING USING MOLD -X10333A. 
MAXIMUM MOMENT (GM-MM)

\begin{tabular}{|c|c|c|c|c|c|c|c|c|}
\hline \multirow{2}{*}{$\begin{array}{r}\text { TEMP } \\
F\end{array}$} & \multicolumn{6}{|c|}{ SAMPLE } & \multirow[t]{2}{*}{ MEAN } & \multirow[t]{2}{*}{ S.D. } \\
\hline & 1 & 2 & 3 & 4 & 5 & 6 & & \\
\hline RTP & 1330 & 1390 & 1620 & 1510 & 1580 & 1590 & 1478 & 126 \\
\hline 200 & 1650 & 1410 & 1830 & 1640 & 1780 & 1640 & 1658 & 4 \\
\hline 250 & 1600 & 1970 & 1430 & 1610 & 1660 & 1110 & 1563 & 283 \\
\hline 300 & 880 & 1200 & 1000 & 1650 & 1500 & 1340 & 1261 & 294 \\
\hline 350 & 1040 & 1500 & 700 & 1040 & 1750 & 1640 & 1278 & 412 \\
\hline 400 & 1060 & 470 & 640 & 620 & 1470 & & 852 & 409 \\
\hline 425 & 490 & 960 & 610 & 1400 & & & 865 & 409 \\
\hline 450 & 1260 & 520 & 900 & 420 & 740 & 430 & 712 & 328 \\
\hline
\end{tabular}

MAXIMUM DEFLECTION (DEGREES)

\begin{tabular}{|c|c|c|c|c|c|c|c|c|}
\hline \multirow{2}{*}{$\begin{array}{r}\text { TEMP } \\
F\end{array}$} & \multicolumn{6}{|c|}{ SAMPLE } & \multirow[t]{2}{*}{ MEAN } & \multirow[t]{2}{*}{ S.D. } \\
\hline & 1 & 2 & 3 & 4 & 5 & 6 & & \\
\hline RTP & 19.50 & 19.50 & 22.00 & 19.50 & 19.50 & 22.00 & 20.00 & 1.00 \\
\hline 200 & 23.70 & 19.50 & 23.50 & 22.50 & 26.50 & 22.50 & 23.00 & 2.00 \\
\hline 250 & 25.50 & 28.50 & 23.00 & 22.00 & 23.50 & 18.00 & 23.00 & 3.0 \\
\hline 300 & 29.50 & 22.00 & 27.00 & 21.00 & 24.50 & 28.50 & $* 25.00$ & 3.00 \\
\hline 350 & 27.00 & 24.50 & 39.00 & 26.00 & 24.50 & 27.00 & $* 28.00$ & 5.0 \\
\hline 400 & 27.00 & 37.00 & 28.50 & 34.00 & 26.00 & & $\star 30.00$ & .0 \\
\hline 425 & 27.00 & 30.00 & 18.00 & 37.50 & & & 28.00 & 8.0 \\
\hline 450 & 20.50 & 15.00 & 32.00 & 37.50 & 19.00 & 18.00 & 24.00 & 9.00 \\
\hline
\end{tabular}

* Indicates groups which were statistically different $(p<0.01)$ from the paired control shown above.

TABLE 2. MAXIMUM MOMENT AND MAXIMUM DEFLECTION VS HEATING TEMPERATURE USING MOLD -X10333A. 


\begin{tabular}{|c|c|c|c|c|c|c|c|c|}
\hline \multirow{2}{*}{$\begin{array}{l}\text { DEFLECTION } \\
\text { (DEGREES) }\end{array}$} & \multicolumn{8}{|c|}{ AVERAGE MOMENT IN GM-MM FOR HEATING TEMPERATURE OF: } \\
\hline & RTP & $200 \mathrm{~F}$ & $250 \mathrm{~F}$ & $300 \mathrm{~F}$ & $350 \mathrm{~F}$ & $400 \mathrm{~F}$ & $425 \mathrm{~F}$ & $450 \mathrm{~F}$ \\
\hline 0.00 & 0 & 0 & 0 & 0 & 0 & 0 & 0 & 0 \\
\hline 2.50 & 230 & 220 & 210 & 180 & 150 & 130 & 130 & 170 \\
\hline 5.00 & 450 & 430 & 390 & 340 & 290 & 230 & 230 & 290 \\
\hline 7.50 & 650 & 620 & 570 & 490 & 420 & 340 & 320 & 410 \\
\hline 10.00 & 850 & 810 & 750 & 630 & 560 & 440 & 410 & 510 \\
\hline 12.50 & 1030 & 990 & 920 & 760 & 680 & 520 & 500 & 590 \\
\hline 15.00 & 1200 & 1180 & 1080 & 880 & 810 & 610 & 570 & 660 \\
\hline 17.50 & 1380 & 1360 & 1230 & 1000 & 920 & 690 & 630 & 740 \\
\hline 20.00 & 1460 & 1500 & 1390 & 1110 & 970 & 740 & 700 & 780 \\
\hline 22.50 & 1610 & 1640 & 1530 & 1190 & 1080 & 810 & 730 & 770 \\
\hline 25.00 & & 1750 & 1640 & 1160 & 1190 & 820 & 750 & 760 \\
\hline 27.50 & & 1780 & 1810 & 1070 & 1260 & 820 & 750 & 800 \\
\hline 30.00 & & & 1970 & & 1280 & 790 & & 810 \\
\hline 32.50 & & & & & 1300 & 700 & & 810 \\
\hline 35.00 & & & & & 1280 & 600 & & \\
\hline 37.50 & & & & & & 550 & & \\
\hline 40.00 & & & & & & 470 & & \\
\hline
\end{tabular}

TABLE 3. MOMENT VS DEFLECTION CURVES USING MOLD -X10333A. 
MODULUS PRIOR TO HEATING

\begin{tabular}{|c|c|c|c|c|c|c|c|c|}
\hline \multirow{2}{*}{$\begin{array}{r}\text { TEMP } \\
F\end{array}$} & \multicolumn{6}{|c|}{ SAMPLE } & \multirow[t]{2}{*}{ MEAN } & \multirow[t]{2}{*}{ S.D. } \\
\hline & 1 & 2 & 3 & 4 & 5 & 6 & & \\
\hline RTP & 2.93 & 3.01 & 3.19 & 3.03 & 3.03 & 3.29 & 3.08 & 0.13 \\
\hline 200 & 2.89 & 2.78 & 2.96 & 3.01 & 3.05 & 2.95 & 2.94 & 0.10 \\
\hline 250 & 3.07 & 2.95 & 2.79 & 3.19 & 2.93 & 2.91 & 2.97 & 0.14 \\
\hline 300 & 3.12 & 2.98 & 3.21 & 2.94 & 2.80 & 3.13 & 3.03 & 0.15 \\
\hline 350 & 3.00 & 3.13 & 3.08 & 3.08 & 2.91 & & 3.04 & 0.09 \\
\hline 400 & 2.98 & 3.24 & 2.90 & 3.01 & 3.12 & 3.04 & 3.05 & 0.12 \\
\hline 450 & 3.21 & 3.21 & 3.05 & 2.96 & 2.77 & 2.83 & 3.01 & 0.19 \\
\hline 500 & 2.86 & 3.06 & 2.97 & 2.89 & 3.23 & 3.29 & 3.05 & 0.18 \\
\hline & & & & & IEANC & OTAL & 3.02 & 0.14 \\
\hline
\end{tabular}

MODULUS AFTER HEATING

\begin{tabular}{|c|c|c|c|c|c|c|c|c|}
\hline \multirow{2}{*}{$\begin{array}{r}\text { TEMP } \\
F \\
\end{array}$} & \multicolumn{6}{|c|}{ SAMPLE } & \multirow[t]{2}{*}{ MEAN } & \multirow[t]{2}{*}{ S.D. } \\
\hline & 1 & 2 & 3 & 4 & 5 & 6 & & \\
\hline RTP & 2.93 & 2.87 & 2.79 & 2.89 & 2.86 & 2.74 & 2.85 & 0.07 \\
\hline 200 & 2.98 & 2.77 & 2.72 & 2.89 & 2.72 & 2.98 & 2.84 & 0.12 \\
\hline 250 & 2.62 & 2.87 & 3.05 & 3.33 & 2.68 & 3.01 & 2.93 & 0.26 \\
\hline 300 & 2.47 & 2.45 & 2.62 & 2.62 & 2.25 & 2.45 & * 2.48 & 0.14 \\
\hline 350 & 2.21 & 2.36 & 2.27 & 2.25 & 2.44 & & $* 2.31$ & 0.09 \\
\hline 400 & 2.65 & 2.43 & 1.84 & 2.13 & 2.40 & 2.12 & * $\quad 2.26$ & 0.29 \\
\hline 450 & 1.59 & 1.72 & 1.70 & 1.65 & 1.38 & 2.07 & * 1.68 & 0.22 \\
\hline 500 & 1.32 & 1.72 & 1.53 & 1.54 & 2.10 & 1.47 & * 1.61 & 0.27 \\
\hline
\end{tabular}

* Indicates groups which were statistically different $(p<0.01)$ from the paired control shown above.

TABLE 4. CHANGE IN MODULUS WITH HEATING USING MOLD -X10364. 
MAXIMUM MOMENT (GM-MM)

\begin{tabular}{|c|c|c|c|c|c|c|c|c|}
\hline \multirow{2}{*}{$\begin{array}{r}\text { TEMP } \\
F \\
\end{array}$} & \multicolumn{6}{|c|}{ SAMPLE } & \multirow[t]{2}{*}{ MEAN } & \multirow[t]{2}{*}{ S.D. } \\
\hline & 1 & 2 & 3 & 4 & 5 & 6 & & \\
\hline RTP & 1870 & 2060 & 1870 & 1910 & 1960 & 2040 & 1952 & 83 \\
\hline 200 & 1900 & 1840 & 2070 & 1970 & 2300 & 1920 & 2000 & 166 \\
\hline 250 & 2030 & 2140 & 1930 & 1970 & 1830 & 2200 & 2017 & 137 \\
\hline 300 & 1820 & 1880 & 1700 & 1920 & 1680 & 1520 & 1753 & 149 \\
\hline 350 & 1750 & 1620 & 1660 & 1620 & 1620 & & *1654 & 56 \\
\hline 400 & 1730 & 1320 & 940 & 1490 & 1670 & 1510 & $* 1443$ & 286 \\
\hline 450 & 1710 & 1290 & 1330 & 1200 & 950 & 1400 & $* 1313$ & 249 \\
\hline 500 & 1040 & 990 & 1220 & 800 & 1580 & 1050 & $* 1113$ & 265 \\
\hline
\end{tabular}

MAXIMUM DEFLECTION (DEGREES)

\begin{tabular}{|c|c|c|c|c|c|c|c|c|}
\hline \multirow{2}{*}{$\begin{array}{r}\text { TEMP } \\
F \\
\end{array}$} & \multicolumn{6}{|c|}{ SAMPLE } & \multirow[t]{2}{*}{ MEAN } & \multirow[t]{2}{*}{ S.D. } \\
\hline & 1 & 2 & 3 & 4 & 5 & 6 & & \\
\hline RTP & 26.00 & 28.00 & 23.50 & 26.00 & 26.00 & 28.50 & 26.00 & 2.00 \\
\hline 200 & 25.50 & 25.50 & 30.50 & 25.50 & 30.00 & 23.50 & 27.00 & 3.00 \\
\hline 250 & 28.00 & 28.00 & 26.50 & 23.50 & 23.50 & 27.50 & 26.00 & 2.00 \\
\hline 300 & 29.00 & 28.50 & 27.00 & 29.00 & 28.50 & 27.50 & 28.00 & 1.00 \\
\hline 350 & 30.00 & 27.50 & 30.00 & 30.00 & 27.50 & & 29.00 & 1.00 \\
\hline 400 & 25.50 & 22.50 & 24.00 & 27.50 & 27.50 & 27.50 & 26.00 & 2.00 \\
\hline 450 & 32.00 & 30.00 & 31.00 & 28.00 & 32.00 & 30.00 & 30.00 & 2.00 \\
\hline 500 & 29.50 & 25.00 & 32.50 & 27.50 & 30.00 & 32.50 & 30.00 & 3.00 \\
\hline
\end{tabular}

* Indicates groups which were statistically different $(p<0.01)$ from the RTP control.

TABLE 5. MAXIMUM MOMENT AND MAXIMUM DEFLECTION VS HEATING TEMPERATURE USING MOLD -X10364. 


\begin{tabular}{|c|c|c|c|c|c|c|c|c|}
\hline \multirow{2}{*}{$\begin{array}{l}\text { DEFLECTION } \\
\text { (DEGREES) }\end{array}$} & \multicolumn{8}{|c|}{ AVERAGE MOMENT IN GM-MM FOR HEATING TEMPERATURE OF: } \\
\hline & RTP & $200 \mathrm{~F}$ & $250 \mathrm{~F}$ & $300 \mathrm{~F}$ & $350 \mathrm{~F}$ & $400 \mathrm{~F}$ & $450 \mathrm{~F}$ & $500 \mathrm{~F}$ \\
\hline 0.00 & 0 & 0 & 0 & 0 & 0 & 0 & 0 & 0 \\
\hline 2.50 & 230 & 230 & 230 & 200 & 190 & 180 & 130 & 130 \\
\hline 5.00 & 420 & 420 & 430 & 360 & 340 & 340 & 250 & 240 \\
\hline 7.50 & 620 & 620 & 650 & 540 & 500 & 490 & 370 & 360 \\
\hline 10.00 & 820 & 810 & 840 & 710 & 660 & 640 & 490 & 470 \\
\hline 12.50 & 1020 & 1040 & 1040 & 870 & 820 & 800 & 610 & 580 \\
\hline 15.00 & 1190 & 1200 & 1220 & 1030 & 950 & 940 & 710 & 680 \\
\hline 17.50 & 1390 & 1370 & 1430 & 1170 & 1110 & 1080 & 830 & 790 \\
\hline 20.00 & 1550 & 1530 & 1630 & 1330 & 1260 & 1190 & 930 & 860 \\
\hline 22.50 & 1710 & 1710 & 1770 & 1490 & 1390 & 1300 & 1040 & 960 \\
\hline 25.00 & 1840 & 1860 & 1890 & 1610 & 1520 & 1520 & 1130 & 1010 \\
\hline 27.50 & 1920 & 1920 & 2010 & 1700 & 1620 & 1560 & 1230 & 1170 \\
\hline 30.00 & 2050 & 2080 & 2120 & 1820 & 1680 & & 1300 & 1260 \\
\hline 32.50 & & 2180 & & & & & 1600 & 1220 \\
\hline 35.00 & & & & & & & 1710 & \\
\hline 37.50 & & & & & & & & \\
\hline 40.00 & & & & & & & & \\
\hline
\end{tabular}

TABLE 6. MOMENT VS DEFLECTION CURVES USING MOLD -X10364. 
MODULUS PRIOR TO HEATING

\begin{tabular}{|c|c|c|c|c|c|c|c|c|}
\hline \multirow{2}{*}{$\begin{array}{r}\text { TEMP } \\
\mathrm{F} \\
\end{array}$} & \multicolumn{6}{|c|}{ SAMPLE } & \multirow[t]{2}{*}{ MEAN } & \multirow[t]{2}{*}{ S.D. } \\
\hline & 1 & 2 & 3 & 4 & 5 & 6 & & \\
\hline RTP & 2.89 & 3.12 & 2.95 & 3.10 & 2.97 & 3.07 & 3.02 & 0.09 \\
\hline 200 & 3.01 & 2.85 & 3.01 & 3.00 & 3.17 & 3.07 & 3.02 & 0.10 \\
\hline 250 & 2.96 & 3.02 & 3.01 & 3.15 & 2.9 & 3.20 & 3.05 & 0.11 \\
\hline 300 & 2.96 & 3.00 & 3.15 & 3.03 & 2.8 & 2.72 & 2.94 & 0.16 \\
\hline 350 & 3.11 & 3.05 & 3.22 & 2.85 & 2.8 & 3.04 & 3.02 & 0.15 \\
\hline \multirow[t]{2}{*}{400} & 3.03 & 2.80 & 3.17 & 2.79 & 2.96 & 3.07 & 2.97 & 0.15 \\
\hline & \multicolumn{6}{|c|}{ MEAN OF TOTAL } & 3.00 & \\
\hline
\end{tabular}

MODULUS AFTER HEATING

\begin{tabular}{|c|c|c|c|c|c|c|c|c|}
\hline \multirow{2}{*}{$\begin{array}{r}\text { TEMP } \\
F\end{array}$} & \multicolumn{6}{|c|}{ SAMPLE } & \multirow[t]{2}{*}{ MEAN } & \multirow[t]{2}{*}{ S.D. } \\
\hline & 1 & 2 & 3 & 4 & 5 & 6 & & \\
\hline RTP & 3.11 & 3.11 & 2.95 & 2.96 & 3.12 & 3.06 & 3.05 & 0.08 \\
\hline 200 & 2.66 & 2.87 & 2.83 & 2.63 & 2.50 & 2.74 & 2.71 & 0.14 \\
\hline 250 & 2.82 & 2.57 & 2.48 & 2.72 & 2.55 & 2.38 & 2.59 & 0.16 \\
\hline 300 & 2.11 & 2.46 & 2.50 & 2.26 & 2.49 & 2.12 & 2.32 & 0.18 \\
\hline 350 & 2.23 & 2.50 & 1.86 & 1.96 & 2.39 & 2.84 & 2.30 & 0.36 \\
\hline 400 & 1.71 & 2.26 & 1.97 & 2.24 & 1.89 & 2.29 & 2.06 & 0.24 \\
\hline
\end{tabular}

* Indicates groups which were statistically different $(p<0.01)$ from the paired control shown above.

TABLE 7. CHANGE IN MODULUS WITH HEATING USING MOLD -X10333B. 
MAXIMUM MOMENT (GM-MM)

\begin{tabular}{|c|c|c|c|c|c|c|c|c|}
\hline \multirow{2}{*}{$\begin{array}{r}\text { TEMP } \\
F\end{array}$} & \multicolumn{6}{|c|}{ SAMPLE } & \multirow[t]{2}{*}{ MEAN } & \multirow[t]{2}{*}{ S.D } \\
\hline & 1 & 2 & 3 & 4 & 5 & 6 & & \\
\hline RTP & 1840 & 1860 & 1770 & 1550 & 1610 & 1720 & 1725 & 124 \\
\hline 200 & 1780 & 1460 & 1200 & 1730 & 1750 & 1600 & 1587 & 224 \\
\hline 250 & 1710 & 1760 & 1310 & 1530 & 1680 & 1330 & 1553 & 196 \\
\hline 300 & 1640 & 1530 & 1300 & 1230 & 1690 & 1150 & 1423 & 227 \\
\hline 350 & 1510 & 1490 & 1250 & 1040 & 1350 & 2010 & 1442 & 328 \\
\hline 400 & 1000 & 1130 & 1340 & 920 & 960 & 1360 & $* 1118$ & 193 \\
\hline
\end{tabular}

MAXIMUM DEFLECTION (DEGREES)

\begin{tabular}{|c|c|c|c|c|c|c|c|c|}
\hline \multirow{2}{*}{$\begin{array}{r}\text { TEMP } \\
F\end{array}$} & \multicolumn{6}{|c|}{ SAMPLE } & \multirow[t]{2}{*}{ MEAN } & \multirow[t]{2}{*}{ S.D. } \\
\hline & 1 & 2 & 3 & 4 & 5 & 6 & & \\
\hline RTP & 25.00 & 25.00 & 25.00 & 22.50 & 20.00 & 22.50 & 23.00 & 2.00 \\
\hline 200 & 27.50 & 22.50 & 20.00 & 25.00 & 27.50 & 22.50 & 24.00 & .0 \\
\hline 250 & 22.50 & 27.50 & 22.50 & 22.50 & 25.00 & 22.50 & 24.00 & 2.00 \\
\hline 300 & 30.00 & 25.00 & 20.00 & 22.50 & 25.00 & 22.50 & 24.00 & 3.00 \\
\hline 350 & 27.50 & 25.00 & 27.50 & 20.00 & 22.50 & 27.50 & 25.00 & 3. \\
\hline 400 & 27.50 & 22.50 & 32.50 & 20.00 & 20.00 & 25.00 & 25.00 & 5.00 \\
\hline
\end{tabular}

* Indicates groups which were statistically different $(p<0.01)$ from the paired control shown above.

TABLE 8. MAXIMUM MOMENT AND MAXIMUM DEFLECTION VS HEATING TEMPERATURE USING MOLD - X10333B. 


\begin{tabular}{|c|c|c|c|c|c|c|}
\hline $\begin{array}{l}\text { DEFLECTION } \\
\text { (DEGREES) }\end{array}$ & $\begin{array}{r}\text { AVERAG } \\
\text { RTP }\end{array}$ & $\begin{array}{l}\text { MOMEN } \\
200 \mathrm{~F}\end{array}$ & $\begin{array}{l}\text { VGM-M } \\
250 \mathrm{~F}\end{array}$ & $\begin{array}{l}\text { FOR HE } \\
300 \mathrm{~F}\end{array}$ & $\begin{array}{l}\text { ING TE } \\
350 \mathrm{~F}\end{array}$ & $\begin{array}{l}\text { ERATURE OF: } \\
400 \mathrm{~F}\end{array}$ \\
\hline 0.00 & 0 & 0 & 0 & 0 & 0 & 0 \\
\hline 2.50 & 230 & 210 & 200 & 180 & 170 & 170 \\
\hline 5.00 & 450 & 400 & 380 & 350 & 340 & 300 \\
\hline 7.50 & 670 & 590 & 570 & 510 & 510 & 450 \\
\hline 10.00 & 880 & 770 & 750 & 670 & 670 & 580 \\
\hline 12.50 & 1090 & 950 & 910 & 830 & 820 & 710 \\
\hline 15.00 & 1270 & 1110 & 1080 & 960 & 960 & 810 \\
\hline 17.50 & 1440 & 1280 & 1230 & 1120 & 1100 & 910 \\
\hline 20.00 & 1600 & 1390 & 1360 & 1230 & 1240 & 1000 \\
\hline 22.50 & 1710 & 1550 & 1480 & 1330 & 1410 & 1110 \\
\hline 25.00 & 1820 & 1700 & 1660 & 1550 & 1520 & 1150 \\
\hline 27.50 & & 1760 & 1760 & 1540 & 1590 & 1110 \\
\hline 30.00 & & & & 1640 & & 1290 \\
\hline 32.50 & & & & & & 1340 \\
\hline 35.00 & & & & & & \\
\hline 37.50 & & & & & & \\
\hline 40.00 & & & & & & \\
\hline
\end{tabular}

TABLE 9. MOMENT VS DEFLECTION CURVES USING MOLD -X10333B. 
MODULUS PRIOR TO HEATING

\begin{tabular}{|c|c|c|c|c|c|c|c|c|}
\hline \multirow{2}{*}{$\begin{array}{r}\text { TEMP } \\
F\end{array}$} & \multicolumn{6}{|c|}{ SAMPLE } & \multirow[t]{2}{*}{$\overline{\text { MEAN }}$} & \multirow[t]{2}{*}{ S.D. } \\
\hline & 1 & 2 & 3 & 4 & 5 & 6 & & \\
\hline RTP & 2.74 & 2.74 & 2.75 & 2.75 & 2.76 & 2.76 & 2.75 & 0.0 \\
\hline 200 & 2.70 & 2.70 & 2.70 & 2.71 & 2.73 & 2.74 & 2.71 & \\
\hline 250 & 2.86 & 2.86 & 2.88 & 2.88 & 2.90 & 2.90 & 2.88 & \\
\hline 300 & 2.39 & 2.43 & 2.49 & 2.51 & 2.55 & 2.57 & 2.49 & 0 \\
\hline 350 & 2.91 & 2.92 & 2.92 & 2.93 & 2.94 & 2.94 & 2.93 & \\
\hline 400 & 2.94 & 2.95 & 2.96 & 2.96 & 2.97 & 2.98 & 2.96 & 0.1 \\
\hline & & & & & IEANO & TOTAL & 2.79 & \\
\hline
\end{tabular}

MODULUS AFTER HEATING

\begin{tabular}{|c|c|c|c|c|c|c|c|c|}
\hline \multirow{2}{*}{$\begin{array}{r}\text { TEMP } \\
F\end{array}$} & \multicolumn{6}{|c|}{ SAMPLE } & \multirow[t]{2}{*}{ MEAN } & \multirow[t]{2}{*}{ S.D. } \\
\hline & 1 & 2 & 3 & 4 & 5 & 6 & & \\
\hline RTP & 2.96 & 2.93 & 2.57 & 2.96 & 3.04 & 2.48 & 2.82 & 0.2 \\
\hline 200 & 2.52 & 2.57 & 2.59 & 2.48 & 2.66 & 2.53 & 2.56 & \\
\hline 250 & 2.54 & 2.42 & 2.29 & 2.66 & 2.03 & 2.41 & 2.39 & \\
\hline 300 & 2.15 & 2.47 & 2.49 & 1.97 & 2.69 & 2.08 & 2.31 & \\
\hline 350 & 2.35 & 2.39 & 1.87 & 2.33 & 1.82 & 2.53 & 2.21 & \\
\hline 400 & 1.84 & 2.27 & 2.53 & 2.42 & 2.25 & 2.06 & 2.23 & \\
\hline
\end{tabular}

* Indicates groups which were statistically different $(p<0.01)$ from the paired control shown above.

TABLE 10. CHANGE IN MODULUS WITH HEATING USING MOLD -X10361. 
MAXIMUM MOMENT (GM-MM)

\begin{tabular}{|c|c|c|c|c|c|c|c|c|}
\hline \multirow{2}{*}{$\begin{array}{r}\text { TEMP } \\
F\end{array}$} & \multicolumn{6}{|c|}{ SAMPLE } & \multirow[t]{2}{*}{ MEAN } & \multirow[t]{2}{*}{ S.D. } \\
\hline & 1 & 2 & 3 & 4 & 5 & 6 & & \\
\hline RTP & 1800 & 1690 & 2130 & 1930 & 1660 & 2070 & 1880 & 196 \\
\hline 200 & 1730 & 1700 & 1390 & 1420 & 1750 & 1350 & 1557 & 18 \\
\hline 250 & 1750 & 1790 & 1300 & 1700 & 1230 & 1490 & 1543 & 240 \\
\hline 300 & 1510 & 1470 & 1440 & 1260 & 1720 & 1300 & 1450 & 165 \\
\hline 350 & 1060 & 830 & 1130 & 1490 & 1340 & 1290 & $* 1190$ & 233 \\
\hline 400 & 990 & 1230 & 1520 & 1100 & 1610 & 730 & . 1197 & 331 \\
\hline
\end{tabular}

MAXIMUM DEFLECTION (DEGREES)

\begin{tabular}{|c|c|c|c|c|c|c|c|c|}
\hline \multirow{2}{*}{$\begin{array}{r}\text { TEMP } \\
F\end{array}$} & \multicolumn{6}{|c|}{ SAMPLE } & \multirow[t]{2}{*}{ MEAN } & \multirow[t]{2}{*}{ S.D. } \\
\hline & 1 & 2 & 3 & 4 & 5 & 6 & & \\
\hline RTP & 23.00 & 22.50 & 25.50 & 24.60 & 22.50 & 27.00 & 24.00 & 1.80 \\
\hline 200 & 25.00 & 25.50 & 19.00 & 21.00 & 23.00 & 24.00 & 23.00 & 2.50 \\
\hline 250 & 25.00 & 27.50 & 25.00 & 20.00 & 32.50 & 26.00 & 26.00 & 4.00 \\
\hline 300 & 26.00 & 22.60 & 21.00 & 26.00 & 23.00 & 21.00 & 23.00 & 2.30 \\
\hline 350 & 16.50 & 18.00 & 21.00 & 26.30 & 28.00 & 18.60 & 21.00 & 4.70 \\
\hline 400 & 24.60 & 21.20 & 20.70 & 16.30 & 26.90 & 12.00 & 20.00 & 5.40 \\
\hline
\end{tabular}

* Indicates groups which were statistically different $(p<0.01)$ from the RTP control.

TABLE 11. MAXIMUM MOMENT AND MAXIMUM DEFLECTION VS HEATING TEMPERATURE USING MOLD -X10361. 


\begin{tabular}{|c|c|c|c|c|c|c|}
\hline $\begin{array}{l}\text { DEFLECTION } \\
\text { (DEGREES) }\end{array}$ & $\begin{array}{r}\text { AVERAG } \\
\text { RTP }\end{array}$ & $\begin{array}{l}10 M E N \\
200 \mathrm{~F}\end{array}$ & $\begin{array}{l}\text { GM-M } \\
250 F\end{array}$ & $\begin{array}{l}\text { OR HE } \\
300 \mathrm{~F}\end{array}$ & $\begin{array}{l}\text { NG TEN } \\
350 \mathrm{~F}\end{array}$ & $\begin{array}{l}\text { ERATURE OF: } \\
400 \mathrm{~F}\end{array}$ \\
\hline $\begin{array}{r}0.00 \\
2.50 \\
5.00 \\
7.50 \\
10.00 \\
12.50 \\
15.00 \\
17.50 \\
20.00 \\
22.50 \\
25.00 \\
27.50 \\
30.00 \\
32.50 \\
35.00 \\
37.50 \\
40.00\end{array}$ & $\begin{array}{r}0 \\
230 \\
420 \\
620 \\
800 \\
990 \\
1190 \\
1360 \\
1500 \\
1660 \\
1770 \\
1940 \\
2100\end{array}$ & $\begin{array}{r}0 \\
190 \\
380 \\
560 \\
730 \\
900 \\
1060 \\
1200 \\
1350 \\
1470 \\
1600 \\
1710\end{array}$ & $\begin{array}{r}0 \\
180 \\
360 \\
520 \\
700 \\
870 \\
1040 \\
1200 \\
1330 \\
1430 \\
1440 \\
1650 \\
1500 \\
1230\end{array}$ & $\begin{array}{r}0 \\
170 \\
340 \\
510 \\
680 \\
840 \\
990 \\
1140 \\
1290 \\
1380 \\
1460 \\
1380\end{array}$ & $\begin{array}{r}0 \\
170 \\
330 \\
490 \\
640 \\
800 \\
920 \\
1020 \\
1090 \\
1220 \\
1320 \\
1360 \\
1340\end{array}$ & $\begin{array}{r}0 \\
170 \\
340 \\
490 \\
640 \\
790 \\
930 \\
1060 \\
1150 \\
1240 \\
1190 \\
1250 \\
1610\end{array}$ \\
\hline
\end{tabular}

TABLE 12. MOMENT VS DEFLECTION CURVES USING MOLD -X10361 
MODULUS PRIOR TO HEATING

\begin{tabular}{|c|c|c|c|c|c|c|c|c|}
\hline \multirow{2}{*}{$\begin{array}{r}\text { TEMP } \\
F\end{array}$} & \multicolumn{6}{|c|}{ SAMPLE } & \multirow[t]{2}{*}{ MEAN } & \multirow[t]{2}{*}{ S.D. } \\
\hline & 1 & 2 & 3 & 4 & 5 & 6 & & \\
\hline RTP & 2.98 & 2.99 & 3.02 & 3.06 & 3.07 & 3.11 & 3.04 & 0.05 \\
\hline 150 & 2.66 & 2.74 & 2.79 & 2.80 & 2.84 & & 2.77 & 0.07 \\
\hline 200 & 2.88 & 2.89 & 2.91 & 2.95 & 2.97 & & 2.92 & 0.04 \\
\hline 250 & 3.17 & 3.19 & 3.20 & 3.23 & 3.24 & 3.25 & 3.21 & 0.03 \\
\hline 300 & 2.26 & 2.41 & 2.57 & 2.58 & 2.62 & & 2.49 & 0.15 \\
\hline 350 & 3.26 & 3.27 & 3.30 & 3.30 & 3.32 & & 3.29 & 0.02 \\
\hline & & & & & MEAN OF & & 2.96 & 0.28 \\
\hline
\end{tabular}

MODULUS AFTER HEATING

\begin{tabular}{|c|c|c|c|c|c|c|c|c|}
\hline \multirow{2}{*}{$\begin{array}{r}\text { TEMP } \\
F\end{array}$} & \multicolumn{6}{|c|}{ SAMPLE } & \multirow[t]{2}{*}{ MEAN } & \multirow[t]{2}{*}{ S.D. } \\
\hline & 1 & 2 & 3 & 4 & 5 & 6 & & \\
\hline RTP & 2.31 & 2.84 & 2.48 & 3.03 & 3.36 & 3.11 & 2.85 & 0.40 \\
\hline 150 & 2.14 & 3.05 & 3.15 & 2.77 & 2.77 & & 2.78 & 0.39 \\
\hline 200 & 2.49 & 2.06 & 2.72 & 2.72 & 2.45 & & 2.49 & 0.27 \\
\hline 250 & 1.77 & 2.35 & 1.68 & 2.06 & 2.07 & 1.97 & * 1.98 & 0.24 \\
\hline 300 & 1.44 & 1.62 & 1.97 & 1.24 & 1.79 & & * 1.61 & 0.29 \\
\hline 350 & 1.15 & 1.96 & 0.94 & 1.22 & 1.53 & & * 1.36 & 0.40 \\
\hline
\end{tabular}

* Indicates groups which were statistically different $(p<0.01)$ from the paired control shown above.

TABLE 13. CHANGE IN MODULUS WITH HEATING USING MOLD -X10354. 
MAXIMUM MOMENT (GM-MM)

\begin{tabular}{|c|c|c|c|c|c|c|c|c|}
\hline TEMP & & & SAM & LE & & & MEAN & S.D. \\
\hline$F$ & 1 & 2 & 3 & 4 & 5 & 6 & & \\
\hline RTP & 980 & 1200 & 1140 & 1230 & 1090 & 1120 & 1127 & 88 \\
\hline 150 & 1120 & 1120 & 1220 & 1040 & 1220 & 1220 & 1157 & 75 \\
\hline 200 & 920 & 830 & 960 & 900 & 780 & & * 878 & 72 \\
\hline 250 & 790 & 910 & 620 & 670 & 610 & 650 & * 708 & 118 \\
\hline 300 & 540 & 660 & 540 & 480 & 570 & & * 558 & 66 \\
\hline 350 & 650 & 640 & 350 & 510 & 510 & & • 532 & 122 \\
\hline 400 & 500 & & & & & & * 500 & 0 \\
\hline
\end{tabular}

MAXIMUM DEFLECTION (DEGREES)

\begin{tabular}{|c|c|c|c|c|c|c|c|c|}
\hline \multirow{2}{*}{$\begin{array}{r}\text { TEMP } \\
F\end{array}$} & \multicolumn{6}{|c|}{ SAMPLE } & \multirow[t]{2}{*}{ MEAN } & \multirow[t]{2}{*}{ S.D. } \\
\hline & 1 & 2 & 3 & 4 & 5 & 6 & & \\
\hline RTP & 36.00 & 35.00 & 36.00 & 32.00 & 27.00 & 32.00 & 33.00 & 3.50 \\
\hline 150 & 36.00 & 36.00 & 35.00 & 31.00 & 37.00 & & 35.00 & 2.50 \\
\hline 200 & 35.00 & 31.00 & 38.00 & 32.00 & 33.00 & & 34.00 & 3.00 \\
\hline 250 & 45.00 & 41.00 & 40.00 & 40.00 & 38.00 & 23.00 & 38.00 & 7.50 \\
\hline 300 & 30.00 & 38.00 & 33.00 & 25.00 & 25.00 & & 30.00 & 5.50 \\
\hline 350 & 35.00 & 34.00 & 34.00 & 40.00 & 25.00 & & 34.00 & 5.50 \\
\hline 400 & 24.00 & & & & & & 24.00 & 0.00 \\
\hline
\end{tabular}

- Indicates groups which were statistically different $(p<0.01)$ from the RTP control.

TABLE 14. MAXIMUM MOMENT AND MAXIMUM DEFLECTION VS HEATING TEMPERATURE USING MOLD -X10354. 


\begin{tabular}{|c|c|c|c|c|c|c|c|}
\hline \multirow{2}{*}{$\begin{array}{l}\text { DEFLECTION } \\
\text { (DEGREES) }\end{array}$} & \multicolumn{7}{|c|}{ AVERAGE MOMENT IN GM-MM FOR HEATING TEMPERATURE OF: } \\
\hline & RTP & $150 \mathrm{~F}$ & $200 \mathrm{~F}$ & $250 \mathrm{~F}$ & $300 \mathrm{~F}$ & $350 \mathrm{~F}$ & $400 \mathrm{~F}$ \\
\hline 0.00 & 0 & 0 & 0 & 0 & 0 & 0 & 0 \\
\hline 2.50 & 230 & 240 & 200 & 170 & 140 & 120 & 220 \\
\hline 5.00 & 440 & 420 & 380 & 300 & 250 & 210 & 340 \\
\hline 7.50 & 610 & 590 & 530 & 420 & 340 & 290 & 390 \\
\hline 10.00 & 760 & 710 & 650 & 510 & 420 & 360 & 480 \\
\hline 12.50 & 850 & 860 & 710 & 580 & & & \\
\hline 15.00 & 940 & 900 & 760 & 620 & 500 & 440 & 500 \\
\hline 17.50 & 1000 & & 800 & 660 & & & \\
\hline 20.00 & 1040 & 1030 & 830 & 670 & 550 & 480 & 500 \\
\hline 22.50 & 1070 & & 850 & 690 & & & 500 \\
\hline 25.00 & 1090 & 1100 & 870 & 700 & 560 & 510 & 500 \\
\hline 27.50 & 1100 & & 870 & 700 & & & \\
\hline 30.00 & 1070 & 1110 & 870 & 700 & & 530 & 500 \\
\hline 32.50 & 1070 & & 740 & 700 & & & \\
\hline 35.00 & 1070 & 1130 & & & & 520 & \\
\hline 37.50 & 1060 & 1220 & & & & & \\
\hline 40.00 & 1010 & 1190 & & 590 & & & \\
\hline 42.50 & & & & & & & \\
\hline 45.00 & & & & 740 & & & \\
\hline
\end{tabular}

TABLE 15. MOMENT VS DEFLECTION CURVES USING MOLD -X10354. 

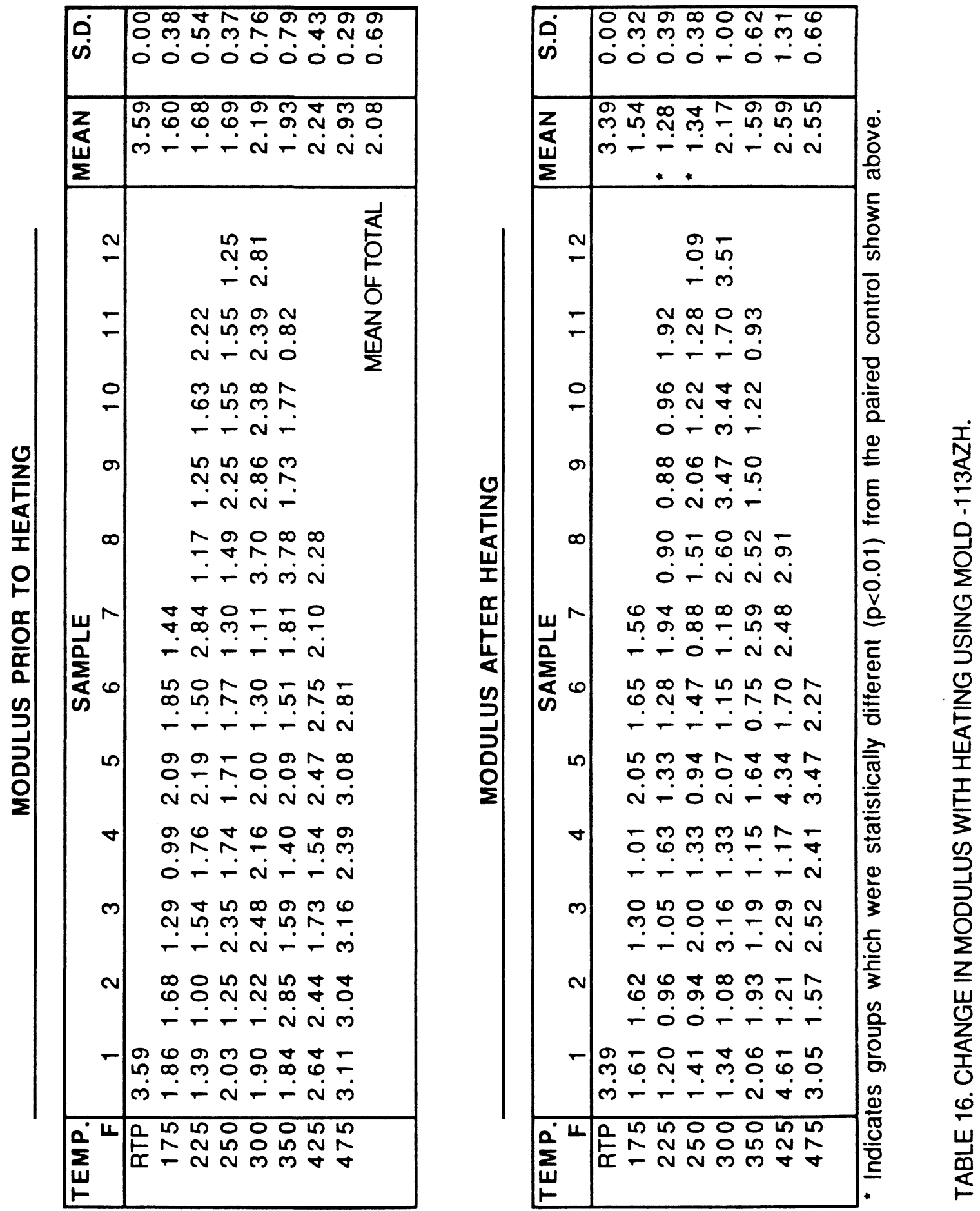

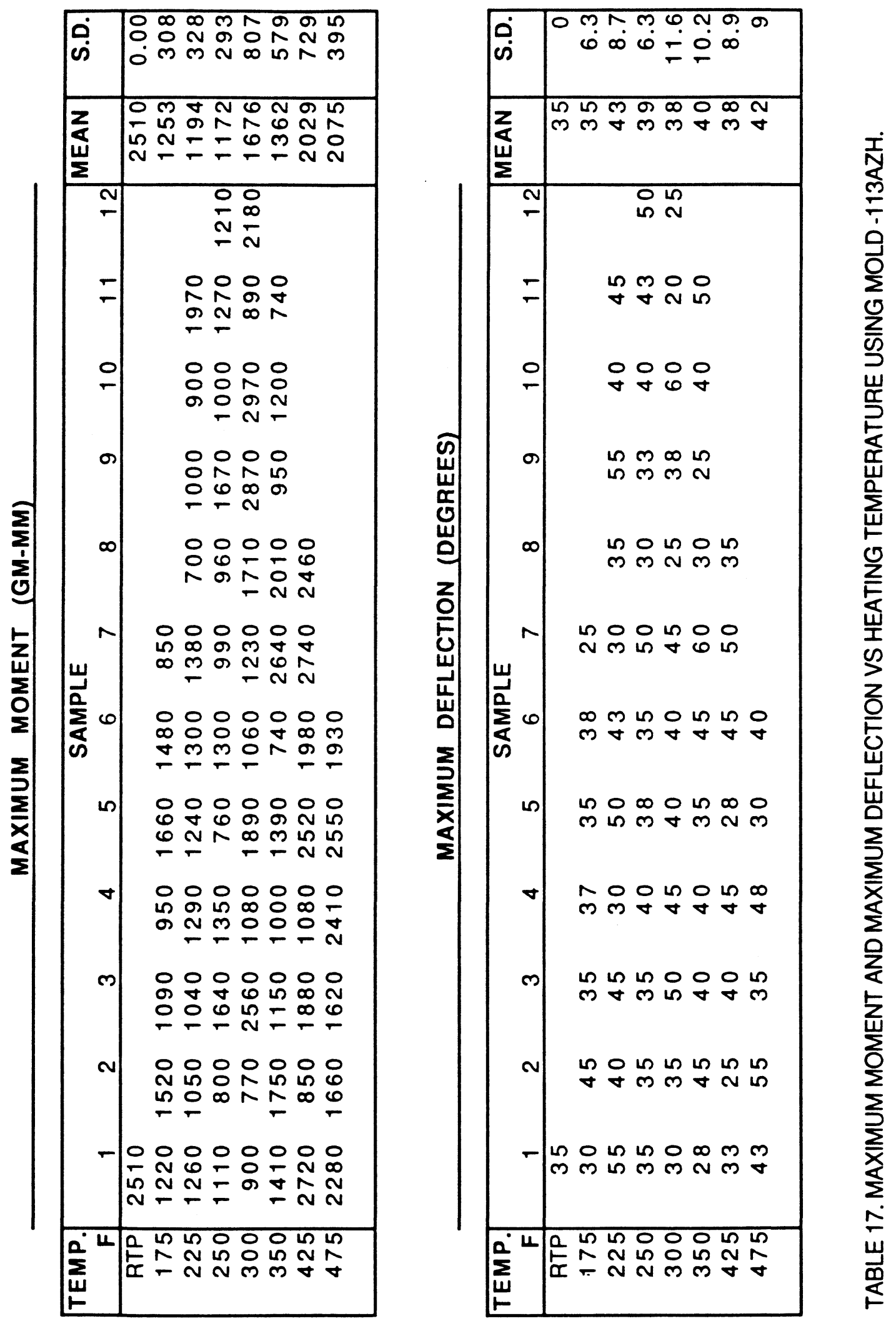


\begin{tabular}{|c|c|c|c|c|c|c|c|c|}
\hline DEFLECTION & $\overline{\text { AVERAC }}$ & EMOM & NT ING & M-MMFC & R HEATI & VG TEMF & ERATUF & EOF: \\
\hline (DEGREES) & RTP & $175 \mathrm{~F}$ & $225 \mathrm{~F}$ & $250 \mathrm{~F}$ & $300 \mathrm{~F}$ & $350 \mathrm{~F}$ & $425 \mathrm{~F}$ & $475 \mathrm{~F}$ \\
\hline 0.00 & 0 & 0 & 0 & 0 & 0 & 0 & 0 & $\overline{0}$ \\
\hline 5.00 & 560 & 270 & 210 & 230 & 380 & 270 & 455 & 480 \\
\hline 7.50 & & & & & & & & \\
\hline 10.00 & 1070 & 490 & 400 & 420 & 690 & 530 & 855 & 820 \\
\hline 12.50 & & & & & & & & \\
\hline 15.00 & 1510 & 680 & 580 & 600 & 955 & 695 & 1115 & 1100 \\
\hline 17.50 & & & & & & & & \\
\hline 20.00 & 1940 & 880 & 730 & 760 & 1190 & 875 & 1415 & 1400 \\
\hline 22.50 & & & & & & & & \\
\hline $\begin{array}{l}25.00 \\
27.50\end{array}$ & 2270 & 1040 & 880 & 910 & 1440 & 1030 & 1660 & 1630 \\
\hline 30.00 & 2450 & 1190 & 1000 & 1020 & 1570 & 1230 & 1900 & 1790 \\
\hline 32.50 & & & & & & & & \\
\hline 35.00 & 2510 & 1290 & 1020 & 1120 & 1750 & 1245 & 2005 & 1700 \\
\hline 37.50 & & 1210 & & & & & & \\
\hline 40.00 & & & 1160 & 1050 & 1940 & 1230 & 1770 & 1960 \\
\hline 42.50 & & & & & & & & \\
\hline 45.00 & & & 1310 & 1090 & 1910 & 1390 & 1660 & 2060 \\
\hline 47.50 & & & & & & & & \\
\hline 50.00 & & & 1080 & 1100 & 2670 & 1610 & 2740 & 2010 \\
\hline & & & & & & & & \\
\hline 55.00 & & & 1130 & & 2850 & 2590 & & 1660 \\
\hline
\end{tabular}

TABLE 18. MOMENT VS DEFLECTION CURVES USING MOLD -113AZH. 
MODULUS PRIOR TO FORMING

\begin{tabular}{|r|rrrrrrr|r|r|}
\hline TEMP & \multicolumn{7}{|c|}{ SAMPLE } & MEAN & S.D. \\
\hline F & 1 & 2 & 3 & 4 & 5 & 6 & 7 & & \\
\hline RTP & 2.80 & 2.76 & 2.86 & 2.99 & 2.86 & 3.04 & 2.85 & 2.88 & 0.10 \\
175 & 2.79 & 2.74 & 2.72 & 2.78 & 2.77 & 2.76 & & 2.76 & 0.03 \\
250 & 2.64 & 2.82 & 2.87 & 2.73 & 2.65 & 2.85 & & 2.76 & 0.10 \\
300 & 3.13 & 2.92 & 2.80 & 2.84 & 2.94 & 3.08 & & 2.95 & 0.17 \\
350 & 2.79 & 2.67 & 2.79 & 2.78 & 2.72 & 2.70 & & 2.74 & 0.05 \\
400 & 2.69 & 2.68 & 2.89 & 2.86 & 2.74 & 2.81 & 2.78 & 0.11 \\
& & & & & & MEAN OF TOTAL & 2.81 & 0.11 \\
& & & & & & & & &
\end{tabular}

MODULUS AFTER FORMING -O MM DEF

\begin{tabular}{|r|rrrrrrr|r|r|}
\hline TEMP & \multicolumn{7}{|c|}{ SAMPLE } & MEAN & S.D. \\
\hline F & 1 & 2 & 3 & 4 & 5 & 6 & 7 & & \\
\hline RTP & 2.80 & 2.76 & 2.86 & 2.99 & 2.86 & 3.04 & 2.85 & 2.88 & 0.10 \\
175 & 1.58 & 1.55 & 1.24 & 2.00 & 1.43 & 1.17 & & 1.49 & 0.30 \\
250 & 2.03 & 2.08 & 1.76 & 2.00 & 1.94 & 2.01 & & 1.97 & 0.14 \\
300 & 2.06 & 2.15 & 2.44 & 2.08 & 2.32 & 2.25 & & 2.22 & 0.20 \\
350 & 1.71 & 1.86 & 2.35 & 1.51 & 1.72 & 2.65 & & 1.97 & 0.44 \\
400 & 1.67 & 1.92 & 1.98 & 1.79 & 1.75 & 1.94 & & 1.84 & 0.14 \\
\hline
\end{tabular}

* Indicates groups which were statistically different $(p<0.01)$ from the paired control shown above.

TABLE 19. CHANGE IN MODULUS WITH HEATING USING OVEN -

O MM DEFLECTION - X10333A. 
MODULUS PRIOR TO FORMING

\begin{tabular}{|r|rrrrrrr|r|r|}
\hline TEMP & \multicolumn{7}{|c}{ SAMPLE } & MEAN & S.D. \\
\hline F & 1 & 2 & 3 & 4 & 5 & 6 & 7 & & \\
\hline RTP & 2.80 & 2.76 & 2.86 & 2.99 & 2.86 & 3.04 & 2.85 & 2.88 & 0.10 \\
175 & 2.79 & 2.74 & 2.72 & 2.78 & 2.77 & 2.76 & & 2.76 & 0.03 \\
250 & 2.72 & 2.82 & 2.88 & 2.95 & 2.82 & 2.85 & & 2.84 & 0.10 \\
300 & 2.43 & 2.93 & 2.74 & 2.90 & 2.71 & 2.77 & & 2.75 & 0.18 \\
350 & 2.79 & 2.70 & 2.79 & 2.71 & 2.77 & 2.73 & 2.75 & 0.04 \\
& & & & & & MEANOF TOTAL & 2.80 & 0.11 \\
& & & & & & & & \\
\end{tabular}

MODULUS AFTER FORMING -10 MM DEF

\begin{tabular}{|r|rrrrrrr|r|r|}
\hline TEMP & \multicolumn{7}{|c|}{ SAMPLE } & MEAN & S.D. \\
\hline F & 1 & 2 & 3 & 4 & 5 & 6 & 7 & & \\
\hline RTP & 2.80 & 2.76 & 2.86 & 2.99 & 2.86 & 3.04 & 2.85 & 2.88 & 0.10 \\
175 & 1.58 & 1.55 & 1.24 & 2.00 & 1.43 & 1.17 & & 1.49 & 0.30 \\
250 & 2.03 & 1.54 & 2.14 & 1.78 & 1.98 & 1.76 & & $* 87$ & 0.27 \\
300 & 1.97 & 2.62 & 1.58 & 2.50 & 2.42 & 1.92 & & 2.17 & 0.48 \\
350 & 1.71 & 1.40 & 1.44 & 1.51 & 1.32 & 1.25 & & 1.44 & 0.16 \\
\hline
\end{tabular}

* Indicates groups which were statistically different $(p<0.01)$ from the paired control shown above.

TABLE 20. CHANGE IN MODULUS WITH HEATING USING OVEN 10 MM DEFLECTION - X10333A. 

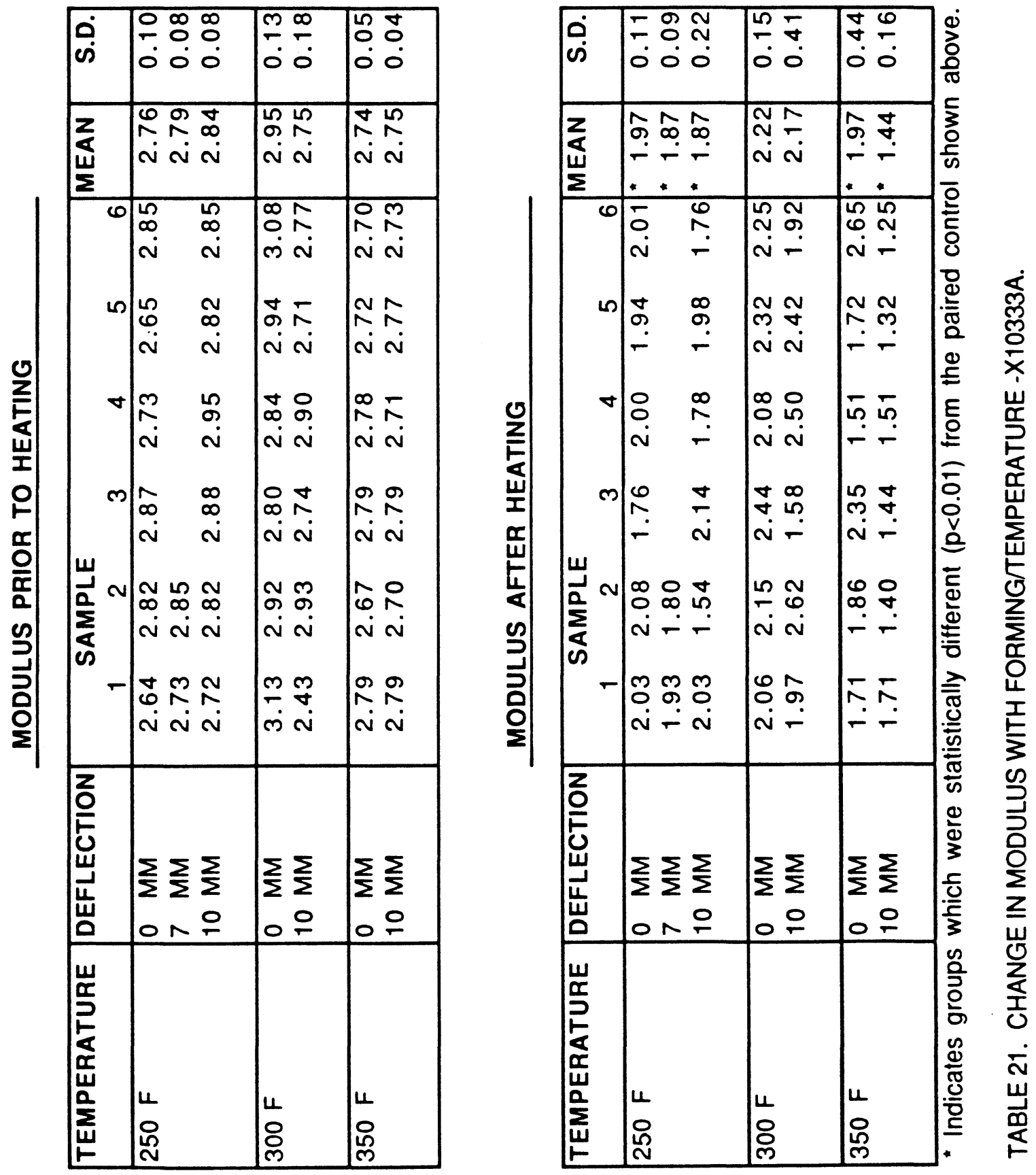
Source:

df: SS: MS:

\begin{tabular}{|l|r|r|r|r|r|}
\hline TEMPERATURE (A) & 2 & 1.061 & 0.531 & 11.115 & 0.0002 \\
DEFLECTION (B) & 1 & 0.315 & 0.315 & 6.591 & 0.0155 \\
AB & 2 & 0.19 & 0.095 & 1.993 & 0.154 \\
subjects w. groups & 30 & 1.432 & 0.048 & & \\
Repeated Measure (C) & 1 & 13.296 & 13.296 & 321.478 & 0.0001 \\
AC & 2 & 0.45 & 0.225 & 5.442 & 0.0096 \\
BC & 1 & 0.155 & 0.155 & 3.746 & 0.0624 \\
ABC & 2 & 0.359 & 0.179 & 4.339 & 0.0221 \\
C x subjects w. groups & 30 & 1.241 & 0.041 & & \\
& & & & & \\
\hline
\end{tabular}

There were no missing cells found

TABLE 22. ANOVA TABLE (3-FACTOR REPEATED MEASURES) SHOWING SIGNIFICANCE OF FORMING, TEMPERATURE, AND REPEATED MEASURE

- X10333A. 
MODULUS PRIOR TO HEATING

\begin{tabular}{|c|c|c|c|c|c|c|}
\hline METHOD & DURATION & & AMPL & & MEAN & S.D. \\
\hline & & 1 & 2 & 3 & & \\
\hline $\begin{array}{l}\text { MOLD } \\
\text { MOLD }\end{array}$ & $\begin{array}{l}5 \text { MIN } \\
10 \text { MIN }\end{array}$ & $\begin{array}{l}3.17 \\
3.13\end{array}$ & $\begin{array}{l}3.16 \\
3.19\end{array}$ & $\begin{array}{l}3.14 \\
3.06\end{array}$ & $\begin{array}{l}3.16 \\
3.13\end{array}$ & $\begin{array}{l}0.02 \\
0.07\end{array}$ \\
\hline $\begin{array}{l}\text { ONEN } \\
\text { OVEN }\end{array}$ & $\begin{array}{l}5 \mathrm{MIN} \\
10 \mathrm{MIN}\end{array}$ & $\begin{array}{l}2.69 \\
2.88\end{array}$ & $\begin{array}{l}2.89 \\
2.87\end{array}$ & $\begin{array}{l}2.86 \\
2.84\end{array}$ & $\begin{array}{l}2.81 \\
2.86\end{array}$ & $\begin{array}{l}0.1 \\
0.0\end{array}$ \\
\hline
\end{tabular}

MODULUS AFTER HEATING

\begin{tabular}{|c|c|c|c|c|c|c|}
\hline METHOD & DURATION & & AMPL & & MEAN & S.D. \\
\hline & & 1 & 2 & 3 & & \\
\hline MOLD & $5 \mathrm{MIN}$ & 1.80 & $\overline{1.14}$ & 1.97 & 1.64 & 0.44 \\
\hline MOLD & $10 \mathrm{MIN}$ & 1.46 & 1.58 & 1.34 & 1.46 & 0.12 \\
\hline OVEN & $5 \mathrm{MIN}$ & 1.67 & 1.98 & 1.79 & 1.81 & 0.16 \\
\hline OVEN & $10 \mathrm{MIN}$ & 1.46 & 1.73 & 1.92 & 1.70 & 0.23 \\
\hline
\end{tabular}

TABLE 23. EFFECT OF METHOD AND DURATION OF HEATING AT $410 \mathrm{~F}$. 


Source:
\begin{tabular}{|l|r|r|r|r|r|}
\hline METHOD (A) & Sf: & \multicolumn{1}{l}{ MS: } & F-test: & P value: \\
DURATION (B) & 1 & 0.014 & 0.014 & 0.358 & 0.5663 \\
AB & 1 & 0.026 & 0.026 & 0.687 & 0.4311 \\
subjects w. groups & 1 & 0.008 & 0.008 & 0.204 & 0.6638 \\
Repeated Measure (C) & 8 & 0.303 & 0.038 & & \\
AC & 1 & 10.733 & 10.733 & 318.618 & 0.0001 \\
BC & 1 & 0.398 & 0.398 & 11.81 & 0.0089 \\
ABC & 1 & 0.036 & 0.036 & 1.07 & 0.3313 \\
C x subjects w. groups & 1 & $3.75 E-05$ & $3.75 E-05$ & 0.001 & 0.9742 \\
& 8 & 0.27 & 0.034 & & \\
\hline
\end{tabular}

There were no missing cells found

TABLE 24. ANOVA TABLE (3-FACTOR REPEATED MEASURES) SHOWING SIGNIFICANCE OF METHOD AND DURATION OF HEATING AT $410 \mathrm{~F}$, AND REPEATED MEASURE - X10333A. 
MODULUS PRIOR TO HEATING

\begin{tabular}{|l|rrr|r|r|}
\hline GROUP & \multicolumn{3}{|c|}{ SAMPLE } & MEAN & S.D. \\
\hline CONIRO & 2.69 & 2.89 & 2.86 & 2.81 & 0.11 \\
\hline $\begin{array}{l}\text { VACUUM DRYING + } \\
\text { VACUUM HEATING }\end{array}$ & 2.69 & 2.68 & 2.67 & 2.68 & 0.01 \\
\hline $\begin{array}{l}\text { VACUUM DRYING + } \\
\text { ATMOS. HEATING }\end{array}$ & 2.89 & 2.86 & 2.88 & 2.88 & 0.02 \\
\hline
\end{tabular}

MODULUS AFTER HEATING

\begin{tabular}{|l|rrr|r|r|}
\hline GROUP & \multicolumn{3}{|c|}{ SAMPLE } & MEAN & S.D. \\
\hline CONIROL & 1 & 2 & 3 & & \\
\hline $\begin{array}{l}\text { VACUUM DRYING + } \\
\text { VACUUM HEATING }\end{array}$ & 1.67 & 1.98 & 1.79 & 1.81 & 0.16 \\
\hline $\begin{array}{l}\text { VACUUM DRYING } \\
\text { ATMOS. HEATING }\end{array}$ & 1.98 & 1.79 & 1.85 & 1.88 & 0.10 \\
\hline
\end{tabular}

TABLE 25. EFFECT OF PRE-DRYING AND VACUUM HEATING AT $400 \mathrm{~F}$. 
Source:

TYPE (A)

subjects $W$. groups

Repeated Measure (B) $A B$

$B \times$ subjects $w$. groups df: Ss:

\begin{tabular}{c|c} 
MS: \\
\hline 2 & 0.056
\end{tabular}

0.092

4.166

0.014

0.031

F-test: $\quad P$ value:

\begin{tabular}{|r|r|r|}
0.028 & 1.828 & 0.24 \\
0.015 & & \\
4.166 & 815.17 & 0.0001 \\
0.007 & 1.371 & 0.3234 \\
0.005 & & \\
\hline
\end{tabular}

There were no missing cells found

TABLE 26. ANOVA TABLE (2-FACTOR REPEATED MEASURES) SHOWING

SIGNIFICANCE OF PRE-DRYING, VACUUM HEATING AT $400 \mathrm{~F}$, AND

REPEATED MEASURE - X10333A. 


\section{A. Hewelett-Packard measurement and plotting recorder}

The HP 7090 (Hewelett Packard, San Diego, CA.) is a three-channel analog-to-digital acquisition system and a digital plotter. It can operate as a conventional $X-Y$ recorder, a data acquisition system component, or a vector plotter.

The three floating and guarded analog input channels accept a maximum input voltage of $200 \mathrm{~V}$, dc or peak, and provide $\mathrm{X}-\mathrm{Y}$ or $\mathrm{Y}-\mathrm{T}$ direct recording for signals up to approximately $10 \mathrm{~Hz}$. The range sensitivity of each channel may be set independently from $5 \mathrm{mV}$ to $100 \mathrm{~V}$ full scale.

The direct recording mode is functionally equivalent to an $X-Y$ recorder and is used to produce real-time recordings of low frequency analog siginals (amplitude dependent to $10 \mathrm{~Hz}$ ). The sampling rate is 250 samples/s. Any one of the three input channels may be plotted against time. Sweep time for Y-T (versus- time) measurements is determined by the total time setting, and times of 1.0 second to 24.0 hours may be used.In addition to versus-time measurements, $X-Y$ (versus-chan3) 
measurements can be made in which channel 1 or channel 2 is plotted against channel 3.

The buffered recording mode is functionally equivalent to a wave form recorder and can be used to perform both versus-time and versus-chan 3 measurements. In this mode, 1000 samples from each channel are digitized and measurement durations from 0.03 seconds to 24.0 hours are allowed. The stored sample values can subsequently be plotted or sent to a computer.

The plotter mode allows the HP 7090 to be used as a conventional digital plotter to produce graphs of the data received.

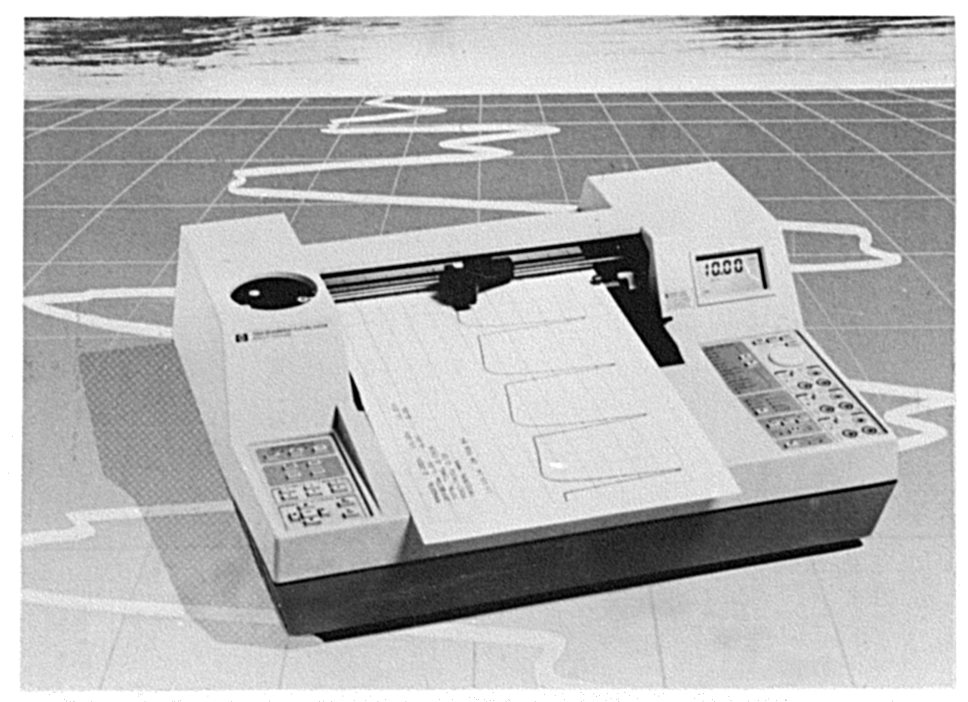

Fig. 45: Hewelett- Packard measurement and plotting recorder. 


\section{B. Thermocouple to millivolt converter}

The OMEGA TAC 80 (Omega Engineering Inc., Stamford, CT.) is a univesal thermocouple amplifier and linearizer which provides a precision $1 \mathrm{mV} / \mathrm{C}$ or $\mathrm{F}$ signal for type $\mathrm{J}, \mathrm{K}$, or $\mathrm{T}$ thermocouples. Cold junction compensation is provided. The TAC 80 turns a chart recorder or voltmeter into an accurate, wide-range temperature measuring instrument.

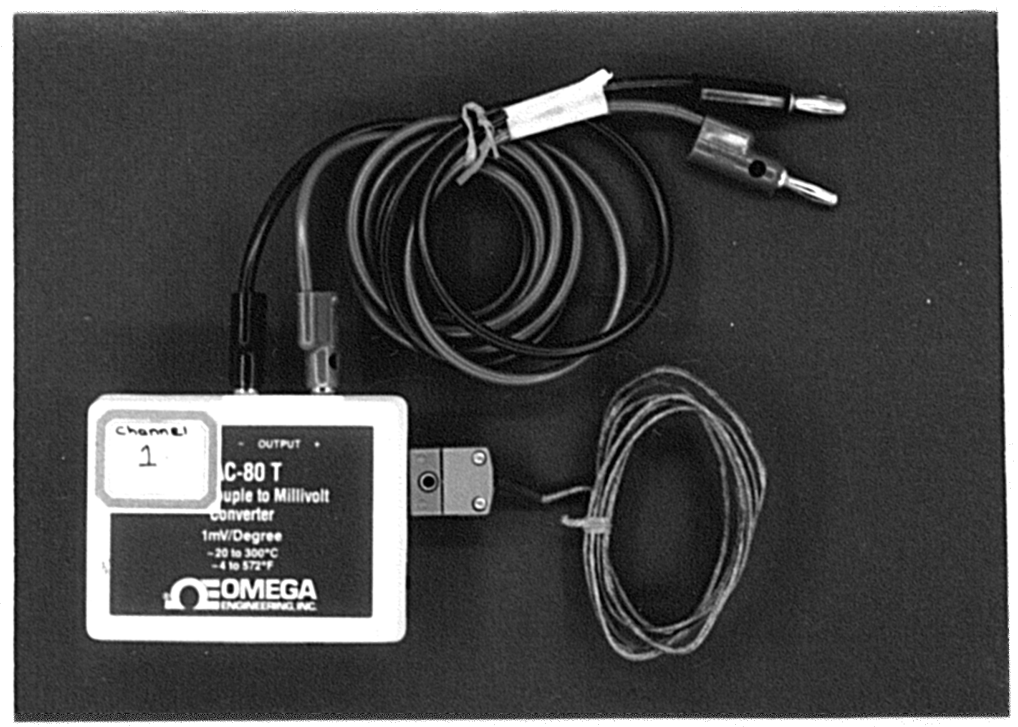

Fig. 46: Thermocouple to millivolt convertor. 


\section{c. Type I thermecouples}

These thermocouples (Omega Engineering Inc., Stamford, CT.) are made from copper and constantan. They are suitable for use in oxidizing, reducing, inert or vacuum atmospheres up to $700 \mathrm{~F}(370 \mathrm{C})$. The insulation is glass to glass with an exposed measuring junction. An exposed junction is recommended for the measurement of static or flowing non-corrosive gas temperatures where fast response time is required. The junction extends beyond the protective sheath to help achieve this. The diameter of the thermocouple is $0.010 \mathrm{in}$. 


\section{Carver laboratory model $C$ hydraulic press}

This press (F.S. Carver Inc., Menomonee Falls, Wis.) consists basically of a hydraulic system, ram, and two platens with bearing surfaces $152 \mathrm{~mm}$ square, with $457 \mathrm{~mm}$ adjustable opening. The electrically heated platens are of hard aluminum alloy and $25 \mathrm{~mm}$ thick. The maximum surface temperature possible is $500 \mathrm{~F}$. It reaches $400 \mathrm{~F}$ in 9 minutes. Each platen has a temperature controller and dial thermometer scaled $150-750 \mathrm{~F}$. The hand operated press can develop up to 24,000 psi (170 MPa) pressure. The pressure is measured by the gauge which is graduated to $24,000 \mathrm{lb}$ in 200-lb divisions.

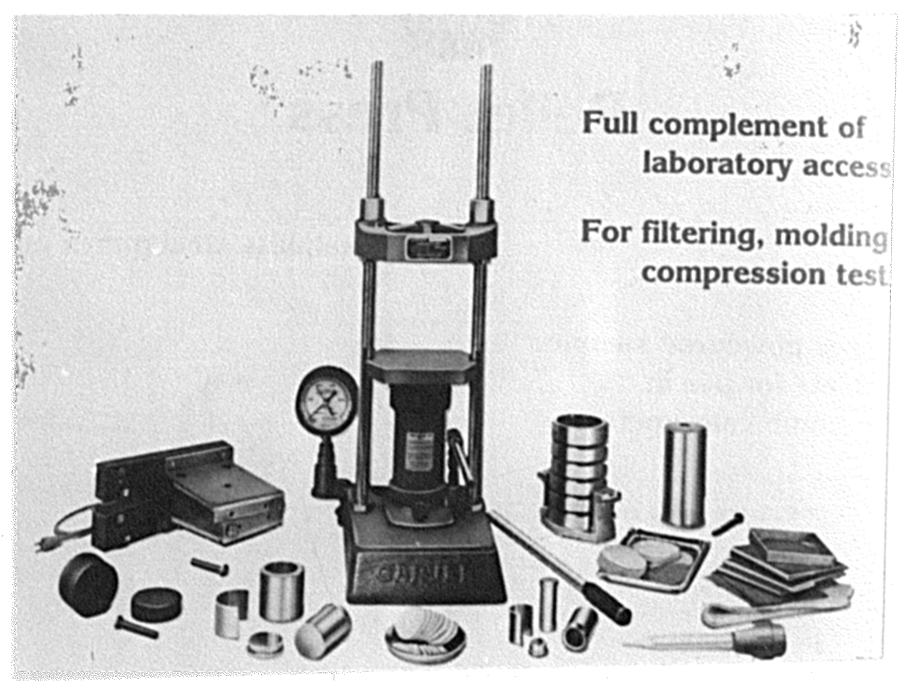

Fig. 47: Carver laboratory model C hydraulic press. 


\section{E. Instron oven}

This is a typical electric oven (Instron Corporation, Canton, Ma.) with a chamber of stainless steel and a windowed chamber. The top surface has an approximately two inch diameter opening in the center. This allows the introduction and manuvering of other accessories such as thermocouples and a deflection rod. The maximum temperature possible is $450 \mathrm{~F}$. The oven reaches a temperature of $400 \mathrm{~F}$ in 20 minutes. 